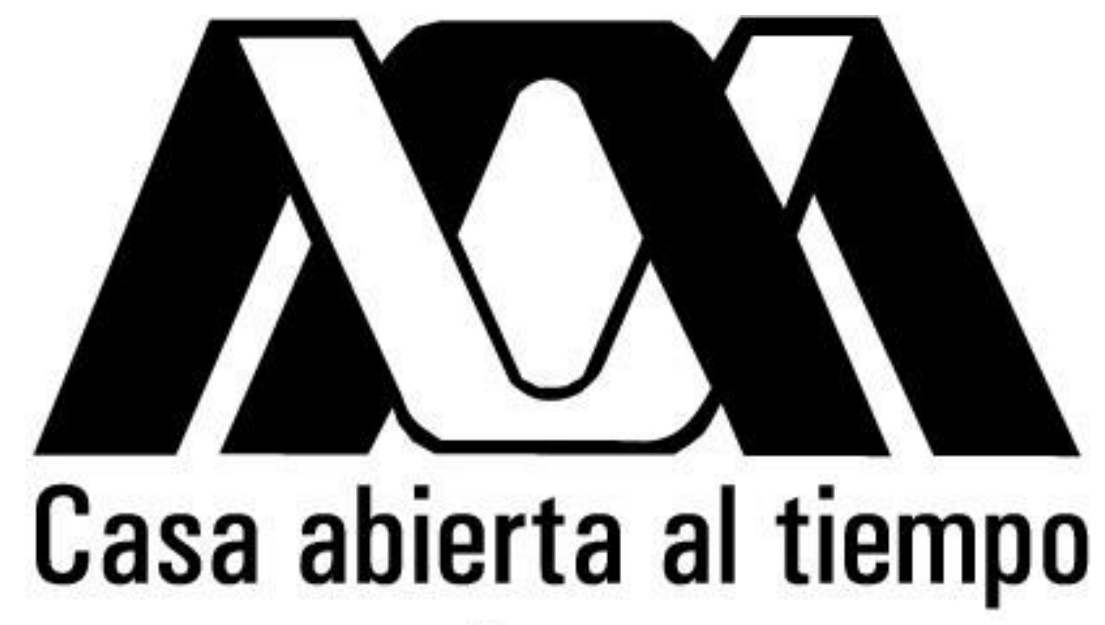

UNIVERSIDAD AUTÓNOMA METROPOLITANA 


\title{
AQ1
}

Casa abierta al tiempo

UNIVERSIDAD AUTONOMA METROPOLITANA

I z t a pa la pa

DIVISIÓN DE CIENCIAS BIOLÓGICAS Y DE LA SALUD

MAESTRÍA EN BIOLOGÍA

\section{EFECTOS DE LA PRECIPITACIÓN Y DÍA/NOCHE SOBRE LA ESTRUCTURA DE LA COMUNIDAD DE PECES DE UN ESTUARIO INTERMITENTE (SITIO RAMSAR)}

TESIS
Que para obtener el grado de Maestra en Biología

\section{Presenta}

Biól. Alma Monserrat Martínez Sarabia

\author{
Director de Tesis \\ Dr. Manuel Castillo Rivera
}

Asesores

Dra. Rocío Zárate Hernández

M. en C. Selene Ortiz Burgos

Fecha

Noviembre 2019 
La Maestría de Biología de la

Universidad Autónoma Metropolitana

pertenece al Padrón de

Posgrados de Calidad del CONACyT.

La presente tesis se llevó a cabo en el laboratorio de Peces del Departamento de Biología en la Universidad Autónoma Metropolitana Unidad Iztapalapa, dentro del proyecto "Ecología de poblaciones y comunidades de peces" con el financiamiento de la UAM-Iztapalapa. 
El jurado designando por la

División de Ciencias Biológicas y de la Salud

de la Unidad Iztapalapa aprobó la tesis que presentó

Biól. Alma Monserrat Martínez Sarabia

El día 26 de noviembre del año de 2019

Comité Tutoral y Jurado

Tutor: Dr. Manuel A. Castillo Rivera

Asesor: Dra. Ma. Del Roció Zárate Hernández

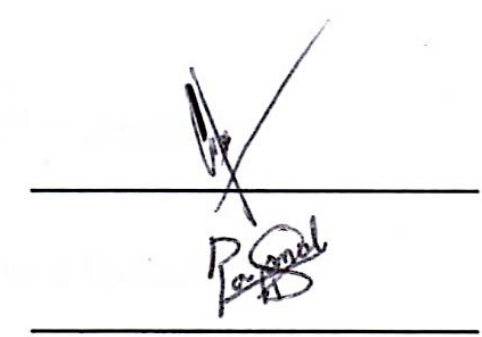

Asesor: M. en C. Selene Ortiz Burgos

Sinodal: Juan Jacobo Schmitter Soto

Sinodal: Francisco José Gutiérrez Mendieta

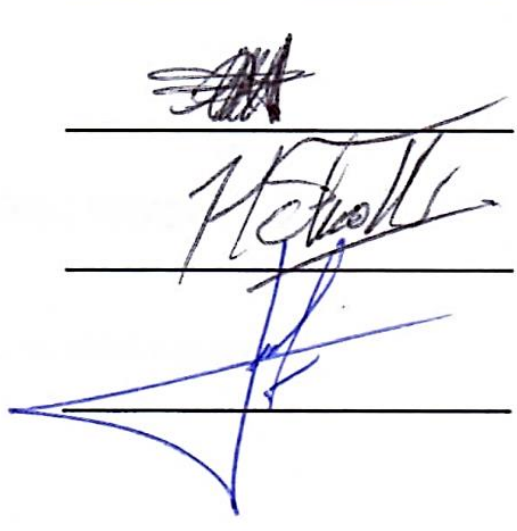




\title{
COMITÉ TUTORIAL
}

\author{
Dr. Manuel A. Castillo Rivera \\ Director de tesis \\ Universidad Autónoma Metropolitana Iztapalapa
}

Dra. María del Rocío Zarate Hernández

Asesora

Universidad Autónoma Metropolitana Iztapalapa

\begin{abstract}
M. en C. Gabriela Selene Ortiz Burgos
Asesora

Universidad Autónoma Nacional de México
\end{abstract}




\section{Agradecimientos}

Primero quiero agradecer a Dios ya que sin él no hubiera podido llegar a culminar esta etapa de mi vida, ya que me ha dado las fuerzas, el aliento, el amor, para seguir adelante cuando sentía que ya no podía.

Agradezco a mis papás, Héctor Martínez-López y Alma Sarabia-Torres, y hermano, Geovanny Martínez-Sarabia, que son el otro pilar de mi vida. Gracias papás por su apoyo, dirección, amor que nos han brindado a mi hermano y a mí, que sin ustedes no seríamos las personas que somos hoy en día.

Por otro lado, agradezco enormemente la dirección, el tiempo y apoyo incondicional del Dr. Manuel Castillo-Rivera desde que ingrese al laboratorio de peces hasta el culmino de la maestría. También agradezco la Dra. Rocío ZárateHernández, a la M. en C. Selene Ortiz-Burgos, que formaron parte también del comité tutorial, y al Dr. Francisco Gutiérrez-Mendieta y al Dr. Juan Jacobo Schmitter-Soto, que formaron parte de los miembros del jurado, por su apoyo, además de sus comentarios, sugerencias que ayudaron a enriquecer este trabajo.

A mis compañeros y ex compañeros del laboratorio de peces, Elizabeth Hernández, Alejandra Pille, Guillermo Constante, Juan Velásquez, Thelma Rodríguez Parra, Omar Beltrán y Ángeles Mecalco, que entre tantas risas, ocurrencias y locuras la estadía en el laboratorio ha sido más confortable y agradable con todos ustedes.

A Blanca Canela López, Guadalupe Morgado, Dulce Flores Garcilazo, Perla Trujillo Tolentino, Diana Sánchez, Yuriko García, a mi tío Jesús Coronado y a mis pastores Teresa García y Enrique García, los cuales he conocido en diferentes etapas de mi vida, pero que han permanecido hasta ahora y han sido cómplices en esta en particular. Así como, a miembros de la familia, congregación, amigos y compañero de generación. Gracias por cada palabra de aliento, apoyo, por cada consejo, regaño y por cada ¿cómo va la maestría, la tesis?, échale ganas, tu puedes, tu esfuerzo tendrá recompensas, no te rindas, etc. 
“El da fuerzas al cansado, y multiplica las fuerzas al que no tiene ningunas. Los muchachos se fatigan y se cansan, los jóvenes flaquean y caen, pero los que esperan en Jehová tendrán nuevas fuerzas; levantaran alas como las águilas; correrán, y no se cansarán: caminaran, y no se fatigarán”.

\section{Isaías 40:29-31}

Reina Valera, 1960 


\section{Índice general}

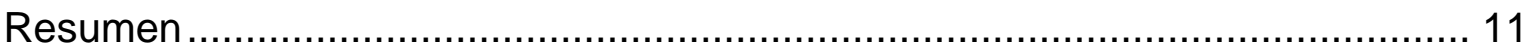

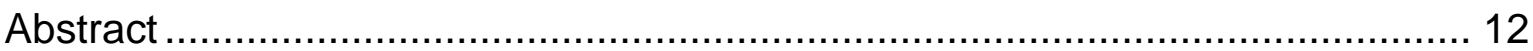

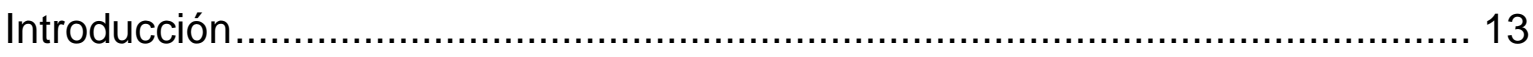

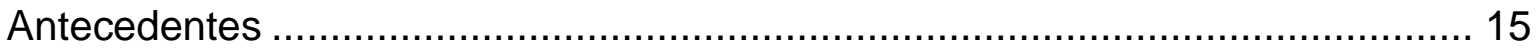

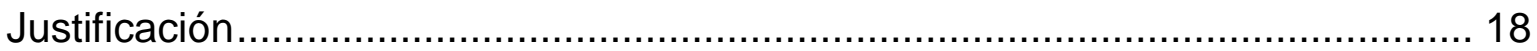

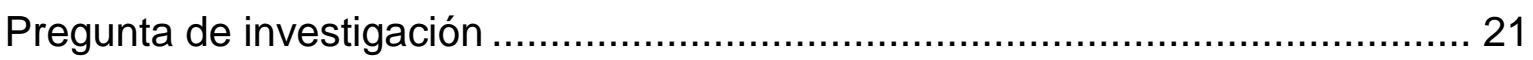

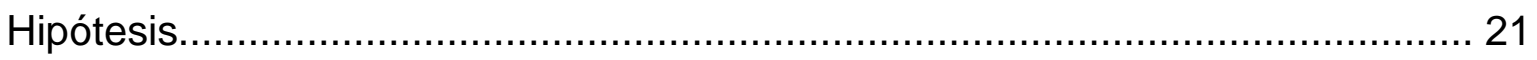

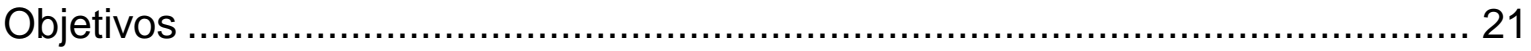

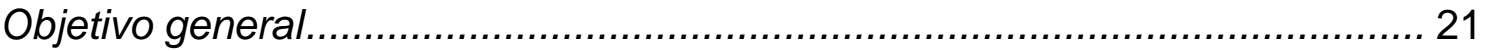

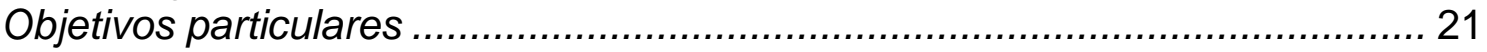

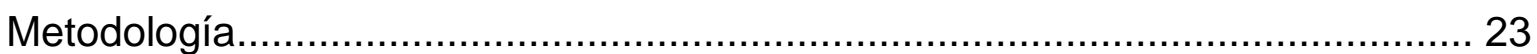

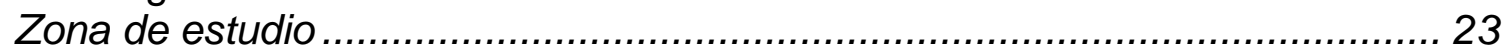

Muestreo y obtención de datos ............................................................... 25

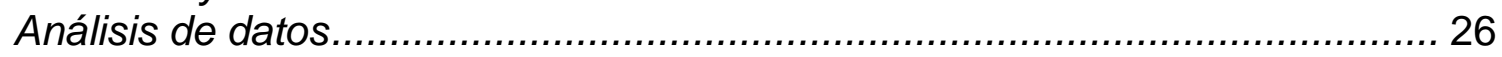

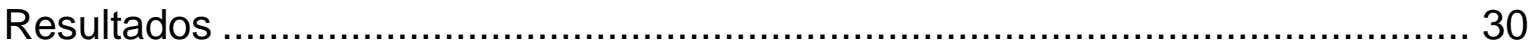

Aspectos generales de la comunidad ..................................................... 30

Análisis de la abundancia y la biomasa ......................................................... 32

Análisis de los parámetros de la comunidad................................................ 38

Variación estacional y circadiana en la estructura de la comunidad................ 45

Influencia de las variables ambientales sobre la abundancia de las especies. 55

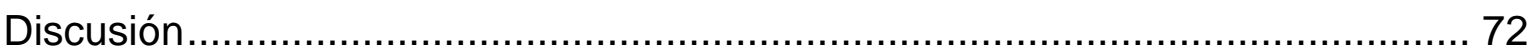

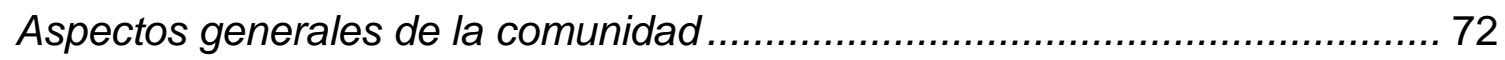

Análisis de la abundancia y la biomasa ....................................................... 75

Análisis de los parámetros de la comunidad.................................................. 79

Variación estacional y circadiana en la estructura de la comunidad.................. 84

Influencia de las variables ambientales sobre la abundancia de las especies.. 88

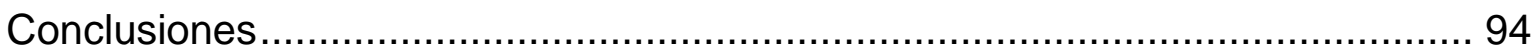

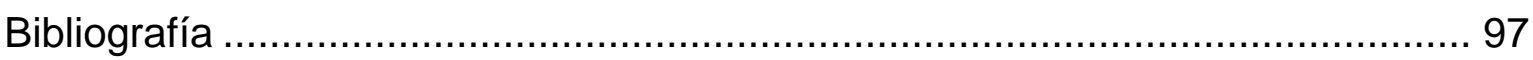




\section{Índice de Tabla}

Tabla 1. Número de familias y especies registradas por época climática. ....................................31

Tabla 2. Prueba de independencia de Durbin-Watson aplicado a los meses. ................................ 33

Tabla 3. Análisis de PERMANOVA univariada, sobre la abundancia total en número y la biomasa.

Tabla 4. Abundancia y peso total para cada época del sistema.

Tabla 5. Análisis de PERMANOVA univariada sobre la riqueza de especies, diversidad y Equidad.

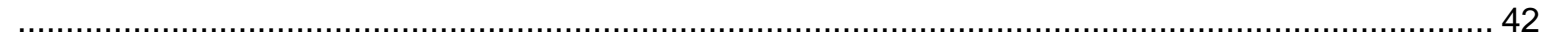

Tabla 6. Promedio de los parámetros de la comunidad registrada para cada época climática. ..... 43

Tabla 7. Resultados del ACC aplicados a las variables ambientales y a los parámetros de la

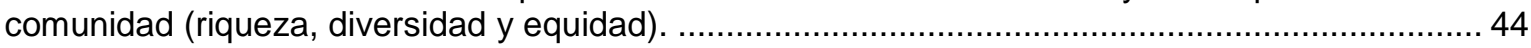

Tabla 8. Análisis de PERMANOVA multivariada sobre la composición de especies. ...................... 46

Tabla 9. Matriz de similitud (ANOSIM) entre los meses del año. ................................................. 49

Tabla 10. Matriz de similitud (ANOSIM) entre las épocas del año. ............................................ 51

Tabla 11. Análisis de similitud (ANOSIM) entre las horas del día. .................................................54

Tabla 12. Resultados del ACC aplicados a las variables ambientales y a la abundancia de la

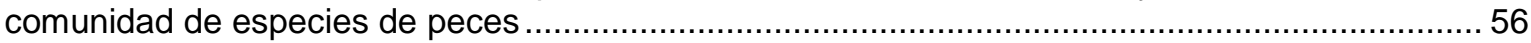

\section{Índice de Figura}

Figura 1. Ubicación de la laguna costera La Mancha, Veracruz.. ............................................. 23

Figura 2. Estimación del número acumulado de especies. ....................................................... 32

Figura 3. Variación promedio de la abundancia en número y biomasa de los organismos a lo largo

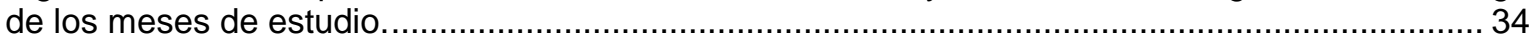

Figura 4.Variación circadiana por hora de la abundancia en número y biomasa de los peces ..... 36

Figura 5. Variación estacional de los promedios de los parámetros de la comunidad.................... 40

Figura 6. Variación circadiana de los promedios de los parámetros de la comunidad................... 41

Figura 7. Diagrama de ordenación de las variables ambientales y los parámetros de la comunidad

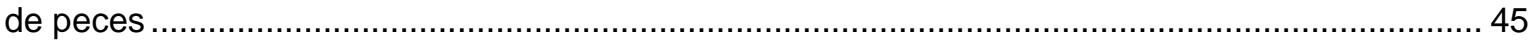

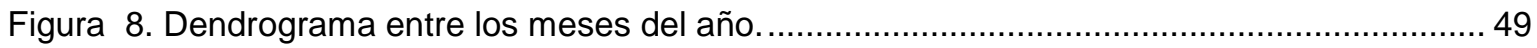


Figura 9. Dendrograma entre las temporadas del año.

Figura 10. Dendrograma entre las horas del día.

Figura 11. Variación estacional de la abundancia total promedio y su relación con las variables ambientales.

Figura 12. Diagrama de ordenación de las variables ambientales y las especies de la comunidad de peces. 57

Figura 13. Variación estacional de la abundancia de Anchoa mitchilli ........................................... 58

Figura 14. Variación estacional de la abundancia de Anchoa lamprotaenia..................................59

Figura 15. Variación estacional de la abundancia de Anchoa hepsetus. ....................................... 60

Figura 16. Variación estacional de la abundancia de Cetengraulis edentulus. .............................. 61

Figura 17. Variación estacional de la abundancia de Ariopsis felis................................................ 61

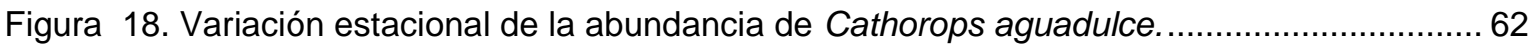

Figura 19. Variación estacional de la abundancia de M. curema ................................................... 63

Figura 20. Variación estacional de la abundancia de Caranx hippos y C. latus............................... 64

Figura 21. Variación estacional de la abundancia de Citharichthys macrops ................................65

Figura 22. Variación estacional de la abundancia de Citharichthys spilopterus.............................. 65

Figura 23. Variación estacional de la abundancia de Centropomus undecimalis. ......................... 66

Figura 24. Variación estacional de la abundancia de Diapterus auratus........................................6 67

Figura 25. Variación estacional de la abundancia de Diapterus rhombeus................................... 68

Figura 26. Variación estacional de la abundancia de Eucinostomus argenteus. .............................68

Figura 27. Variación estacional de la abundancia de Eucinostomus gula.....................................69

Figura 28. Variación estacional de la abundancia de Eucinostomus melanopterus........................ 70

Figura 29. Variación estacional de la abundancia de Lutjanus griseus......................................... 71 


\section{Resumen}

Las lagunas costeras son sistemas con elevados niveles de productividad y una gran diversidad biológica, como resultado de una alta complejidad ecológica, debido a los diferentes procesos ambientales propios de los periodos estacionales, diarios y ciclos de mareas y a los cambios abruptos en las variables ambientales de estos periodos. La variación en las condiciones ambientales juega un papel importante en la composición y estructura de las comunidades de peces en estos sistemas costeros. El objetivo de la presente tesis fue describir y analizar el efecto de la precipitación y del ciclo luz/oscuridad sobre la diversidad y composición de especies de peces de la laguna La Mancha, la cual se encuentra en el municipio de Actopan, Veracruz. Se analizó de un total de 212 muestreos mensuales, abril a diciembre de 2012, circadianos, cada dos horas, frente a la boca del sistema. Asimismo, se analizó la variación estacional y circadiana de la abundancia total en número, biomasa y de los parámetros de la comunidad (riqueza, diversidad y equidad). La riqueza total de especies estuvo representada por 30 familias, 51 géneros y 81 especies. La abundancia total en número de individuos fue mayor en los meses de mayo y octubre, mientras que la biomasa fue mayor en junio y julio. Ambas variables incrementaron durante la noche. La riqueza de especies varió a lo largo del año, siendo mayor durante los meses de julio, septiembre y octubre, y durante las horas de oscuridad. La diversidad fue mayor en julio, septiembre y diciembre, y la equidad en agosto y diciembre; ambos parámetros fueron más elevados en horas de luz. Finalmente, las variables ambientales con mayor influencia sobre la abundancia en número, biomasa y en los parámetros de la comunidad fueron la precipitación, salinidad, oxígeno disuelto, temperatura del agua y aire, estado de la boca (apertura y cierre) y día/noche, variables que podrían estar condicionando el comportamiento y la estructura de peces, lo cual probablemente refleja estrategias para optimizar los recursos y el espacio. 


\section{Abstract}

Coastal lagoons are systems with high levels of productivity and a big biological diversity as a result of a high ecological complexity, due to the different environmental processes that result from seasonal, diel and tides cycles periods and to the abrupt changes of the environmental variables of these periods. The variation in the environmental conditions plays an important role in the composition and structure fish communities in these coastal systems. The objective of this thesis was to describe and analyze the effect of the precipitation and light/dark cycle on the diversity and composition of fish species of the lagoon La Mancha, which is in the municipality of Actopan, Veracruz. For this, biological material was analyzed, from 212 monthly samples, April to December 2012, diel, every two hours, for month, in front the mouth of the system. Also, the seasonal and diel variation of the total abundance in number, biomass and the parameters of the community (richness, diversity and evenness) were analyzed. The fish community was represented by 30 families, 51 genera and 81 species. Total abundance in number was higher in the months of May and October, whereas biomass was higher in June and July. Both variables were higher during the night. Richness varied throughout the year, being higher during the months of July, September and October and during the night. Diversity was higher in July, September and December, and evenness was in August and December, both parameters higher during the day. Finally, the environmental variables with higher influence on abundance, biomass and of the community parameters were precipitation, salinity, dissolved oxygen, temperature of water and air, state of the mouth (open/close) and time of day, variables that could be conditioning of the behavior and structure of fish which probably reflects strategies to optimize resources and space. 


\section{Introducción}

Las lagunas costeras son humedales marino-costeros (Berlanga-Robles et al., 2008; CONAGUA, 2016). Se caracterizan por su alta complejidad ecológica, debido a los diferentes procesos ambientales propios de los periodos estacionales, diarios y ciclos de mareas, así como por cambios abruptos en la temperatura, precipitación, salinidad, nutrientes, concentración de oxígeno disuelto, tipo de sustrato y vegetación, ciclo de mareas, régimen de precipitación y de apertura/cierre de la boca de estos periodos, teniendo como resultado altos índices de productividad y una gran diversidad biológica (Chavance et al., 1984; Yañéz-Arancibia, 1985; Day et al., 1989; Allen \& Baltz, 1997; Christensen et al., 1997), la cual se encuentra relacionada con la colonización de organismos tanto marinos como dulceacuícolas y los típicamente estuarinos, pero en comparación con los sistemas de agua dulce y marinos la diversidad es relativamente más baja (Contreras \& Castañeda, 2004; Penk, 2018).

Debido a la importancia que tienen estos sistemas, la Comisión Nacional de Áreas Naturales Protegidas (CONANP) ha decretado, hasta 2014, 142 sitios RAMSAR para México, humedales de importancia internacional con características particulares por ser sitios representativos, raros, únicos, con especies vulnerables, en peligro de extinción o amenazadas e importantes para mantener la diversidad biológica de una región biogeográfica (Ramsar, 1971; CONANP, 2014), los cuales incluyen las lagunas costeras de San Ignacio, El Caimán, La Mancha, Alvarado, Términos, Madre, entre otras más. Dichos sistemas acuáticos son importantes para la conservación de la biodiversidad y el uso racional de los recursos naturales. 
Estos sistemas acuáticos funcionan como zonas de reclutamiento, crianza y refugio de una gran variedad de especies de peces, en alguna etapa de su vida, que están bajo la influencia de presiones fisiológicas y ambientales, debido a la alta variabilidad de las condiciones ambientales antes mencionadas (Castillo-Rivera et al., 2011).

Por causa, de lo antes menciona, el costo energético es alto, lo cual lleva a desarrollar complejas relacionadas con actividades a su de ciclos de vida, lo cual provoca cambios importantes en la estructura de las comunidades. Así también, influyendo en los tiempos en los que ocurre la reproducción, desove, crianza, maduración, reclutamiento, fluctuaciones en la disponibilidad de alimento y migraciones, derivando una sucesión estacional de las poblaciones (Chavance et al., 1984; Yáñez-Arancibia et al., 1994; Castillo-Rivera et al., 2011).

Así, se ha observado que la precipitación influye en la dinámica de las comunidades de peces estuarinos. Durante la época de lluvias existe un mayor escurrimiento de ríos, aportando materia orgánica alóctona, y fortaleciendo los procesos de producción. Esto influye en los hábitos alimenticios de las especies (fitoplanctófagos y zooplanctófagos, depredadoras y detritívoras). Asimismo, se ha determinado que las fluctuaciones en la precipitación tienen un efecto significativo en su distribución (Castillo-Rivera \& Zárate-Hernández, 2001; Castillo-Rivera, 2013; Castillo-Rivera et al., 2010; 2017).

Finalmente, se ha observado que la variación circadiana (ciclos de 24 horas), en relación con salida y puesta del sol, tiene un efecto sobre la conducta y 
actividades de los organismos. Así, las especies pueden ser diurnas, nocturnas o crepusculares, para evadir depredadores o alimentarse (Castillo-Rivera et al., 2010; Zárate-Hernández et al., 2012). Por otro lado, algunos autores han mostrado que la marea influye de manera importante las poblaciones de peces, influyendo en sus tolerancias fisiológicas, debido a que la marea puede condicionar la variación de la temperatura y la salinidad en los ciclos diarios y por ende sobre la comunidad (Wootton, 1990; Castillo-Rivera et al., 2005).

\section{Antecedentes}

La República Mexicana cuenta con 11,592.77 km de litoral, de los cuales 1, 567,300 ha están cubiertas por estuarios, en el océano Pacífico posee 892,800 ha y en el Golfo de México 674,500 ha. Cuenta con alrededor de 179 lagunas costeras (Contreras-Espinosa, 2010).

En el país, se han realizado diversas investigaciones en las lagunas costeras, pero la mayoría de los enfocados en las comunidades ícticas, sólo han incluido listas de las especies de peces (Zárate-Hernández et al., 2012) y pocos estudios han aportado información sobre el papel que juegan los factores ambientales en la variación estacional y nictémera del comportamiento de la abundancia de las especies de peces (Castillo-Rivera y Zárate-Hernández, 2001; Zárate-Hernández et al., 2012). 
En el Golfo de México, de los diversos trabajos realizados, solo en la Laguna de Términos (Yáñez-Arancibia et al., 1982), la Laguna de Pueblo Viejo (ZárateHernández, 2003; Castillo-Rivera et al., 2010; Zárate-Hernández et al., 2012) y Tampamachoco (Hernández et al., 2006) analizaron las variaciones circadianas y estacionales. Por un lado, en Términos se analizó la dinámica diaria y estacional de la comunidad, de los años de 1980 y 1890, mientras que en Pueblo Viejo se analizaron las variaciones diarias y estacionales de la abundancia total de peces, así como los parámetros de la comunidad y la influencia que ejercen sobre las especies, en sitios con vegetación sumergida y de sustrato blando (ZárateHernández, 2003; Castillo-Rivera et al., 2010; Zárate-Hernández et al., 2012) y en el caso de la Laguna de Tampamachoco se analizó la composición, abundancia y la influencia de las variables termohalinas sobre el ictioplancton, realizando muestreos estacionales en horas de luz y de oscuridad. Asimismo, se han realizado trabajos en otras lagunas, los cuales solo evaluaron a nivel estacional, mismos que se llevaron a cabo en los sistemas de Tamiahua (Franco-López \& Chávez-López, 1992, Ocaña-Luna \& Sánchez-Ramírez, 2016); Alvarado (Chávez-López et al., 2005); y Sontecomapan (Rodríguez-Varela et al., 2010), enfocados en especies de peces adultos y en el ictioplancton.

En el Pacífico mexicano, algunos de los estudios realizados, se encuentran los efectuados en la laguna costera Santa María la Reforma, al sureste del Golfo de California, sobre la composición y los cambios estacionales en la comunidad de peces (Amezcua \& Amezcua-Linares, 2014); sobre la evaluación ecológica, de diversidad, abundancia y conjuntos ictiofaunísticos en sistemas lagunares del 
estado de Chiapas (Díaz-Ruiz et al., 2004, 2006); así como de la diversidad y abundancia en un estuario del estado de Nayarit (Benítez-Valle et al., 2007); y la variación estacional en la diversidad, abundancia y composición de especies en la laguna de Chacahua, Oaxaca (Mendoza et al., 2009), los cuales no abordaron la variación diaria de las especies de peces.

En la laguna La Mancha, la mayoría de los trabajos realizados corresponden a listas ictiofaunísticas, las cuales son los llevados a cabo por Lozano-Vilano et al., 1993; Pérez-Hernández y Torres-Orozco, 2000; Lara-Domínguez et al., 2011). Además, se encuentran los trabajos de Juárez-Eusebio y colaboradores (2006), los cuales analizaron la composición de especies de peces entre estaciones del año; de Díaz-Ruiz y colaboradores (2018) que estudiaron la influencia de los factores ambientales (salinidad, temperatura, oxígeno disuelto y $\mathrm{pH}$ ) en la ictiofauna. Por otro lado, trabajos más específicos, en el área de estudio, incluyen el análisis en la variación estacional y circadiana de la abundancia y estructura de tallas de mojarras (familia Gerreidae), incluidos los factores ambientales (Martínez-Aguilar, 2015); el estudio de peces bénticos (Hernández-Gorrosquieta, 2016); y el análisis de la variación estacional y circadiana, así como la influencia de variables ambientales sobre la abundancia de las especies de la familia Lutjanidae (Constante-Pérez, 2016). En estos últimos trabajos, realizaron muestreos estacionales con regularidad, aunados a muestreos diarios cada dos horas en un ciclo completo de 24 horas, lo que permitió una evaluación más precisa de los cambios diarios que ocurren en la abundancia y que a diferencia de muestreos temporales de baja 
frecuencia, proporcionan una mejor interpretación de la variación en las especies (Pessanha et al., 2003; Castillo-Rivera et al., 2010, 2017; Vasconcellos et al., 2010).

Finalmente, respecto a la influencia e importancia que tiene la precipitación sobre las comunidades de peces, están los trabajos realizados en la laguna de Pueblo Viejo, los cuales fueron determinar la influencia que ejerce la precipitación en la distribución y abundancia de peces (Castillo-Rivera \& Zárate-Hernández, 2001; Castillo-Rivera et al., 2002). Asimismo, se han analizado los patrones de distribución estacional y circadiana de dos especies de gerreidos, Diapterus auratus y Eucinostomus melanopterus, con picos de abundancia en lluvias (Castillo-Rivera et al., 2005), evaluando los cambios espaciales, diarios y estacionales en la estructura de la comunidad de peces, con las lluvias como una variable ambiental importante (Zárate-Hernández et al., 2012; Castillo-Rivera, 2013).

\section{Justificación}

La laguna de La Mancha es un sistema acuático de suma importancia, debido a su valor ecológico, biológico y geomorfológico (CONANP, 2003). Asimismo, es una zona esencial para el refugio, crianza y reclutamiento, en cierta etapa de vida de un gran número de especies de peces que viven e ingresan al sistema (Chavance et al., 1984; Yáñez-Arancibia et al., 1994; Castillo-Rivera et al., 2011). En este sentido, es importante el estudio de la variación estacional y circadiana de la comunidad de peces, en el sistema lagunar, así como la influencia que ejercen 
las variables ambientales, principalmente de la precipitación, sobre las especies, mismas que son importantes en la dinámica de la laguna.

A pesar de que se cuenta con información de las lagunas costeras, principalmente sobre comunidades de peces, los trabajos son aún escasos y todavía hay muchos aspectos ecológicos que no han sido estudiados ampliamente, por lo que se tienen que realizar investigaciones más exhaustivas para, por ejemplo, lograr una mayor comprensión del papel que juegan la variabilidad ambiental sobre los organismos, específicamente, sobre las especies de peces.

Lo anterior sucede en La Mancha, ya que como se pudo observar en los antecedentes, la información obtenida en relación a la variación estacional de las especies de peces y el efecto de las variables ambientales, con énfasis en el efecto de la precipitación, sobre las mismas, es poca y nula en el caso de la variación diaria de estas.

Asimismo, se ha reconocido la importancia de la precipitación por la relevante influencia que ejerce en la estructuración de las comunidades de peces estuarinos (Castillo-Rivera et al., 2002; 2010; Zárate-Hernández et al., 2012; Castillo-Rivera et al., 2017). Esto se relaciona con el hecho que durante la época de lluvias hay un aporte significativo de nutrientes y materia orgánica alóctona, estimulando la producción primaria. Así, las lluvias y su asociado incremento en los procesos de producción influyen en la abundancia de peces (Yáñez-Arancibia et al., 1993, Meynecke et al., 2006; Gillson, 2011; Castillo-Rivera, 2013). Por lo que, el presente 
trabajo permite determinar la influencia que ejercen las lluvias sobre las especies de la laguna de La Mancha.

A nivel nictémero, existen estudios que han inferido cambios circadianos en las comunidades de peces estuarinos a partir de muestreos temporales de baja frecuencia, colectando durante solo unas pocas horas del día y la noche, o durante las mareas altas y bajas, por períodos de 24 horas (Castillo-Rivera et al., 2010). Estos análisis reducen la variación circadiana solamente a comparaciones entre el día y la noche, existiendo pocos estudios que hayan adoptado una aproximación más continua, esto es, tomando muestras más regulares cada 203 horas (Pessanha et al., 2003; Castillo-Rivera et al., 2010; Vasconcellos et al., 2010; Castillo-Rivera et al., 2017). Este tipo de aproximación, permite una evaluación más precisa en que ocurren los cambios diarios en la abundancia de peces a lo largo del ciclo de 24 horas.

Finalmente, el conocimiento obtenido sobre la dinámica de las comunidades estuarinas de peces tropicales, contribuyen al conocimiento del sistema, generando beneficios a nivel social, principalmente al sector pesquero para el aprovechamiento económico y sustentable de los recursos pesqueros, debido a la importancia que la pesquería artesanal tiene dentro de la laguna, cuyas comunidades se dedican principalmente a la extracción de peces como robalo, mojarra, lisa, entre otras (Contreras, 1993). 


\section{Pregunta de investigación}

¿La precipitación y las variaciones en el ciclo luz/oscuridad tienen un efecto significativo en la estructura de la comunidad de peces de la laguna costera de La Mancha, Veracruz?

\section{Hipótesis}

La precipitación y la variación nictémera del ciclo luz/oscuridad tendrán una influencia sobre las poblaciones de peces, así como en sus respuestas tróficas y estrategias de protección y evasión de depredadores; generando cambios importantes en la estructura de la comunidad.

\section{Objetivos}

\section{Objetivo general}

Describir y analizar el efecto de la precipitación y ciclo luz/oscuridad sobre la diversidad y composición de especies en un estuario tropical.

\section{Objetivos particulares}

1. Contribuir al conocimiento del comportamiento estacional y circadiano de la abundancia total de las especies en la laguna costera de La Mancha. 
2. Contribuir al conocimiento del comportamiento estacional y circadiano de los parámetros de la comunidad (riqueza de especies, diversidad y equidad) en la laguna costera de La Mancha.

3. Determinar la influencia de factores ambientales, con principal énfasis en la precipitación y efecto de la luz/oscuridad, sobre la composición de especies y los parámetros de la comunidad. 


\section{Metodología}

\section{Zona de estudio}

La laguna costera La Mancha, se encuentra ubicada en la planicie del Golfo de México, en la región central de la costa del estado de Veracruz, en el municipio de Actopan, ubicada entre las coordenadas geográficas: $19^{\circ} 44^{\prime} 7.47^{\prime \prime}-19^{\circ} 25^{\prime} 46.01^{\prime \prime} \mathrm{N}$ y $96^{\circ} 32$ ' 22.80"- 96 18' 40.79" O (Figura 1). Tiene una extensión de 132 ha, con una longitud máxima aproximada de $3 \mathrm{~km}$. Cuenta con dos aportes de agua dulce permanentes al sur de sistema costero conocidos como Caño Grande o río Gallego y el río Sábalo, y al norte con el riachuelo San José (Juárez-Eusebio et al., 2006).

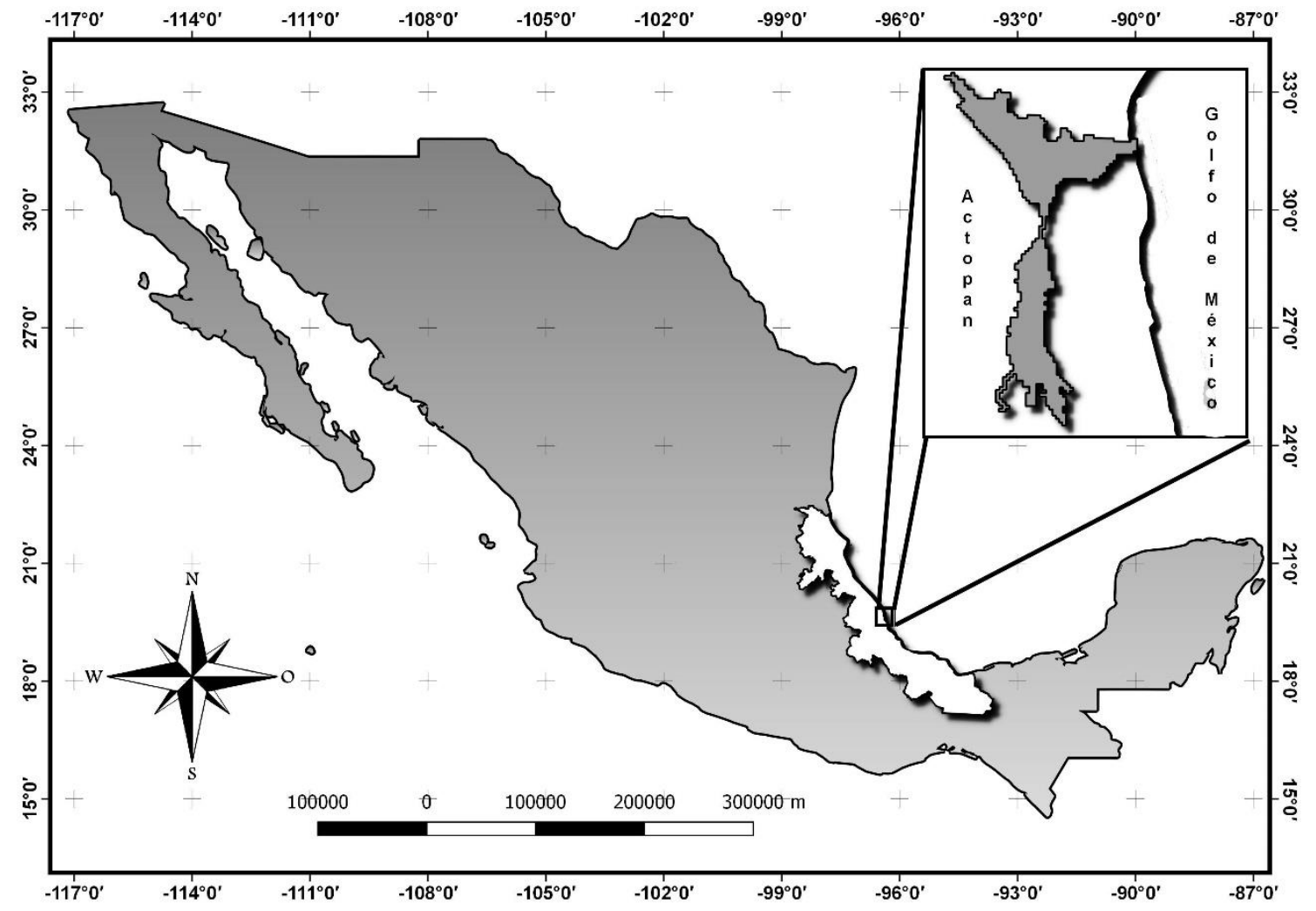

Figura 1. Ubicación de la laguna costera La Mancha, Veracruz. Mapa elaborado con el software Qgis versión 2.14. 
La Mancha tiene un clima cálido subhúmedo con lluvias en verano (Aw2), con una temperatura promedio anual entre 22 y $26{ }^{\circ} \mathrm{C}$. Su precipitación oscila entre 1200 y 1500 mm anuales (García, 2004). La época lluviosa abarca de junio a octubre (con valores promedio mensuales mayores a $100 \mathrm{~mm}$ ) y la de secas de noviembre a mayo (con valores promedio mensuales menores a $60 \mathrm{~mm}$ ) (CONAGUA, 2019).

Esta laguna se encuentra categorizada como un sitio Ramsar, debido a que tiene un importante valor biológico y ecológico, además, es una laguna interdunaria, con valor geomorfológico, ya que permite recargar mantos acuíferos, funciona como filtro natural para la limpieza del agua y brinda protección contra la erosión, tormentas, huracanes, impacto de las olas e inundaciones (CONANP, 2003). Forma parte del corredor de aves rapaces más importante del mundo; es el hábitat de gran variedad de aves acuáticas y es un área de anidación para aves residentes y migratorias. Asimismo, la laguna es sitio de reproducción, alimentación, resguardo y crianza para muchas especies de peces y otros organismos. Este sistema acuático alberga especies vegetales que se encuentra bajo la protección de la NOM-59, como Rhizophora mangle (mangle rojo), Avicennia germinans (mangle negro), Laguncularia racemosa (mangle blanco) y Conocarpus erectus (botoncillo) en la categoría de amenazada, y fauna como Crocodylus moreletii (lagarto negro o de pantano), Egretta rufescens (garza colorada) y Mycteria americana (cigüeña americana) en la categoría de sujetas a protección. Aun a pesar de ser un sitio conservado se ha ido degradando rápidamente por la actividad humana (construcción de casas, actividades agropecuarias, contaminación, turismo, etc.) (Contreras, 1993; CONANP, 2003; SEMARNAT, 2010). 


\section{Muestreo y obtención de datos}

Se analizaron muestreos mensuales de abril a diciembre de 2012, en los cuales, se realizaron ciclos de 24 horas, tomando muestras cada dos horas, con su respectiva réplica, obteniendo un total de 212 muestreos, llevados a cabo frente a la boca del sistema, bajo la condición de luna nueva para maximizar el efecto luz/obscuridad.

La captura se efectuó con un chinchorro playero de 37.1 metros de largo por 1.20 metros de ancho, con una luz de malla de 1 centímetro. Los ejemplares colectados se anestesiaron con una mezcla de agua de la laguna con aceite de clavo (9 partes de aceite de clavo por una de alcohol etílico al $94 \%$, colocando $2 \mathrm{ml}$ por cada 5 litros de agua), para posteriormente ser fijados en formol al $10 \%$ y se conservaron en alcohol etílico al 70\%. De cada especie se determinó su abundancia en número y con la ayuda de la una balanza OHAUS, con $0.01 \mathrm{~g}$ de precisión, se determinó la biomasa. La determinación taxonómica de las especies se basó en las claves Castro-Aguirre et al. (1999), Carpenter (2002a; 2002b), McEachran y Fechhelm (2005) y Miller et al. (2009). Para cada uno de los muestreos se obtuvieron datos in situ de variables biológicas, como clorofila a, densidad fitoplanctónica y zooplanctónica, y de variables abióticas como la temperatura del agua, oxígeno disuelto (medidos con un oxímetro YSI 550A), salinidad (medida con un refractómetro de campo ATAGO S-10E) y estado de la boca (abierta/cerrada). Asimismo, se consideraron variables ambientales con influencia histórica y/o regional, como horas luz por día, precipitación y temperatura ambiental (mínima, normal, máxima) obtenidas del Sistema Meteorológico Nacional (CONAGUA, 2012), mientras que el nivel del agua (mareas) se obtuvo de las tablas de marea del Instituto de Geofísica de la UNAM. 


\section{Análisis de datos}

Para el análisis cuantitativo de la información, se construyeron bases de datos, que contenían en las columnas información de las variables ambientales y de la abundancia y biomasa de las especies, y en las filas las observaciones por época, hora, día/noche, mes y época. Los registros de las muestras se separaron por épocas climáticas: seca cálida (abril-mayo), Iluvias (junio-octubre) y seca fría (noviembrediciembre) para poder evaluar posibles cambios estacionales en la comunidad.

Se calculó la curva de acumulación de las especies del sistema costero con los índices Chao 1: $\left(S_{C h 1}=S_{o b s}+\frac{F_{1}^{2}}{2 F_{2}}\right)$, Chao 2: $\left(S_{C h 2}=S_{o b s}+\frac{Q_{1}^{2}}{2 Q_{2}}\right)$, Jackknife 1: $\left(S_{J 1}=S_{o b s}+Q_{1} \frac{m-1}{m}\right)$ y Jackknife 2: $\left(S_{J 2}=S_{o b s}+\left[Q_{1} \frac{2 m-3}{m}\right]-\left[Q_{2} \frac{(m-2)^{2}}{m(m-1)}\right]\right)$, para evaluar sí el esfuerzo de muestro fue suficiente.

donde:

Sobs $=$ Número de especies observadas .

$F_{1}=$ Número de especies observadas representadas por un solo individuo.

$F_{2}=$ Número de especies observadas representadas por dos individuos.

$Q_{1}=$ Número de especies presentes en una sola muestra.

$Q_{2}=$ Número de especies presentes en dos muestras.

$m$ = Número de muestreos. 
Posteriormente, se evaluó la abundancia total en número y biomasa, así como los parámetros de la comunidad: riqueza de especies (S), diversidad (1-D) y equidad $\left(E_{1 / D}\right)$. La riqueza de especies se determinó como el número de especies presentes en cada colecta; en el caso de la diversidad, se evaluó de acuerdo con el índice de Simpson $\left(1-D=1-\sum\left(p i^{2}\right)\right)$, por último, la equidad se evaluó con el índice de Simpson sesgado, para poblaciones infinitas, $\left(E_{1 / D}=\frac{1-\check{D}}{S}\right)$, índice independiente de la riqueza de especies (Krebs, 1999).

donde:

$P i=$ proporción de individuos de especies $i$ en la comunidad

Ď = Índice de dominancia de Simpson

S= número de peces en el muestreo

Los datos se analizaron vía PERMANOVA (análisis permutacional de varianza), la cual es una rutina para probar la respuesta simultánea de una o más variables a uno o más factores, sobre la base de cualquier medida de semejanza, utilizando múltiples permutaciones aleatorias de los datos a analizar, librando así los supuestos formales análogos a los análisis paramétricos tradicionales (Anderson 2001; Anderson et al., 2008). Para ello se evaluaron diferencias significativas entre periodos diarios (efecto día/noche) y estacionales (meses y efecto de lluvias) como factores fijos y la hora del día como factor aleatorio anidado dentro de períodos diarios. Para datos univariados se usó la distancia euclidiana y para datos multivariados se usó la distancia de similitud de Bray-Curtis (en datos 
transformados en raíz cuadrada y raíz cuarta, respectivamente, con un número de permutaciones=9999), lo cual también permitió comparaciones múltiples a posteriori entre los niveles de cada uno de los factores. Para examinar posibles diferencias en la estructura de los conjuntos de peces se aplicó el análisis para datos multivariados, usando la matriz de similitud de Bray-Curtis (Anderson, 2001; Anderson et al., 2008).

Se aplicó una prueba de Durbin-Watson para cada ciclo de 24 horas, para determinar si el valor de la abundancia en el tiempo $(t+1)$ se verá afectado por el valor de la abundancia en el tiempo (t) como resultado del muestreo intenso a lo largo del día, permitiendo determinar la independencia entre las muestras (Mendenhall \& Sincich, 2003).

Por otro lado, se aplicó el Análisis de Correspondencia Canónica (ACC), utilizando las bases de abundancias de especies (conjunto dependiente) y variables ambientales (conjunto independiente), así como para los parámetros de la comunidad, para interpretar las relaciones entre ambas. El ACC describió y visualizó las preferencias diferenciales del hábitat de las especies dentro de la comunidad, a través de un diagrama de ordenación (ter Braak y Verdonshot, 1995). El análisis permitió evaluar cuáles fueron las variables ambientales que jugaron un papel importante en la determinación en el comportamiento de la estructura de la comunidad (McGarigal et al., 2000). Para las especies dominantes se evaluó el grado de asociación con las variables biológicas y ambientales a través correlaciones simples, evaluando previamente los supuestos paramétricos (Chatterjee y Hadi, 2006). Si los supuestos se cumplían se aplicó la correlación de 
Pearson (r), y si no, la correlación de Spearman $\left(r_{s}\right)(Z a r, 2010)$. Asimismo, se aplicó una correlación cruzada entre dos variables de series temporales, la precipitación y el número de peces, para determinar si uno influye en la otra con un efecto retardado.

Finalmente, se aplicó un Análisis de Conglomerados (Clúster), para evaluar la posible formación de grupos con base en sus similitudes, usando la distancia de Bray-Curtis y el método de agrupamiento jerárquico de UPGMA (método de grupo de pares no ponderados con media aritmética; Krebs, 1999; McGarigal et al., 2000). Para evaluar diferencias significativas en los cambios de los conjuntos de peces, se realizó un análisis de similitud (ANOSIM) a nivel estacional (meses y épocas del año) y circadianos (día/noche y por hora). ANOSIM es una prueba multivariada no paramétrica, análoga al análisis de varianza de una vía, la cual se basa en la medida de similitud de Bray-Curtis de la abundancia de las especies entre muestras y dentro de las muestras, utilizando múltiples permutaciones aleatorias de los datos, para obtener el grado de similitud (R). El parámetro $R$ varía de -1 a 1, en donde los valores cercanos a cero son más similares que los valores cercanos a 1, existiendo diferencia con un nivel de significación $<0.1 \%$ (Clarke, 1993; Chapman \& Underwood, 1999; Marchant et al., 2000). 


\section{Resultados}

\section{Aspectos generales de la comunidad}

Del total de muestreos realizados en el sistema costero, se capturaron un total de 17,101 peces con un peso total de $104.309 \mathrm{Kg}$, correspondientes a 20 órdenes, 30 familias, 51 géneros y 81 especies. La familia mejor representada fue Gerreidae con 10 especies, seguida de Eleotridae, Engraulidae, Carangidae, Lutjanidae y Sciaenidae, con cinco especies cada una.

Por cada época del año se registró el número de familias y especies (Tabla 1). La composición varió a lo largo de las épocas climáticas, con mayor número de registros en la época de lluvia, con 29 familias y 76 especies, mientras que en la época de seca cálida se registraron 23 familias y 46 especies, y en la época de seca frías 21 familias y 53 especies.

La familia Gerreidae fue la más representativa en la época de seca cálida y lluvias, con 9 y 10 especies respectivamente, mientras que en la época de seca fría lo fueron las familias Carangidae y Engraulidae, con cinco especies cada una. 
Tabla 1. Número de familias y especies registradas por época climática.

\begin{tabular}{|c|c|c|c|}
\hline Época & $\begin{array}{c}\text { Secas-cálidas } \\
\text { (mayo-abril) }\end{array}$ & $\begin{array}{c}\text { Lluvias } \\
\text { (junio-octubre) }\end{array}$ & $\begin{array}{c}\text { Secas-frías } \\
\text { (noviembre-diciembre) }\end{array}$ \\
\hline Familias & $\begin{array}{l}\text { Gerreidae(10), } \\
\text { Sciaenidae(3), } \\
\text { Lutjanidae(3), } \\
\text { Centropomidae(3), } \\
\text { Engraulidae(3), } \\
\text { Gobiidae(3), } \\
\text { Hemiramphidae(2), } \\
\text { Ariidae(2), } \\
\text { Paralichthydae(2), } \\
\text { Clupeidae(2), } \\
\text { Belonidae(2), } \\
\text { Sparidae(1), } \\
\text { Ophichthidae(1), } \\
\text { Elopidae(1), } \\
\text { Echeneidae(1), } \\
\text { Trichuridae(1), } \\
\text { Sphyraenidae(1), } \\
\text { Synodontidae(1), } \\
\text { Mugilidae(1), } \\
\text { Poeciliidae(1), } \\
\text { Batrachoididae(1), } \\
\text { Dasyatidae(1), } \\
\text { Carangidae(1). }\end{array}$ & $\begin{array}{l}\text { Gerreidae (11), } \\
\text { Lutjanidae (5), } \\
\text { Engraulidae (5) } \\
\text { Sciaenidae(5), } \\
\text { Carangidae(4), } \\
\text { Gobiidae(4), } \\
\text { Mugilidae(3), } \\
\text { Eleotridae(4), } \\
\text { Belonidae(3), } \\
\text { Centropomidae(3), } \\
\text { Clupeidae(4), } \\
\text { Ariidae(3), } \\
\text { Paralichthydae(3), } \\
\text { Elopidae(1), } \\
\text { Hemiramphidae(2), } \\
\text { Polynemidae(2) } \\
\text { Sparidae(1), } \\
\text { Ophichthidae(2), } \\
\text { Achiridae(1), } \\
\text { Ephippidae(1), } \\
\text { Elopidae(1) } \\
\text { Trichuridae(1), } \\
\text { Sphyraenidae (1) } \\
\text { Serranidae(1), } \\
\text { Batrachoididae(1), } \\
\text { Synodontidae (1) } \\
\text { Dasyatidae(1), } \\
\text { Haemulidae(1), } \\
\text { Sygnathidae(1). }\end{array}$ & $\begin{array}{l}\text { Carangidae(5), } \\
\text { Engraulidae(5) } \\
\text { Mugilidae(4), } \\
\text { Gerreidae(4), } \\
\text { Belonidae(4), } \\
\text { Ariidae(3), } \\
\text { Centropomidae(3), } \\
\text { Lutjanidae(3), } \\
\text { Paralichthydae(3), } \\
\text { Gobiidae(3), } \\
\text { Sciaenidae(3), } \\
\text { Hemiramphidae(2), } \\
\text { Polynemidae(2), } \\
\text { Sygnathidae(2), } \\
\text { Elopidae(1), } \\
\text { Synodontidae(1), } \\
\text { Eleotridae(1), } \\
\text { Achiridae(1), } \\
\text { Batrachoididae(1), } \\
\text { Dasyatidae(1), } \\
\text { Trichuridae(1). }\end{array}$ \\
\hline
\end{tabular}

De acuerdo con los índices estimadores de especies, Chao 1 y 2, y Jackknife 1 y 2, en la Figura 2, se puede ver que se alcanza la asíntota alrededor de los muestreos del 50 al 100, esto se debe, principalmente, a que en los muestreos posteriores a esos ya no se encontrarán de manera significativa especies nuevas. Los índices de Chao 1 y 2 mostraron un acumulado total de alrededor de 84 especies, mientras que Jackknife 1 y 2 de 87 especies. 


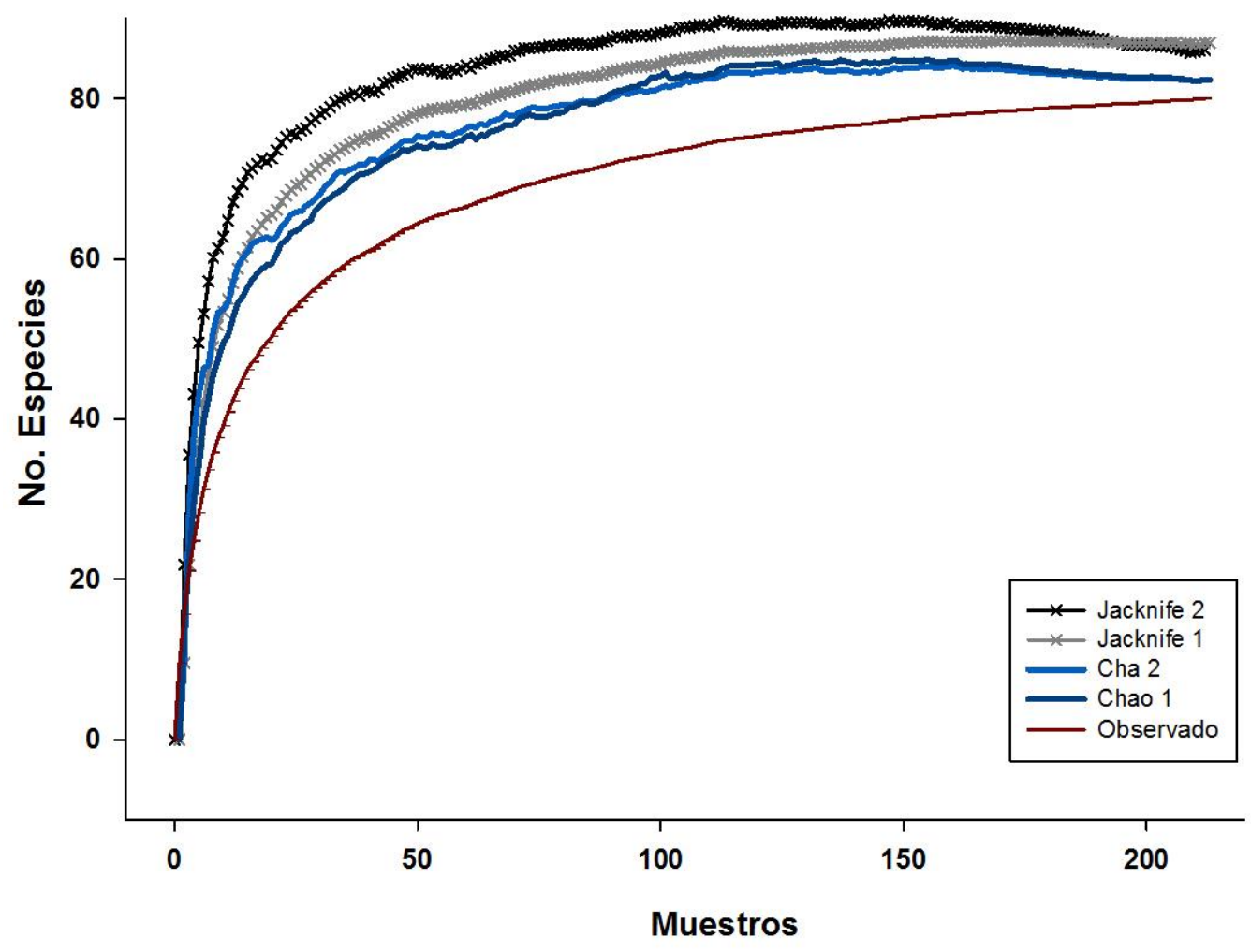

Figura 2. Estimación del número acumulado de especies capturadas en los 212 muestreos realizados, Chao 1, Chao 2, Jackknife 1 y Jackknife 2.

\section{Análisis de la abundancia y la biomasa}

Independencia entre las muestras. Los resultados obtenidos de la prueba de independencia de Durbin-Watson (D-W) para los muestreos realizados, se evaluaron por separado las réplicas uno y dos, para cada uno de los meses (Tabla 2). En este sentido, las muestras son independientes cuando el valor de D-W se encuentra dentro del intervalo de 1.5-2.5 (referencia) y se acepte la hipótesis nula, con una $\mathrm{p}>0.05$. Por lo anterior, si observamos los valores de la Tabla 4 , todos son independientes, es decir, el muestreo en el tiempo $t+1$ no se vio afectado por el 
muestreo en el tiempo t, por lo que el tipo de muestreo realizado no influenció en los resultados obtenidos anteriormente, ya que no hubo una disminución en la abundancia de los peces capturados entre los muestreos.

Tabla 2. Resultados de la prueba de independencia de Durbin-Watson para los muestreos realizados de abril a diciembre tanto para la réplica 1 como para la réplica 2.

\begin{tabular}{|l|c|c|c|c|}
\hline \multirow{2}{*}{ Mes } & \multicolumn{2}{|c|}{ Replica 1 } & \multicolumn{2}{c|}{ Replica 2 } \\
\cline { 2 - 5 } & $\mathrm{D}-\mathrm{W}$ & $\begin{array}{c}\text { Correlación } \\
(\mathrm{P})\end{array}$ & $\mathrm{D}-\mathrm{W}$ & $\begin{array}{c}\text { Correlación } \\
(\mathrm{P})\end{array}$ \\
\hline Abril & 1.511 & 0.704 & 1.720 & 0.575 \\
\hline Mayo & 2.250 & 0.202 & 1.693 & 0.577 \\
\hline Junio & 1.004 & 0.942 & 2.055 & 0.318 \\
\hline Julio & 2.364 & 0.145 & 2.398 & 0.132 \\
\hline Agosto & 2.471 & 0.106 & 1.194 & 0.87 \\
\hline Septiembre & 1.272 & 0.842 & 1.271 & 0.843 \\
\hline Octubre & 1.819 & 0.484 & 1.553 & 0.675 \\
\hline Noviembre & 1.258 & 0.849 & 2.498 & 0.096 \\
\hline Diciembre & 2.513 & 0.092 & 1.240 & 0.857 \\
\hline
\end{tabular}

Análisis estacional y circadiano. Durante los nueve meses analizados, las familias más abundantes fueron Engraulidae con 7,982 individuos con un peso de $10.52 \mathrm{Kg}$; Gerreidae con 3,720 individuos con un peso de $22.99 \mathrm{Kg}$; y Mugilidae con 2,933 individuos con un peso de $14.49 \mathrm{Kg}$, que representan el $46.7 \%, 21.8 \%$ y $17.2 \%$, respectivamente, de la abundancia total en número de la comunidad ictiofaunística.

La variación mensual, anidada en las épocas climáticas, de la abundancia y la biomasa, mostró diferencias significativas, con una media de 81 individuos y 492 g, respectivamente (Tabla 3). La abundancia total en número fue mayor en los meses de mayo y octubre, mientras que en los meses de agosto y diciembre la abundancia disminuyó considerablemente (Figura 3a). La biomasa, en algunos 
meses mostraron un patrón inverso a la variación de la abundancia en número, como se observa en la Figura 3b.
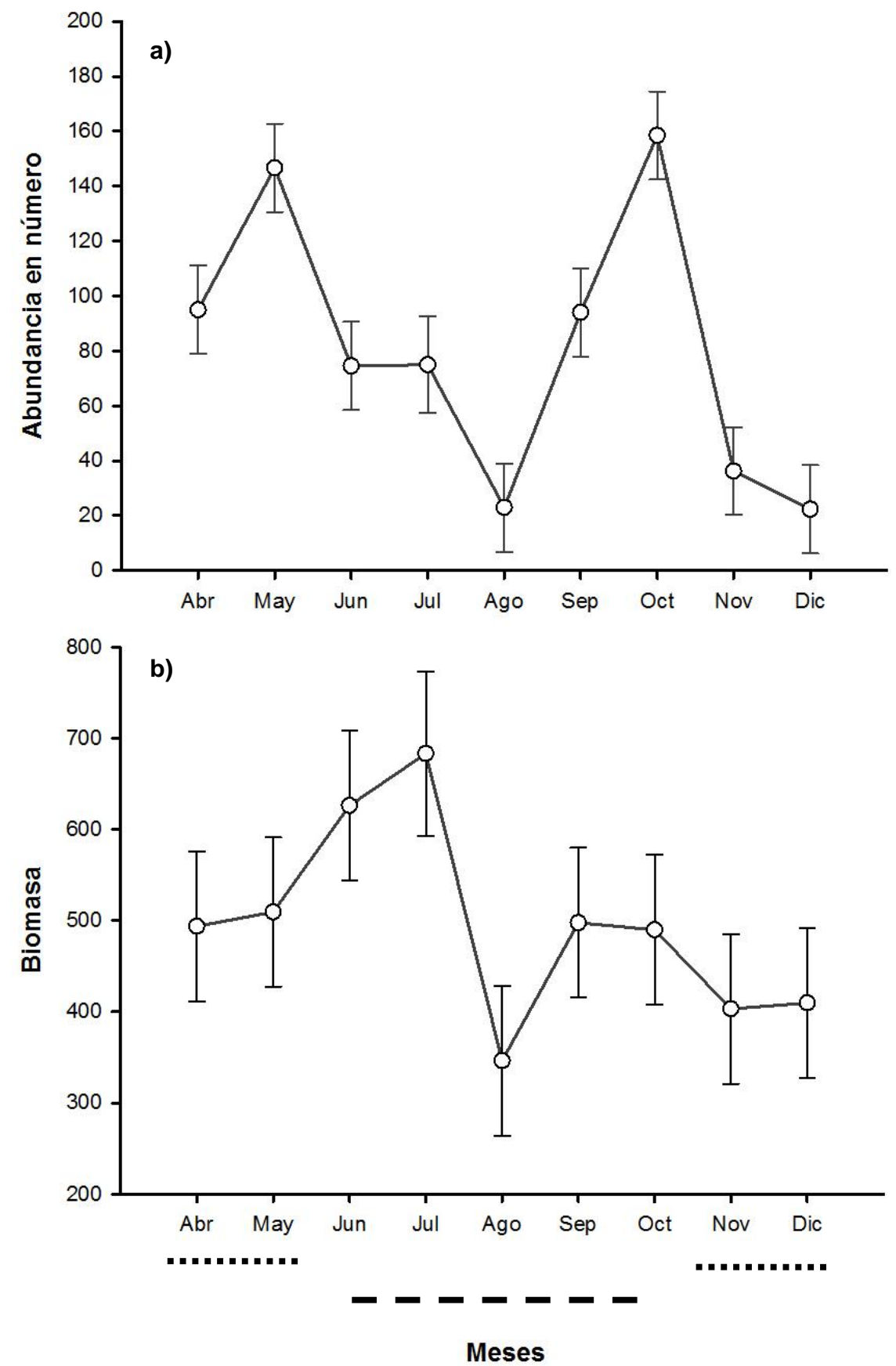

Figura 3. Variación promedio de la abundancia en número (a) y biomasa (b) de los organismos a lo largo de los meses de estudio. La línea punteada representa los meses de la época de secas y la línea punteada representa los meses en la época de lluvias. 
La abundancia en número y la biomasa fue mayor en época de lluvias respecto a las dos épocas de secas (Tabla 4), pero dicha variación no mostró diferencias significativas (Tabla 3).

En el caso de la variación circadiana, la abundancia mostró pulsos importantes en la noche, a las 20, 22 y 4 hrs, además, de uno menor al amanecer (6 hrs), con una disminución en horas de luz, siendo las 14 hrs la abundancia más baja a lo largo del día. Por otro lado, la biomasa sigue un patrón similar al de la abundancia en número (Figura 4). No obstante, la variación de ambas variables no mostró diferencias significativas entre día/noche, ni entre horas. 

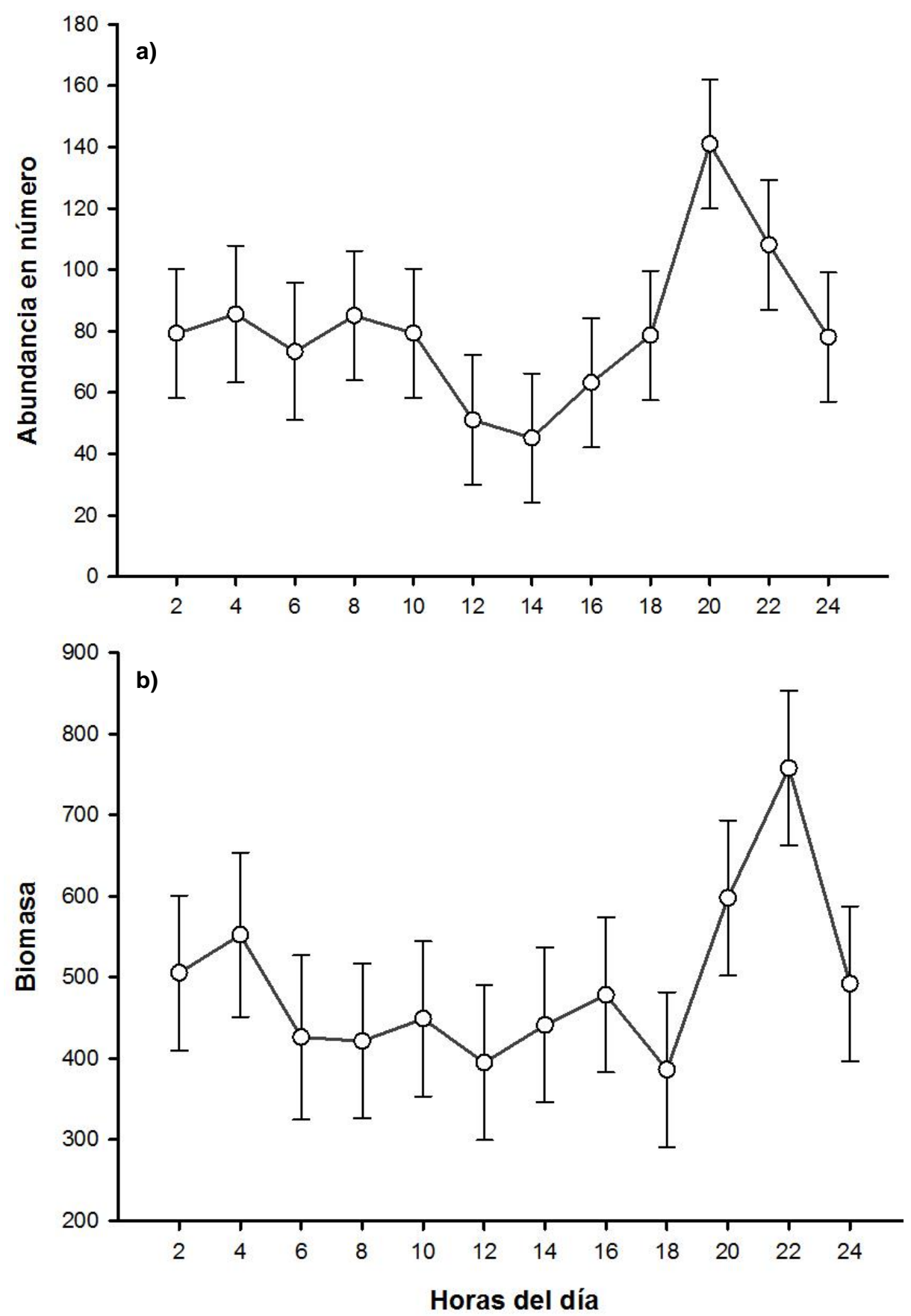

Figura 4.Variación circadiana cada dos hora de la abundancia en número (a) y biomasa (b) de los peces de la laguna costera La Mancha, Veracruz.

Finalmente, el comportamiento de la abundancia y biomasa mostró diferencias significativas entre la interacción entre los meses (anidados en las 
épocas del año) y día/noche, como se observa en la Tabla 3. Esto se debe a que en la mayoría de los meses, la abundancia y biomasa fueron mayores durante la noche, pero en los meses de mayo y julio la abundancia fue mayor durante el día, mientras que la biomasa lo fue en mayo y en junio.

Tabla 3. Análisis de PERMANOVA univariada, anidada, entre épocas del año (Ep), meses (Me), día/noche (DN) y horas (Hrs) sobre la abundancia total en número y la biomasa.

\begin{tabular}{lrrrrr}
\hline $\begin{array}{l}\text { Fuente } \\
\text { variación }\end{array}$ & g.l. & $\begin{array}{r}\text { Suma de } \\
\text { cuadrados }\end{array}$ & $\begin{array}{r}\text { Cuadrados } \\
\text { medios }\end{array}$ & $\begin{array}{r}\text { Pseudo } \\
\text { F }\end{array}$ & P \\
\hline Abundancia & 2 & 456.02 & 228.01 & 1.8086 & 0.1323 \\
Época & 1 & 68.777 & 68.77 & 1.4083 & 0.2317 \\
Día/Noche & 6 & 795.22 & 132.54 & 11.63 & 0.0001 \\
Me(Ep) & 12 & 193.54 & 16.129 & 1.4231 & 0.1848 \\
Hrs(DN) & 2 & 3.8798 & 1.9399 & 0.18964 & 0.9997 \\
Ep x DN & 20 & 250.71 & 12.535 & 1.1042 & 0.3781 \\
Ep x Hrs(DN) & 6 & 342.4 & 57.066 & 5.0077 & 0.0004 \\
DN x Me(Ep) & 58 & 661.04 & 11.397 & 1.1221 & 0.3044 \\
Me(Ep) x Hrs(DN) & 104 & 1056.3 & 10.157 & & \\
Error & 211 & 3945.3 & & & \\
Total & & & & & \\
Biomasa & 2 & 334.29 & 167.14 & 0.96134 & 0.4653 \\
Época & 1 & 532.72 & 532.72 & 3.0985 & 0.056 \\
Día/Noche & 6 & 942.74 & 157.12 & 2.623 & 0.0271 \\
Me(Ep) & 12 & 680.35 & 56.696 & 0.936 & 0.5165 \\
Hrs(DN) & 2 & 204.36 & 102.18 & 0.60605 & 0.7871 \\
Ep x DN & 20 & 1798.1 & 89.454 & 1.4817 & 0.1302 \\
Ep x Hrs(DN) & 6 & 1124.1 & 187.35 & 3.1275 & 0.0086 \\
DN x Me(Ep) & 58 & 3473.4 & 59.88 & 0.81786 & 0.7984 \\
Me(Ep) x Hrs(DN) & 104 & 7615.3 & 73.224 & & \\
Error & 211 & 16442 & & & \\
Total & & & & &
\end{tabular}

Tabla 4. Abundancia y peso total para cada época del sistema.

\begin{tabular}{lrr}
\hline Época & $\begin{array}{r}\text { Abundancia en } \\
\text { número }\end{array}$ & $\begin{array}{r}\text { Abundancia en } \\
\text { peso (g) }\end{array}$ \\
\hline Secas (Abril-Mayo) & 5,775 & $23,649.7$ \\
Lluvias (Junio-Septiembre) & 9,790 & $68,539.6$ \\
Secas (Noviembre-Diciembre) & 1,387 & $19,363.6$ \\
\hline
\end{tabular}




\section{Análisis de los parámetros de la comunidad}

De acuerdo con los análisis realizados hubo diferencias significativas entre meses, anidados en época, para los tres atributos comunitarios, riqueza, diversidad y equidad (Tabla 5). La riqueza de especies mostró pulsos máximos, muy marcados, en los meses de mayo, julio, septiembre y octubre, con $\bar{x}=10.12$, $\bar{x}=11.65, \bar{x}=12.54 \bar{x}=13.25$, respectivamente (Figura 5a), observándose en el mes de agosto la riqueza más baja en el periodo de estudio $(\bar{x}=5.53)$. La diversidad estuvo en un intervalo de 0.5 a 0.8 a lo largo de los meses, con pulsos máximos en julio, septiembre, noviembre y diciembre $(\bar{x}=0.76, \bar{x}=0.74, \bar{x}=0.69, \bar{x}=0.79$, respectivamente), y una diversidad baja en mayo y junio ( $\bar{x}=0.51$ y $\bar{x}=0.51$; Figura 5b). Por otra parte, la equidad tuvo un cierto comportamiento similar a la diversidad (Figura 5c), la cual mostró pulsos máximos en los meses de mayo, agosto y noviembre y diciembre $(\bar{x}=0.48, \bar{x}=0.60, \bar{x}=0.48, \bar{x}=0.66$, respectivamente), con mínimos en mayo y octubre ( $\bar{x}=0.29$ y 0.24$)$.

Por otro lado, entre épocas climáticas, la riqueza de especies fue mayor en la época de lluvias, con $\bar{x}=10.14$, mientras que la diversidad y la equidad lo fueron en la época de seca fría, con una $\bar{x}=0.74$ y $\bar{x}=0.57$ respectivamente (Tabla 6). Estos parámetros no mostraron diferencias significativas (Tabla 5).

Para el caso de la variación circadiana, la riqueza $(\bar{x}=9.48)$ presentó pulsos importantes en la noche, muy conspicuos a las 20 y $22 \mathrm{hrs,} \mathrm{con} \mathrm{un} \mathrm{promedio} \mathrm{de} 11$ y 9 especies respectivamente, y un valor mínimo en horas luz, a las 12 hrs (Figura 6a). En el caso de la diversidad ( $\bar{x}=0.67)$, los pulsos se observaron en horas luz, 
principalmente a las 14 y $16 \mathrm{hrs}$, con $\bar{x}=0.72$ y $\bar{x}=0.68$, y mínimos a las 6 y 24 hrs (Figura 6b). Por último, la equidad también fue mayor durante horas luz, observándose pulsos a las 10,12 y 14 hrs., con $\bar{x}=0.49, \bar{x}=0.56$ y $\bar{x}=0.59$ respectivamente, obteniendo los valores más bajos de las 22 a las 24 hrs, con un promedio de 0.37 para ambas horas (Figura 6c). A pesar de lo anterior, ningún parámetro mostró diferencias significativas entre día/noche y horas. 

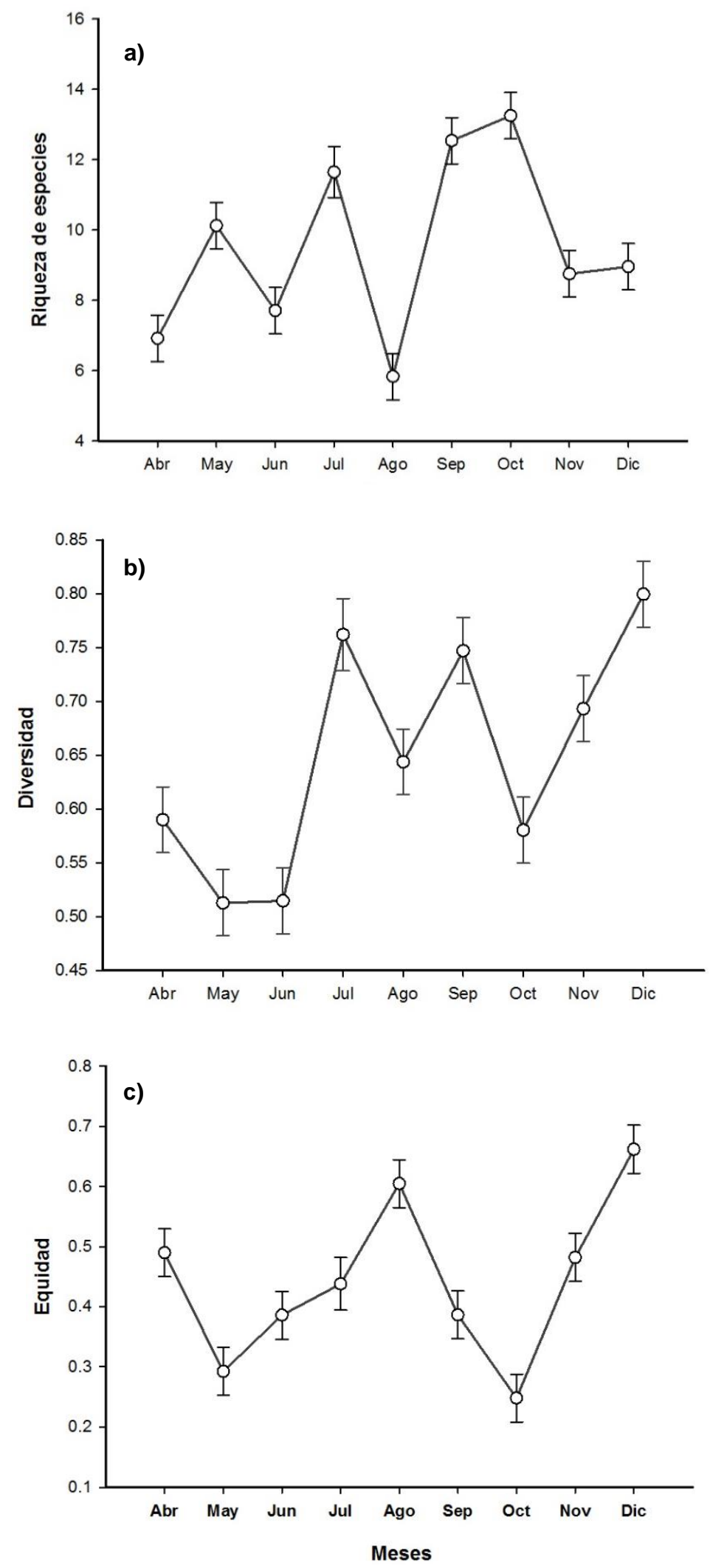

Figura 5. Variación estacional de los promedios de los parámetros de la comunidad: a) riqueza de especies; b) diversidad; c) equidad. 

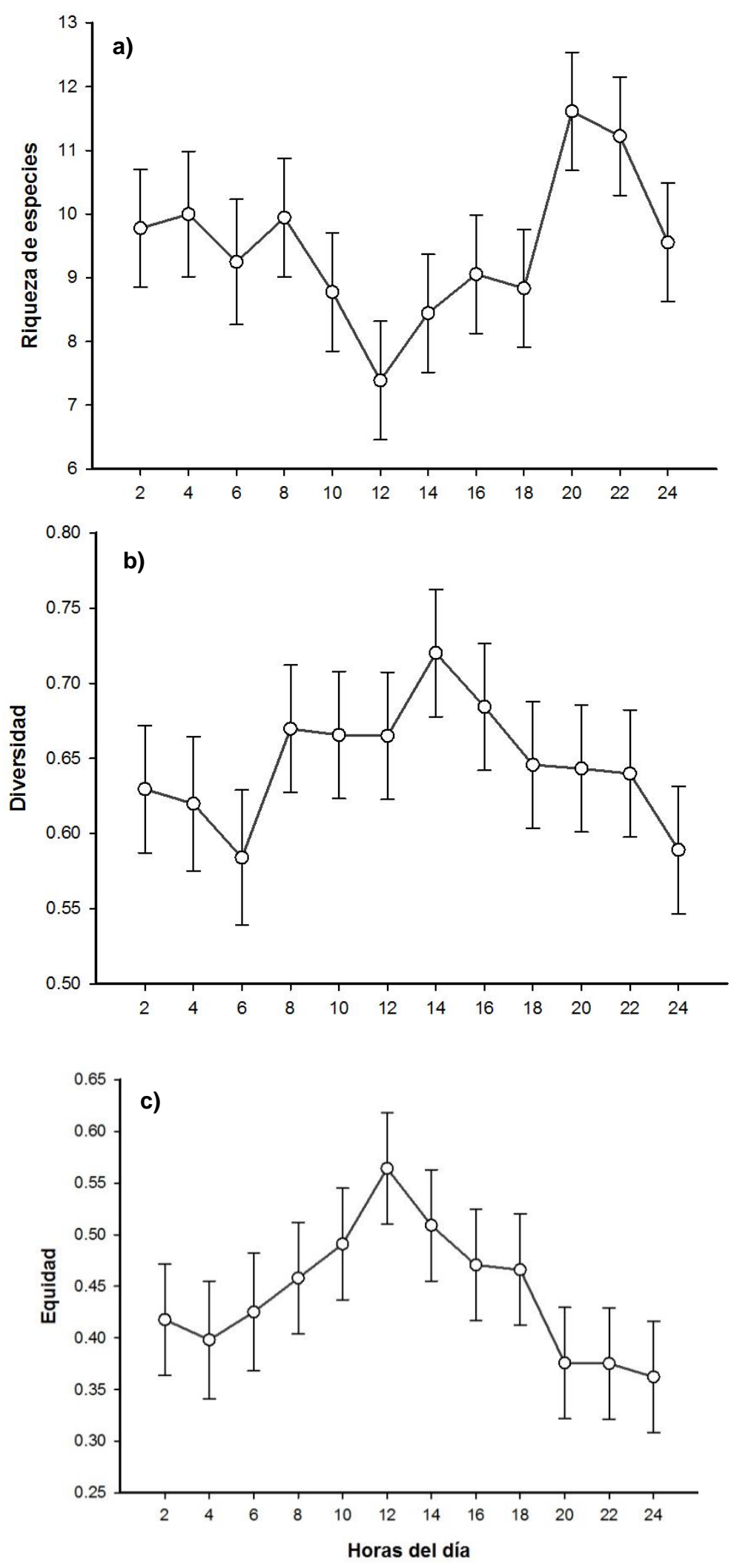

Figura 6. Variación circadiana de los promedios de los parámetros de la comunidad: a) riqueza de especies; b) diversidad; c) equidad. 
Asimismo, la riqueza de especies, la diversidad y la equidad mostraron diferencias significativas en la interacción entre los factores de día/noche respecto a los meses de año, anidados en las épocas climáticas (Tabla 5). Lo anterior, se debe a que se observó que la riqueza de especies en general fue mayor durante horas nocturnas, pero en lo meses de mayo, julio y septiembre este patrón se invirtió, mostrando una mayor riqueza durante horas luz. En el caso de la diversidad, se vio que en los meses de mayo, junio, septiembre y octubre fue mayor durante el día, mientras que en los meses de abril, julio, agosto, noviembre y diciembre el patrón cambió a ser mayor durante la noche. Por último, la equidad fue mayor durante horas luz, pero en los meses de mayo y julio este comportamiento cambió a presentarse una mayor equidad en la noche.

Tabla 5. Análisis de PERMANOVA univariada, anidada, entre los factores de épocas del año (Ep), meses (Me), día/noche (DN) y horas (Hrs) sobre la riqueza de especies, diversidad y Equidad.

\begin{tabular}{lrrrrr}
\hline $\begin{array}{l}\text { Fuente } \\
\text { variación }\end{array}$ & de & g.l. & $\begin{array}{r}\text { Suma de } \\
\text { cuadrados }\end{array}$ & $\begin{array}{r}\text { Cuadrados } \\
\text { medios }\end{array}$ & $\begin{array}{r}\text { Pseudo } \\
\text { F }\end{array}$ \\
\hline Riqueza & 2 & 4.8326 & 2.4163 & 0.5267 & 0.8535 \\
Época & 1 & 2.4537 & 2.4537 & 0.1236 & 0.1236 \\
Día/Noche & 6 & 30.022 & 5.0037 & 0.0001 & 0.0001 \\
Me(Ep) & 12 & 4.8736 & 0.4061 & 0.0686 & 0.0686 \\
Hrs(DN) & 2 & 3.6252 & 1.8126 & 0.2943 & 0.2943 \\
Ep x DN & 20 & 9.0838 & 0.4541 & 0.0201 & 0.0201 \\
Ep x Hrs(DN) & 6 & 7.6405 & 1.2734 & 0.0001 & 0.0001 \\
DN x Me(Ep) & 58 & 12.354 & 0.2129 & 0.9139 & 0.6351 \\
Me(Ep) x Hrs(DN) & 104 & 24.238 & 0.2330 & & \\
Error & 211 & 100.57 & & & \\
Total & & & & & \\
Diversidad & 2 & 0.4566 & 0.22832 & 2.1085 & 0.0778 \\
Época & 1 & 0.05143 & 0.05143 & 0.9675 & 0.3867 \\
Día/Noche & 6 & 0.64263 & 0.10711 & 9.3767 & 0.0001 \\
Me(Ep) & 12 & 0.14121 & 0.01176 & 1.041 & 0.414 \\
Hrs(DN) & 2 & 0.12528 & 0.06263 & 0.9084 & 0.5177 \\
Ep x DN & 20 & 0.34344 & 0.01717 & 1.5153 & 0.2292 \\
Ep x Hrs(DN) & 6 & 0.42307 & 0.07051 & 6.1731 & 0.0002 \\
DN x Me(Ep) & 58 & 0.66268 & 0.01142 & 1.2593 & 0.1533 \\
Me(Ep) x Hrs(DN) & 54 & 0.9436 & 0.00907 & & \\
Error & 104 & & & &
\end{tabular}




\begin{tabular}{lrrrrr} 
Total & 211 & 3.5506 & & & \\
Equidad & & & & & \\
Época & 2 & 0.63842 & 0.31921 & 1.3779 & 0.2475 \\
Día/Noche & 1 & 0.14423 & 0.14423 & 1.8044 & 0.1561 \\
$\mathrm{Me}(\mathrm{Ep})$ & 6 & 1.4575 & 0.24292 & 13.032 & 0.0001 \\
$\mathrm{Hrs}(\mathrm{DN})$ & 12 & 0.18831 & 0.01569 & 0.84801 & 0.5903 \\
Ep x DN & 2 & 0.052879 & 0.02644 & 0.36869 & 0.9696 \\
Ep x Hrs(DN) & 20 & 0.511551 & 0.02557 & 1.379 & 0.1935 \\
$\mathrm{DN} \times \mathrm{Me}(\mathrm{Ep})$ & 6 & 0.61166 & 0.10194 & 5.459 & 0.0005 \\
$\mathrm{Me}(\mathrm{Ep}) \times \mathrm{Hrs}(\mathrm{DN})$ & 58 & 1.0813 & 0.01864 & 1.1684 & 0.2506 \\
Error & 104 & 1.6594 & 0.01595 & & \\
Total & 211 & 6.6395 & & & \\
\hline
\end{tabular}

Tabla 6. Promedio de los parámetros de la comunidad registrada para cada época climática.

\begin{tabular}{lrrc}
\hline Época/estación & Riqueza & Diversidad & Equidad \\
\hline Seca cálida & 8.52 & 0.55 & 0.39 \\
Lluvias & 10.14 & 0.64 & 0.41 \\
Seca fría & 8.85 & 0.74 & 0.57 \\
\hline
\end{tabular}

Por último, de acuerdo con la influencia de los factores ambientales sobre los parámetros de la comunidad, el ACC explicó el 100\% de la varianza acumulada constreñida en los dos primeros ejes. El biplot de las especies-variables ambientales mostró valores del $99.3 \%$ para el eje 1 y un $0.7 \%$ para el eje 2 , con una significancia de $\mathrm{p}=0.002$ (Tabla 7 ). En esta misma Tabla 7 , se presentan los valores de las correlaciones inter-set, los cuales muestran que las variables con mayor influencia sobre la riqueza, diversidad y equidad para el primer eje fueron, según el orden de importancia, la salinidad, el efecto luz/oscuridad, la temperatura ambiental máxima mensual y la precipitación máxima mensual. 
Tabla 7. Resultados del ACC aplicados a las variables ambientales y a los parámetros de la comunidad (riqueza, diversidad y equidad). Variables ambientales con importancia para cada eje canónico fueron marcadas con asterisco $\left({ }^{*}\right)$.

\begin{tabular}{lrr}
\hline & Eje 1 & Eje 2 \\
\hline Porcentaje constreñido acumulado & 99.3 & 100 \\
Correlación especies-variables & 0.549 & 0.169 \\
\hline Correlaciones Inter-set & & \\
Día/noche & $0.2478^{*}$ & 0.0636 \\
Temperatura del agua & 0.0852 & -0.0970 \\
Salinidad & $0.2752^{*}$ & 0.0098 \\
Oxígeno disuelto & 0.0457 & -0.0942 \\
Apertura/cierre de la boca & 0.0186 & $0.1322^{*}$ \\
Precipitación máxima mensual & $-0.1301^{*}$ & 0.0083 \\
Temperatura ambiental máxima mensual & $-0.2088^{*}$ & -0.0912 \\
Fitoplancton & -0.0659 & 0.0252 \\
Zooplancton & -0.0049 & -0.0141 \\
\hline & $\mathrm{F}$ & $\mathrm{P}$ \\
Significancia de los ejes canónicos & 8.830 & 0.002 \\
\hline
\end{tabular}

El diagrama de ordenación (Figura 7) mostró que la riqueza de especies estuvo influenciada principalmente por la temperatura del aire, siendo mayor durante la noche y cuando la boca del sistema se encontraba cerrada. Los análisis de correlación simple mostraron que la diversidad tuvo mayor relación con la salinidad, debido a que presentó una correlación positiva con esta variable, mientras que con el oxígeno disuelto y la temperatura ambiental su relación fue negativa, con una mayor diversidad durante las horas luz y cuando la boca permanecía abierta. Finalmente, la equidad, al igual que la diversidad, tuvo una correlación positiva con la salinidad, con el oxígeno disuelto y la temperatura del agua. La equidad también fue mayor cuando la boca estaba abierta y durante el día. En el caso de la influencia del fitoplancton y el zooplancton sobre los parámetros fue muy baja. 


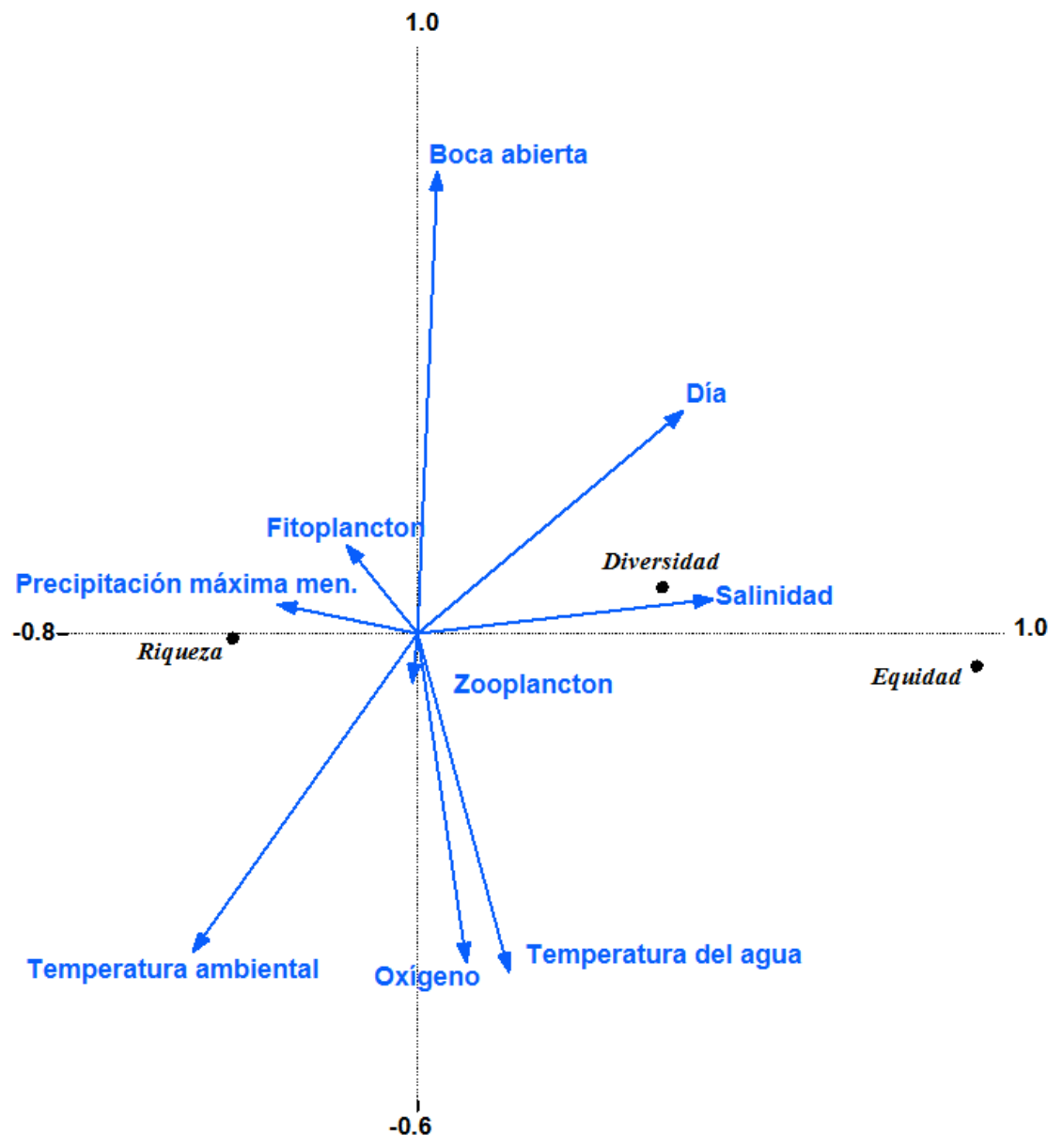

Figura 7. Diagrama de ordenación de las variables ambientales (flechas) y los parámetros de la comunidad de peces (puntos) de La Mancha.

\section{Variación estacional y circadiana en la estructura de la comunidad}

El comportamiento de la abundancia en número del conjunto de especies de toda de la comunidad mostró diferencias significativas entre épocas, meses y día/noche, pero no entre horas. De todas las interacciones entre factores, solo una fue significativa (día/noche y mes, anidado en las épocas climáticas) (Tabla 8). Esto se debió a que especies como Anchoa mitchilli, Diapterus rhombeus, Eucinostomus gula y Mugil curema cambiaron, en algún mes del año, su comportamiento circadiano. Anchoa mitchilli en general fue más abundante durante la noche, pero 
en el mes de julio (lluvias) su abundancia fue mayor durante horas de luz. En el caso de Diapterus rhombeus, así como $A$. mitchilli, presentó con mayor actividad nocturna, pero este comportamiento cambió a ser mayor durante el día en el mes septiembre (época de lluvias). Finalmente, a diferencia de estas especies, E. gula y $M$. curema presentaron una importante actividad durante horas de luz, pero en los meses de abril (secas cálidas) y septiembre (lluvias), respectivamente, dicho comportamiento cambió siendo más abundantes durante la noche.

Tabla 8. Análisis de PERMANOVA multivariada, anidada, entre los factores de épocas del año (Ep), meses (Me), día/noche (DN) y horas (Hrs) sobre la composición de especies.

\begin{tabular}{lrrrrr}
\hline Fuente de variación & g.l. & $\begin{array}{r}\text { Suma de } \\
\text { cuadrados }\end{array}$ & $\begin{array}{r}\text { Cuadrados } \\
\text { medios }\end{array}$ & $\begin{array}{r}\text { Pseudo } \\
\mathbf{F}\end{array}$ & P \\
\hline Épocas (Ep) & 2 & 65622 & 32811 & 1.9024 & 0.0066 \\
Día/Noche (DN) & 1 & 24417 & 24417 & 4.9709 & 0.0001 \\
Mes(Ep) & 6 & 11400000 & 19047 & 13.143 & 0.0001 \\
Horas(DN) & 12 & 19767 & 1647.2 & 1.1318 & 0.2395 \\
Ep x DN & 2 & 8706.7 & 4353.3 & 1.0076 & 0.4541 \\
Ep x Hrs(DN) & 20 & 25952 & 1297.6 & 0.893 & 0.728 \\
DN x Me(Ep) & 6 & 29118 & 4852.9 & 3.3486 & 0.0001 \\
Mes(Ep) x Hora(DN) & 58 & 84023 & 1448.7 & 0.89275 & 0.9474 \\
Error & 104 & $1.69 E+05$ & 1622.7 & & \\
Total & 211 & $5.70 E+05$ & & & \\
\hline
\end{tabular}

Ensambles en las especies de peces. En el análisis de similitud entre los meses del año, obtuvo una $R$ general de 0.482 , con una $p=0.0001$, lo cual significa que la composición de las especies muestra ciertas superposiciones de poblaciones, pero también importantes diferencias entre éstas. Por otro lado, en la Tabla 9 se puede observar que la composición de especies del mes de abril (época seca-cálida) fue la que mostró mayores diferencias con el resto de los meses (principalmente con septiembre y octubre - época de lluvias). Asimismo, las 
menores diferencias se detectaron entre meses de la misma época. Resultados similares se observaron en el dendrograma (Figura 8). La composición y estructura de la comunidad varió de un mes a otro. El mes de abril fue dominada por Anchoa mitchilli y A. hepsetus. En mayo A. mitchilli siguió como la especie dominante, en el sistema, seguida de Mugil curema y A. hepsetus. En junio A. mitchilli, siguió siendo la especie más abundante, seguida de E. gula. En julio la especie dominante cambió, siendo la más abundante $M$. curema, seguida de Caranx hippos y $E$. melanopterus. La abundancia de las especies para el mes de agosto fue muy baja, la composición de la comunidad estuvo dominada por $M$. curema y $E$. melanopterus, con abundancias cerca de 135 individuos. Ya en septiembre la abundancia de las especies aumentó y de igual modo que en el mes anterior, $M$. curema fue la más abundante, seguida de $A$. mitchilli, Diapterus auratus y $E$. melanopterus. En el mes de octubre la comunidad de peces fue dominada de nueva cuenta por A. mitchilli. En el mes de noviembre la abundancia de las especies, disminuyó drásticamente, pero a pesar de la disminución en el número de individuos, la composición de especies siguió dominada por $A$. mitchilli seguida de E. melanopterus y M. curema. Finalmente, para el mes de diciembre, la abundancia de las especies siguió descendiendo hasta llegar a una abundancia por debajo de los 100 individuos, en donde la comunidad estuvo dominada por $D$. rhombeus.

Así también, se pudo observar en el clúster (Figura 8) una clara separación entre los meses de boca cerrada (abril, mayo y junio) y boca abierta (julio, agosto, septiembre, octubre, noviembre y diciembre). El análisis de similitud entre los dos estados de la boca mostró diferencias significativas $(R=0.37 ; p=0.0001)$ en la 
estructura y composición de las especies. Anchoa mitchilli, M. curema y $A$. hepsetus, fueron las especies más abundantes cuando la boca del sistema se encontraba cerrada, mientras que A. mitchilli, M. curema y E. melanopterus lo fueron cuando el sistema se encontraba abierto. De las especies capturadas, en el sistema, 41 se presentaron dentro del mismo en ambos estados de la boca. Por otro lado, La abundancia de A. mitchilli, E. gula, Strongylura notata, Lagodon rhomboides, B. gunteri e Hyporhamphus meeki fue mayor cuando estaba la boca cerrada en comparación cuando está abierta, además, se capturaron 10 especies que no se registraron con la barrera de sistema abierta. Por otro lado, cuando la boca se encuentra abierta la abundancia de 35 especies fue mayor, en relación a cuando se encuentra cerrada la laguna, como M. curema, E. melanopterus, $D$. rhombeus, C. hippos, Ariopsis felis, Citharichthys spilopterus, C macrops, Cetengraulis edentulus, Centropomus undecimalis y Lutjanus griseus. Además, en esta fase de la boca ingresaron al sistema 31 especies que no fueron capturadas cuando el sistema se encontraba cerrado. 
Tabla 9. Matriz de similitud (ANOSIM) entre los meses del año.

\begin{tabular}{|c|c|c|c|c|c|c|c|c|c|}
\hline Mes & Abr & May & Jun & Jul & Ago & Sep & Oct & Nov & Dic \\
\hline \multicolumn{10}{|l|}{ Abr } \\
\hline May & $\begin{array}{l}R=0.297 \\
p=0.0001\end{array}$ & & & & & & & & \\
\hline Jun & $\begin{array}{l}R=0.439 \\
p=0.0001\end{array}$ & $\begin{array}{l}R=0.298 \\
p=0.0001\end{array}$ & & & & & & & \\
\hline Jul & $\begin{array}{l}R=0.787 \\
p=0.0001\end{array}$ & $\begin{array}{l}R=0.593 \\
p=0.0001\end{array}$ & $\begin{array}{l}R=0.547 \\
p=0.0001\end{array}$ & & & & & & \\
\hline Ago & $\begin{array}{l}R=0.701 \\
p=0.0001\end{array}$ & $\begin{array}{l}R=0.559 \\
p=0.0001\end{array}$ & $\begin{array}{l}R=0.437 \\
p=0.0001\end{array}$ & $\begin{array}{l}R=0.301 \\
p=0.0001\end{array}$ & & & & & \\
\hline Sep & $\begin{array}{l}R=0.809 \\
p=0.0001\end{array}$ & $\begin{array}{l}R=0.624 \\
p=0.0001\end{array}$ & $\begin{array}{l}R=0.703 \\
p=0.0001\end{array}$ & $\begin{array}{l}R=0.472 \\
p=0.0001\end{array}$ & $\begin{array}{l}R=0.472 \\
p=0.0001\end{array}$ & & & & \\
\hline Oct & $\begin{array}{l}R=0.83 \\
p=0.0001\end{array}$ & $\begin{array}{l}R=0.662 \\
p=0.0001\end{array}$ & $\begin{array}{l}R=0.697 \\
p=0.0001\end{array}$ & $\begin{array}{l}R=0.546 \\
p=0.0001\end{array}$ & $\begin{array}{l}R=0.575 \\
p=0.0001\end{array}$ & $\begin{array}{l}R=0.149 \\
p=0.0003\end{array}$ & & & \\
\hline Nov & $\begin{array}{l}R=0.585 \\
p=0.0001\end{array}$ & $\begin{array}{l}R=0.453 \\
p=0.0001\end{array}$ & $\begin{array}{l}R=0.536 \\
p=0.0001\end{array}$ & $\begin{array}{l}R=0.435 \\
p=0.0001\end{array}$ & $\begin{array}{l}R=0.327 \\
p=0.0001\end{array}$ & $\begin{array}{l}R=0.326 \\
p=0.0001\end{array}$ & $\begin{array}{l}R=0.270 \\
p=0.0001\end{array}$ & & \\
\hline Dic & $\begin{array}{l}R=0.714 \\
p=0.0001\end{array}$ & $\begin{array}{l}R=0.585 \\
p=0.0001\end{array}$ & $\begin{array}{l}R=0.540 \\
p=0.0001\end{array}$ & $\begin{array}{l}R=0.429 \\
p=0.0001\end{array}$ & $\begin{array}{l}R=0.301 \\
p=0.0001\end{array}$ & $\begin{array}{l}R=0.393 \\
p=0.0001\end{array}$ & $\begin{array}{l}R=0.360 \\
p=0.0001\end{array}$ & $\begin{array}{l}R=0.093 \\
p=0.007\end{array}$ & \\
\hline
\end{tabular}

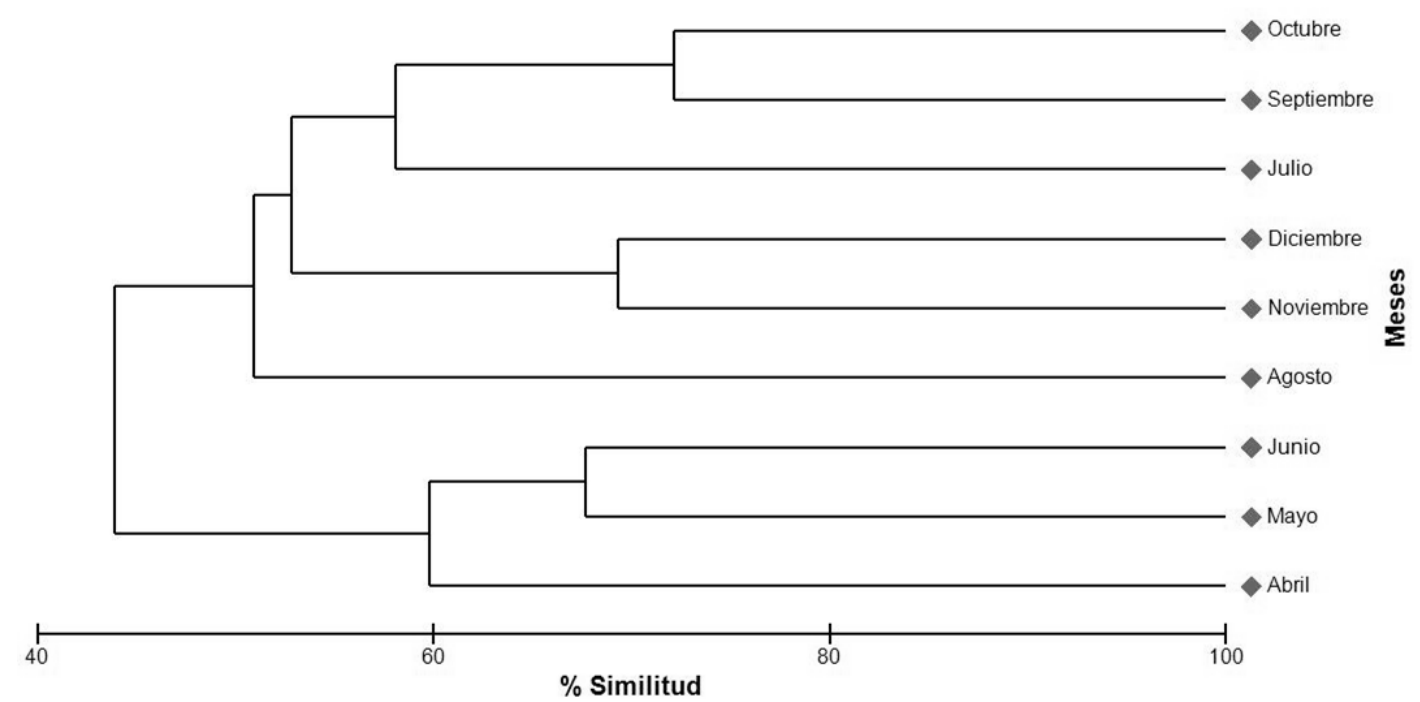

Figura 8. Dendrograma resultante del análisis de conglomerados, entre los meses del año. 
Por otro lado, el ANOSIM entre épocas del año mostró una similitud de una $R$ global de 0.268 y una $p=0.0001$. En la Tabla 8 , se observa que existen pocas diferencias en la composición de especies entre las épocas de lluvias y seca fría, mientras que la máxima diferencia en la composición se observó entre las dos épocas de secas. Resultados similares se pueden observar en el dendrograma (Figura 9), el cual forma dos grupos. El primero lo forman la época de seca-cálida y lluvias, dejando en el segundo grupo solo a la época de seca-fría.

La abundancia de las especies varió entre una y otra época climática. Durante la época de seca-cálida las especies dominantes fueron A. mitchilli, A. hepsetus y M. curema. En la época de lluvias A. mitchilli, M. curema y E. melanopterus fueron las especies más dominantes. Asimismo, en la época de seca-cálida de las especies registradas 9 fueron las más abundantes, respecto a la época de lluvias, mientras que otras 3 solo se registraron en esta época. En la época de lluvias $A$. mitchilli, M. curema y E. melanopterus fueron las especies dominantes en el sistema. Del total de especies registradas en lluvias 33 aumentaron su abundancia respecto a la época de seca-cálida, además, de registrarse 30 especies nuevas que no se registraron en la época anterior.

En la época de seca-fría las especies más abundantes fueron $A$. mitchilli, $E$. melanopterus, M. curema y D. rhombeus. Se observó que especies como Anchoa lamprotaenia, Polydactylus octonemus y Anchoa lyolepis aumentaron su abundancia en comparación con los registros en época de lluvias, además, de registrarse 4 especies que no fueron capturadas en lluvias. Por otro lado, la composición de especies en las dos épocas de secas, mostró que para la época de 
seca-cálida se capturaron 47 especies y 53 especies para la época de seca-fría. De ese registro, 15 especies capturadas en seca-cálida no se registraron en fría, mientras que 21 especies solo fueron capturadas en seca-fría. En ambas épocas de secas se registraron 32 especies comunes, las cuales fueron más abundantes durante la época de seca-cálida que en la época fría. Estas diferencias se corroboraron con el análisis de similitud (Tabla 10), mostrando que a pesar que las condiciones climáticas no son muy diferentes, la estructura de la comunidad difiere bastante entre estas épocas.

Tabla 10. Matriz de similitud (ANOSIM) entre las épocas del año.

\begin{tabular}{|l|l|l|l|}
\hline Época & Seca-cálida & Lluvias & Seca-fría \\
\hline Seca-cálida & & & \\
\cline { 1 - 2 } Lluvias & $R=0.352$ & & \\
& $p=0.0001$ & & \\
\cline { 1 - 2 } Seca-fría & $R=0.579$ & $R=0.175$ & \\
& $p=0.0001$ & $p=0.0001$ & \\
\hline
\end{tabular}
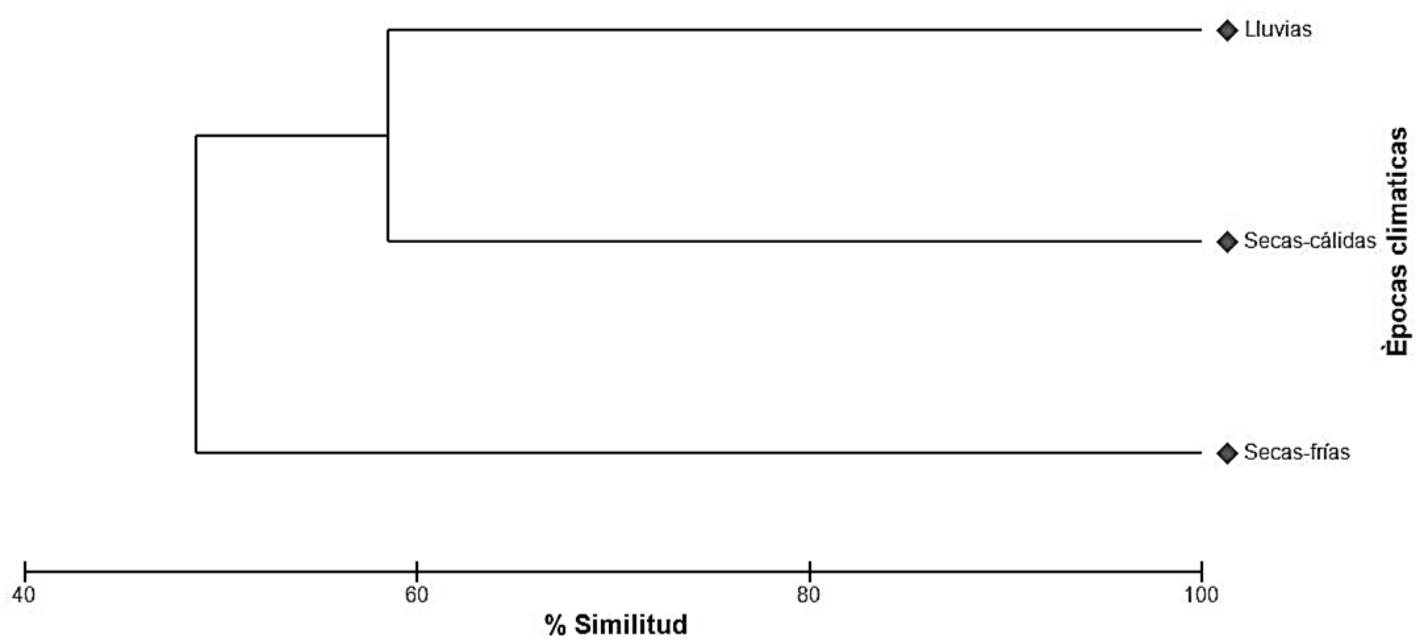

Figura 9. Dendrograma resultante del análisis de conglomerados, entre las temporadas del año. 
Finalmente, el ANOSIM por hora (Tabla 11) mostró que las menores diferencias (regularmente $\mathrm{R}<0.02$ ) se observaron entre las horas de día, las horas de noche y entre las horas de penumbra (06:00 y 18:00 $h ; R=0)$. Diferencias mayores en la estructura $(R>0.2)$ tendieron a observarse entre las horas del día y de la noche $(R=0.081 ; p=0.0001)$. Asimismo, se pudo observar (Figura 10), una clara división formando dos grupos entre las horas luz y las horas oscuridad. El grupo correspondiente a las horas de oscuridad, lo conforman las 24, 22, 20, 6, 4 y 2 hrs, mientras que el segundo grupo que correspondiente a las horas luz, lo conforman las 8, 10, 12 14, 16 y 18 hrs. Así también, si observamos la Tabla 11 y la Figura 10, podemos ver que las $6 \mathrm{hrs,} \mathrm{hora} \mathrm{del} \mathrm{amanecer,} \mathrm{muestra} \mathrm{un} \mathrm{alto} \mathrm{nivel}$ de semejanza con las horas de oscuridad, mientras que las 18 horas, hora crepuscular, tiende a asemejarse mucho con las horas luz. Se observó que existe una semejanza en la composición de especies entre el día y la noche, pero con algunas diferencias $(R=0.178 ; p=0.0001)$.

La composición de las especies, respecto a la separación de las horas entre el día y la noche, radicó en las especies registradas para ambos periodos. Por un lado, se registraron 73 especies para el grupo de las horas de oscuridad, mientras que para las horas luz se registraron 68 especies, de las cuales entre día y noche compartieron 62 especies. Aunado a esto, las especies como M. curema, E. melanopterus y $D$. rhombeus fueron más abundantes durante las horas del día, mientras que $A$. mitchilli y $A$. hepsetus lo fueron en la noche. 


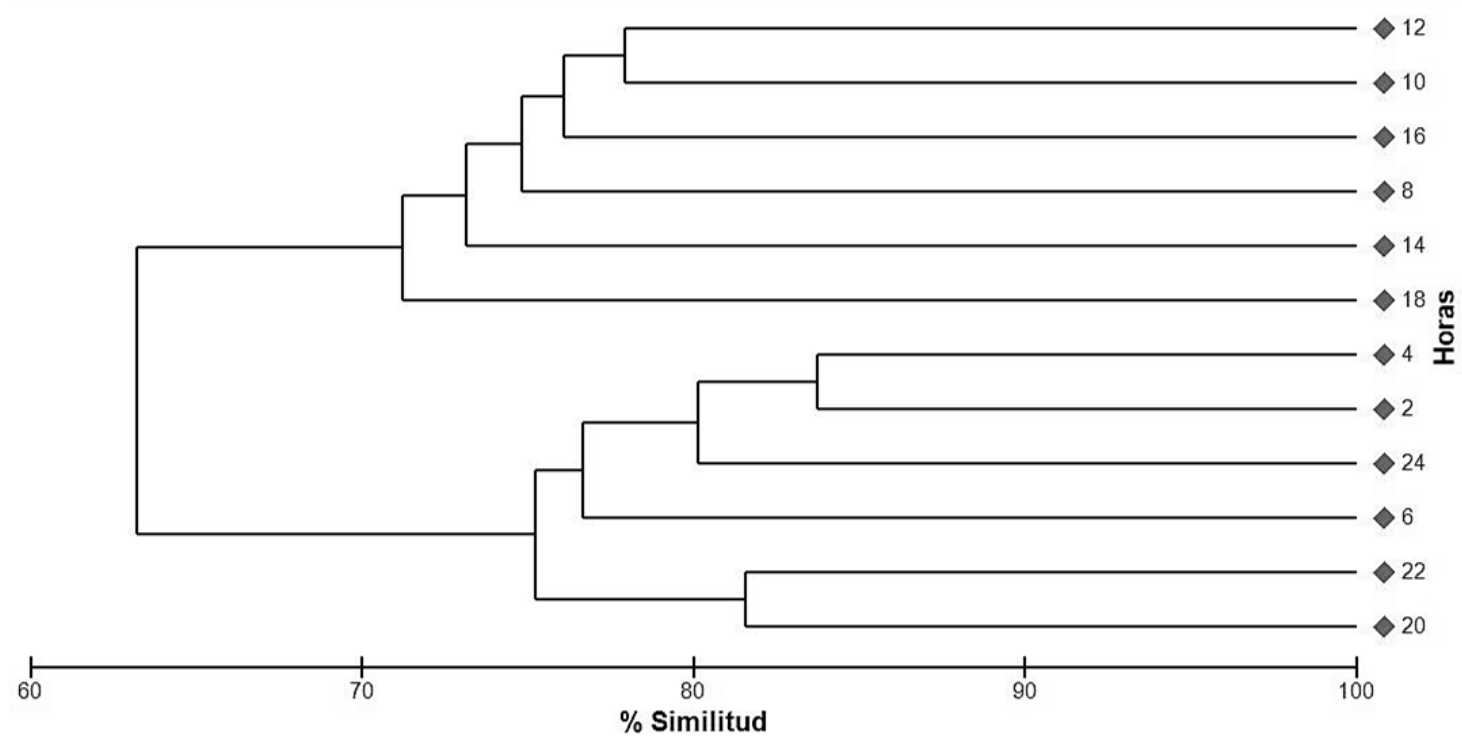

Figura 10. Dendrograma resultante del análisis de conglomerados, entre las horas del día. 
Tabla 11. Análisis de similitud (ANOSIM) entre las horas del día.

\begin{tabular}{|c|c|c|c|c|c|c|c|c|c|c|c|c|}
\hline Hora & 2 & 4 & 6 & 8 & 10 & 12 & 14 & 16 & 18 & 20 & 22 & 24 \\
\hline 2 & & & & & & & & & & & & \\
\hline 4 & $\begin{array}{l}R=-0.063 \\
p=0.976\end{array}$ & & & & & & & & & & & \\
\hline 6 & $\begin{array}{l}R=0.026 \\
p=0.238\end{array}$ & $\begin{array}{l}R=0.014 \\
p=0.298\end{array}$ & & & & & & & & & & \\
\hline 8 & $\begin{array}{l}R=0.193 \\
p=0.0003\end{array}$ & $\begin{array}{l}R=0.152 \\
p=0.003\end{array}$ & $\begin{array}{l}R=-0.004 \\
p=0.483\end{array}$ & & & & & & & & & \\
\hline 10 & $\begin{array}{l}R=0.203 \\
p=0.0002\end{array}$ & $\begin{array}{l}R=0.177 \\
p=0.0006\end{array}$ & $\begin{array}{l}R=-0.008 \\
p=0.537\end{array}$ & $\begin{array}{l}R=-0.041 \\
p=0.90\end{array}$ & & & & & & & & \\
\hline 12 & $\begin{array}{l}R=0.238 \\
p=0.0002\end{array}$ & $\begin{array}{l}R=0.230 \\
p=0.0001\end{array}$ & $\begin{array}{l}R=0.018 \\
p=0.27\end{array}$ & $\begin{array}{l}R=-0.019 \\
p=0.683\end{array}$ & $\begin{array}{l}R=-0.056 \\
p=0.983\end{array}$ & & & & & & & \\
\hline 14 & $\begin{array}{l}R=0.216 \\
p=0.0001\end{array}$ & $\begin{array}{l}R=0.214 \\
p=0.0003\end{array}$ & $\begin{array}{l}R=0.057 \\
p=0.08\end{array}$ & $\begin{array}{l}R=0.028 \\
p=0.193\end{array}$ & $\begin{array}{l}R=0.016 \\
p=0.276\end{array}$ & $\begin{array}{l}R=0.019 \\
p=0.238\end{array}$ & & & & & & \\
\hline 16 & $\begin{array}{l}R=0.225 \\
p=0.0002\end{array}$ & $\begin{array}{l}R=0.204 \\
p=0.0004\end{array}$ & $\begin{array}{l}R=0.007 \\
p=0.37\end{array}$ & $\begin{array}{l}R=-0.045 \\
p=0.927\end{array}$ & $\begin{array}{l}R=-0.048 \\
p=0.955\end{array}$ & $\begin{array}{l}R=0.040 \\
p=0.90\end{array}$ & $\begin{array}{l}R=-0.026 \\
p=0.764\end{array}$ & & & & & \\
\hline 18 & $\begin{array}{l}R=0.138 \\
p=0.04\end{array}$ & $\begin{array}{l}R=0.123 \\
p=0.01\end{array}$ & $\begin{array}{l}R=0.000 \\
p=0.43\end{array}$ & $\begin{array}{l}R=0.017 \\
p=0.275\end{array}$ & $\begin{array}{l}R=-0.020 \\
p=0.692\end{array}$ & $\begin{array}{l}R=0.014 \\
p=0.31\end{array}$ & $\begin{array}{l}R=0.047 \\
p=0.097\end{array}$ & $\begin{array}{l}R=0.013 \\
p=0313\end{array}$ & & & & \\
\hline 20 & $\begin{array}{l}R=-0.01 \\
p=0.565\end{array}$ & $\begin{array}{l}R=0.028 \\
p=0.21\end{array}$ & $\begin{array}{l}R=0.021 \\
p=0.256\end{array}$ & $\begin{array}{l}R=0.108 \\
p=0.04\end{array}$ & $\begin{array}{l}R=0.110 \\
p=0.04\end{array}$ & $\begin{array}{l}R=0.186 \\
p=0.0004\end{array}$ & $\begin{array}{l}R=0.172 \\
p=0.004\end{array}$ & $\begin{array}{l}R=0.135 \\
p=0.02\end{array}$ & $\begin{array}{l}R=0.066 \\
p=0.048\end{array}$ & & & \\
\hline 22 & $\begin{array}{l}R=-0.025 \\
p=0.39\end{array}$ & $\begin{array}{l}R=-0.019 \\
p=0.662\end{array}$ & $\begin{array}{l}R=0.066 \\
p=0.053\end{array}$ & $\begin{array}{l}R=0.155 \\
p=0.0003\end{array}$ & $\begin{array}{l}R=0.157 \\
p=0.0003\end{array}$ & $\begin{array}{l}R=0.223 \\
p=0.0001\end{array}$ & $\begin{array}{l}R=0.24 \\
p=0.0001\end{array}$ & $\begin{array}{l}R=0.217 \\
p=0.0001\end{array}$ & $\begin{array}{l}R=0.151 \\
p=0.001\end{array}$ & $\begin{array}{l}R=-0.037 \\
p=0.877\end{array}$ & & \\
\hline 24 & $\begin{array}{l}R=-0.014 \\
p=0.618\end{array}$ & $\begin{array}{l}R=-0.050 \\
p=0.937\end{array}$ & $\begin{array}{l}R=0.06 \\
p=0.069\end{array}$ & $\begin{array}{l}R=0.168 \\
p=0.0005\end{array}$ & $\begin{array}{l}R=0.189 \\
p=0.248\end{array}$ & $\begin{array}{l}R=0.248 \\
p=0.0001\end{array}$ & $\begin{array}{l}R=0.218 \\
p=0.001\end{array}$ & $\begin{array}{l}R=0.227 \\
p=0.0001\end{array}$ & $\begin{array}{l}R=0.153 \\
p=0.001\end{array}$ & $\begin{array}{l}R=0.008 \\
p=0.359\end{array}$ & $\begin{array}{l}R=-0.075 \\
p=0.740\end{array}$ & \\
\hline
\end{tabular}


Influencia de las variables ambientales sobre la abundancia de las especies

Inicialmente, a la abundancia total en número de peces, se aplicó una correlación simple para observar relaciones con la temperatura del agua, salinidad, oxígeno disuelto, precipitación promedio mensual y concentración de fitoplancton y zooplancton. El análisis sólo mostró una relación inversa significativa con la salinidad en el agua $(r=-0.670, p=0.0479)$ y el zooplancton $(r=-0.714, p=0.0465)$ (Figura 11). Asimismo, se aplicó el análisis de correlación cruzada, el cual no mostró un efecto de retraso de la abundancia total en número en relación con otras variables.

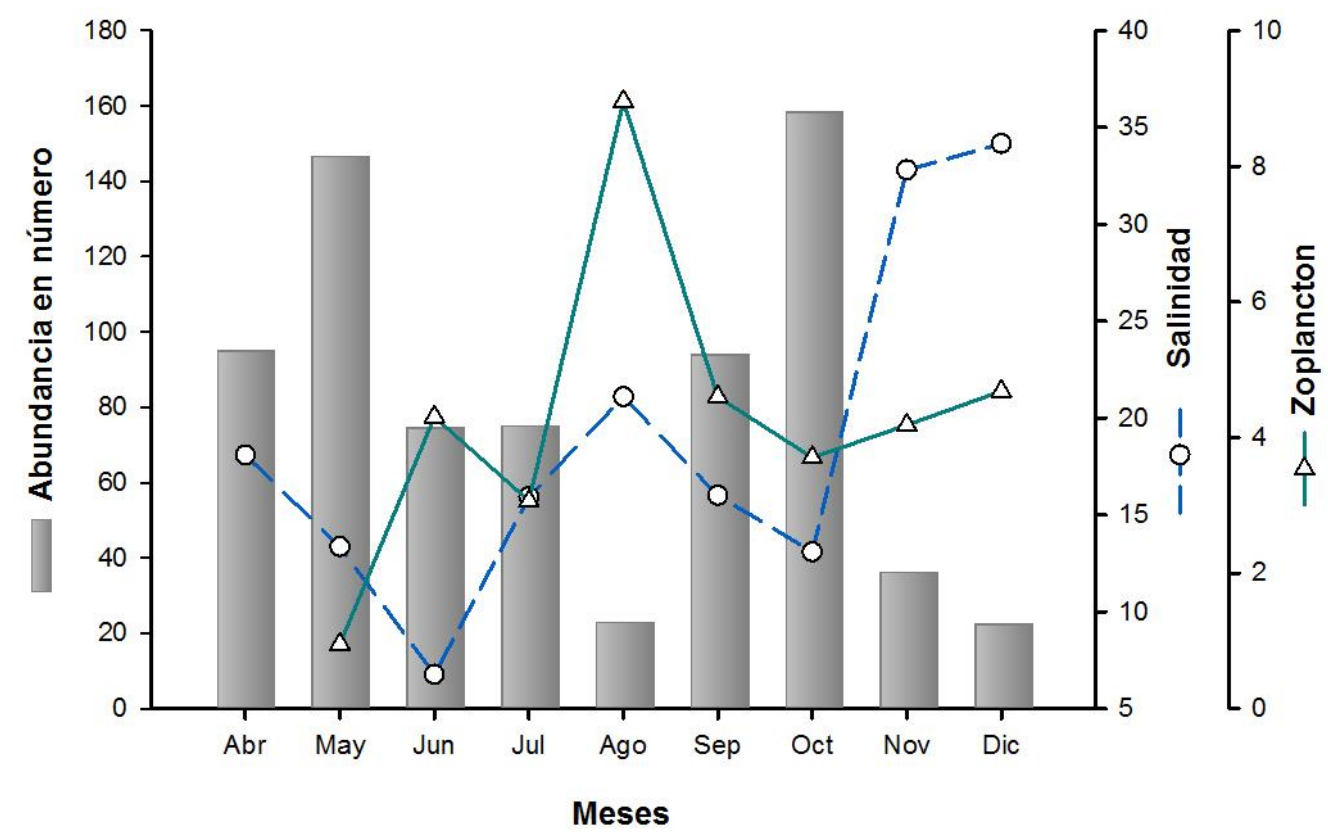

Figura 11. Variación estacional de la abundancia total promedio y su relación con la concentración de la salinidad y el zooplancton.

Respecto a la influencia de las variables ambientales sobre cada una de las especies, también se realizó un Análisis de Correspondencia Canónica (ACC). EI 
ACC (Tabla 12) explicó un $63.8 \%$ de la varianza acumulada constreñida en los dos primeros ejes. El biplot de las especies-variables ambientales mostró valores para el eje 1 de $42.1 \%$ y para el eje 2 de $21.7 \%$, con una significancia de $p=0.002$.

De acuerdo, con los valores de las correlaciones inter-set, las variables ambientales que mostraron mayor influencia sobre la abundancia de las especies para el primer eje fueron, según su orden de importancia, apertura/cierre de la boca, oxígeno disuelto y fitoplancton, mientras que para el segundo eje fueron día/noche, salinidad y precipitación promedio mensual.

Tabla 12. Resultados del ACC aplicados a las variables ambientales y a la abundancia de la comunidad de especies de peces, de la laguna costera "La Mancha". Variables ambientales con importancia para cada eje canónico fueron marcadas con asterisco $\left(^{*}\right)$.

\begin{tabular}{lrr}
\hline & Eje 1 & Eje 2 \\
\hline Porcentaje constreñido acumulado & 42.1 & 63.8 \\
Correlación especies-variables & 0.915 & 0.828 \\
\hline Correlaciones Inter-set & & \\
Día/noche & -0.0304 & $0.6475^{*}$ \\
Temperatura del agua & 0.1828 & -0.2065 \\
Salinidad & -0.2263 & $-0.5369^{*}$ \\
Oxígeno disuelto & $0.4267^{*}$ & -0.1880 \\
Apertura/cierre de la boca & $-0.9030^{*}$ & -0.0238 \\
Precipitación promedio mensual & -0.2589 & $0.4834^{*}$ \\
Fitoplancton & $-0.2893^{*}$ & 0.0095 \\
Zooplancton & -0.1662 & -0.0466 \\
\hline & $\mathrm{F}$ & $\mathrm{P}$ \\
Significancia de los ejes canónicos & 6.713 & 0.002 \\
\hline
\end{tabular}

Asimismo, en el diagrama de ordenación derivado del ACC (Fig. 12), se puede observar la influencia que ejercen las variables ambientales sobre las especies presentes en la laguna costera. 
Aunque en el planteamiento inicial del presente estudio, el estado de la boca (abierta/cerrada) no fue considerado, a partir del ACC esta variable resultó ser un elemento importante sobre las preferencias de hábitat de los peces. En la Figura 12 se puede observar que la mayoría de las especies estuvieron influenciadas por el estado abierto de la boca.

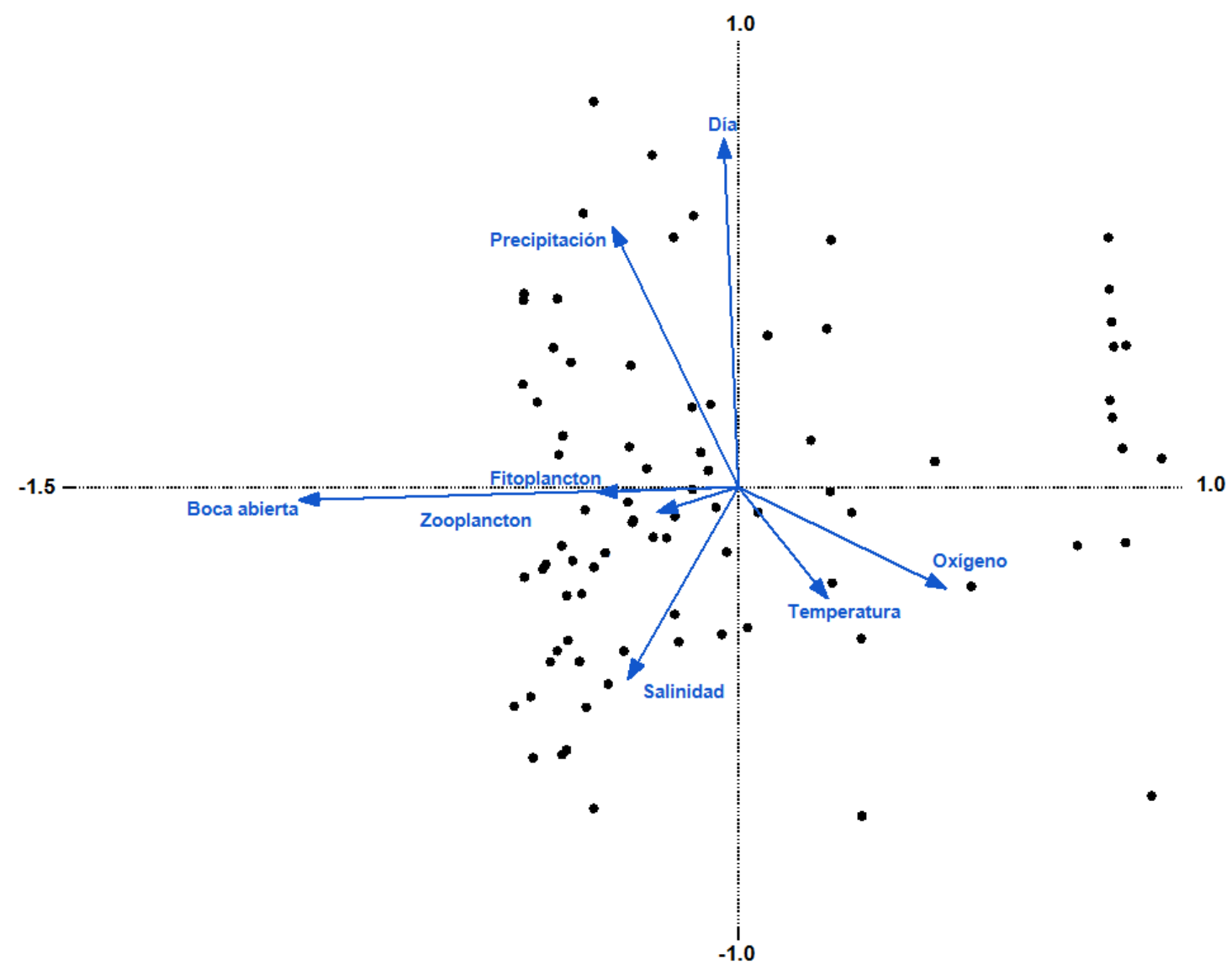

Figura 12. Diagrama de ordenación de las variables ambientales (flechas) y las especies (puntos) de la comunidad de peces de La Mancha.

\section{Variación estacional de la abundancia de las especies dominantes}

Considerando los resultados del ACC, se analizaron individualmente los patrones de abundancia en número de las especies más abundantes $(n>100$ 
individuos), de los cuales ninguno mostró un efecto de retardo en relación a la precipitación.

Anchoa mitchilli. La especie presentó pulsos de abundancia en mayo, en la época de secas cálidas, y en octubre, en el periodo de transición, como se muestra en la Figura 13. Así también, mostró una importante actividad nocturna. Las condiciones del ambiente que prefirió $A$. mitchilli fueron concentraciones bajas de sal en el agua $(r=-0.766, p=0.015)$, como se observa en la Figura 13 , ya que al incrementar la salinidad en el medio la abundancia de la especie disminuyó. También prefirió altas temperaturas, concentraciones altas de oxígeno y bajas concentraciones de fitoplancton y zooplancton en el sistema.

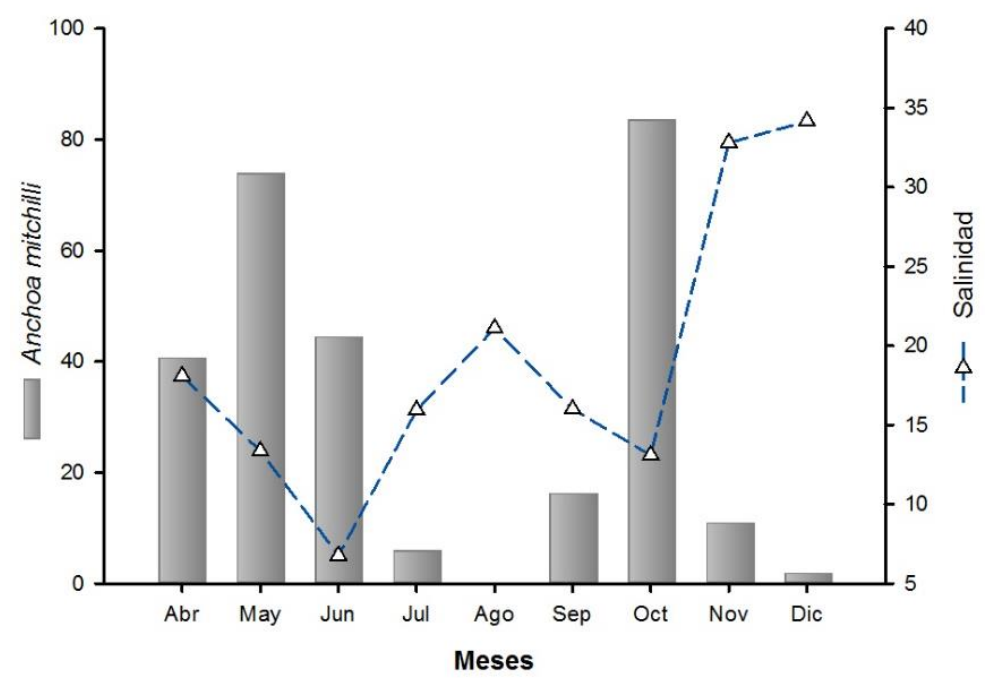

Figura 13. Variación estacional de la abundancia de Anchoa mitchilli y su relación con algunas de las variables ambientales.

Anchoa lamprotaenia. En el caso de esta especie la mayor abundancia se registró en noviembre y diciembre, en la época se secas frías, pero con importantes pulsos en agosto y septiembre, durante la época de lluvias (Figura 14), con 
importante actividad durante la noche. Asimismo, si observamos la Figura 10 la especie mostró preferencias por temperaturas bajas $(r=-0.741, p=0.022)$, concentraciones altas de sal $(r=0.848, p=0.003)$ y de fitoplancton $(r=0.831$, $\mathrm{p}=0.010$ ), además, de concentraciones altas de zooplancton y bajas de oxígeno disuelto.

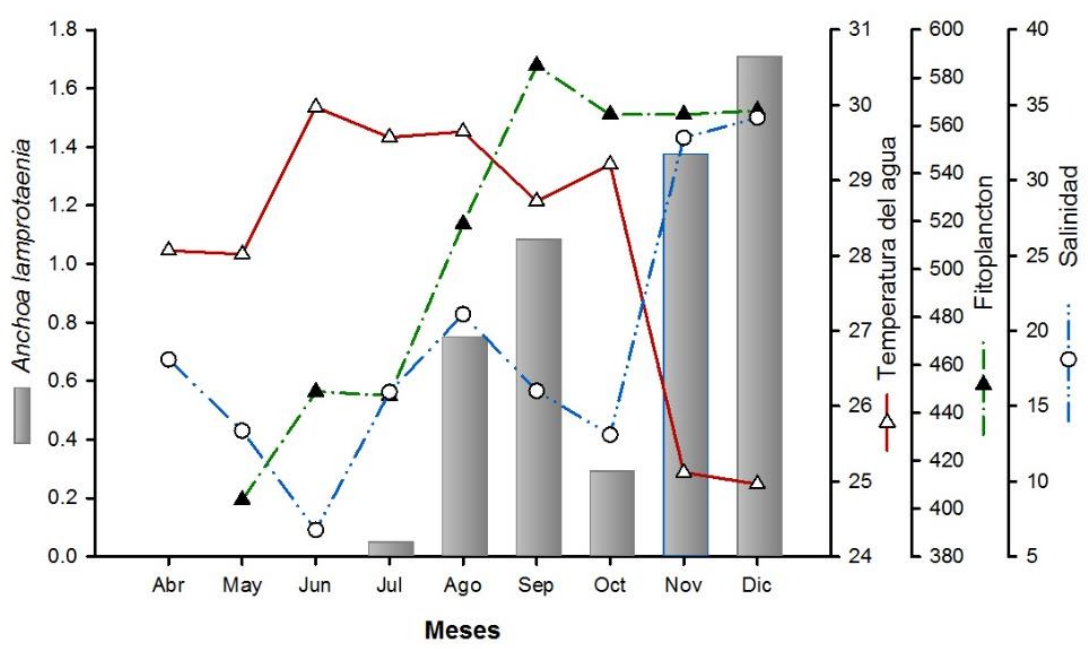

Figura 14. Variación estacional de la abundancia de Anchoa lamprotaenia y su relación con algunas de las variables ambientales.

Anchoa hepsetus. Hubo dos pulsos importantes en su abundancia durante la época de secas cálidas, en los meses de abril y mayo (Figura 15), con importante actividad nocturna. Anchoa hepsetus mostró preferencias por condiciones ambientales, especificas en el agua, como lo fue temperaturas altas, altas concentraciones de oxígeno disuelto, pero bajas en la salinidad. Se observó que la especie prefirió permanecer en el sistema cuando se mantenían bajas concentraciones en el fitoplancton y el zooplancton. 


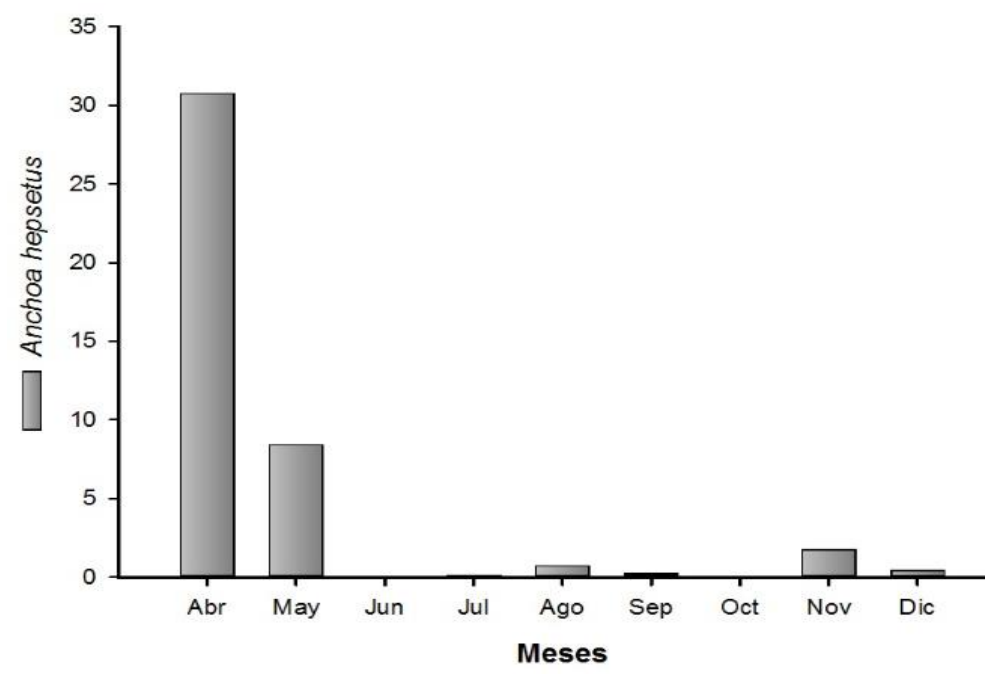

Figura 15. Variación estacional de la abundancia de Anchoa hepsetus.

Cetengraulis edentulus. La abundancia de la especie mostró importantes pulsos en los meses de septiembre (lluvias) y octubre (periodo de transición), como se muestra en la Figura 16, y así como todas las especies del género Anchoa, también se observó que $C$. edentulus tuvo importante actividad durante la noche. Se observó que prefirió temperaturas altas en el agua, bajas concentraciones de sal y tendió a altas concentraciones de oxígeno, además, de mostrar preferencias por zooplancton. 


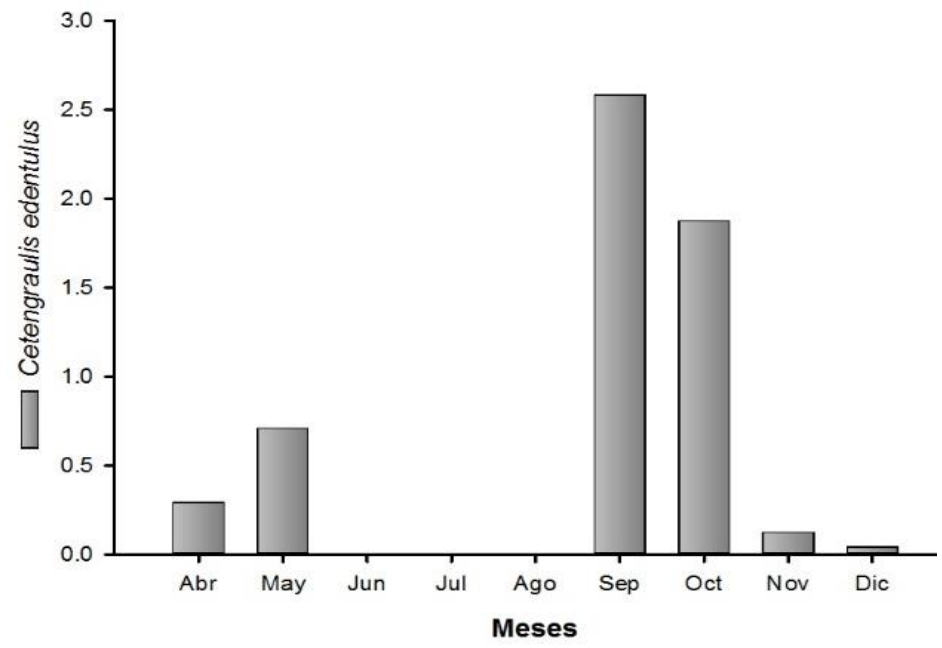

Figura 16. Variación estacional de la abundancia de Cetengraulis edentulus.

Ariopsis felis. Esta especie fue una de las que tuvo presencia en el sistema durante todo el año, pero con importantes pulsos en su abundancia en los meses de octubre (periodo de transición) y noviembre (secas frías), como se observa en la Figura 17, con importante actividad durante horas luz. La especie se mantuvo en el sistema cuando la temperatura del agua era baja, con concentraciones bajas de oxígeno, altas concentraciones de salinidad y presencia, considerable, de fitoplancton y zooplancton.

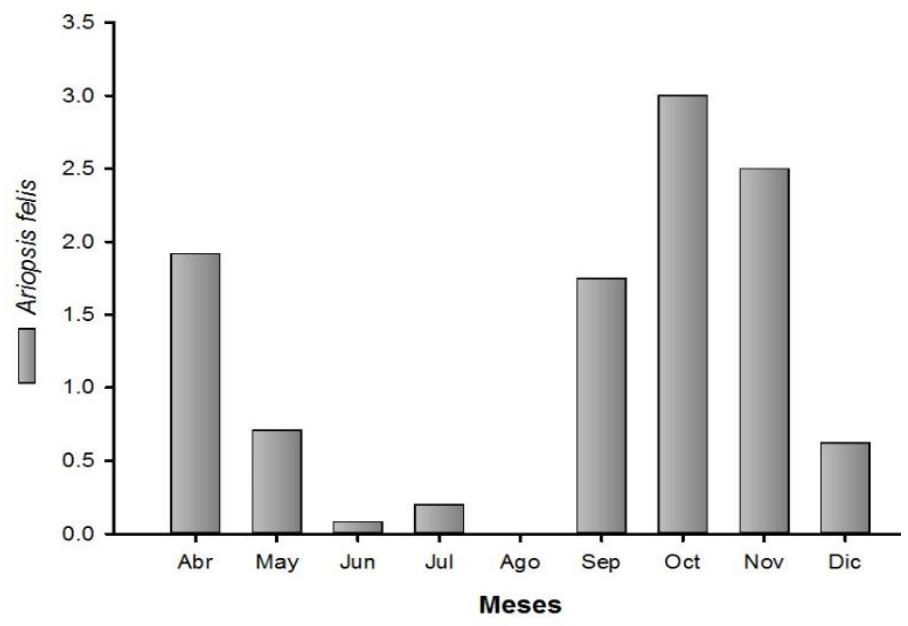

Figura 17. Variación estacional de la abundancia de Ariopsis felis. 
Cathorops aguadulce. Este bagre estuvo presente todo el periodo de estudio, con pulsos importantes en mayo, septiembre y octubre, pero siendo más abundantes en la época de lluvias, como se observa en la Figura 18, con actividad importante durante la noche. Las condiciones ambientales que prefirió la especie fueron temperaturas moderadas, concentraciones bajas tanto de oxígeno disuelto como de salinidad, además, de no preferir, de manera importante zooplancton y fitoplancton.

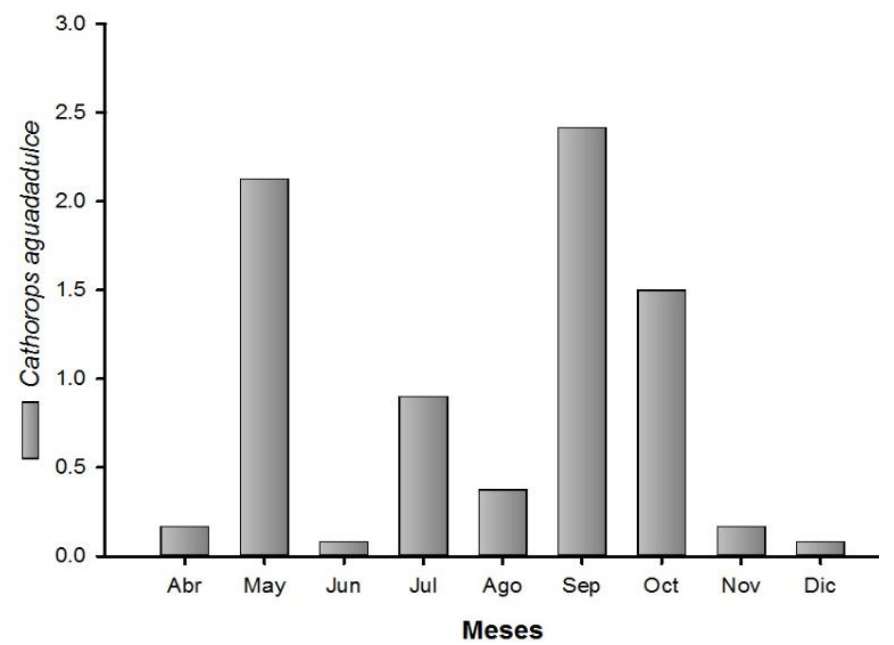

Figura 18. Variación estacional de la abundancia de Cathorops aguadulce.

Mugil curema. Esta especie se encuentra en casi todo el año de muestreo (Figura 19), de la cual se observan pulsos de abundancia en los meses de mayo, septiembre y octubre. Es una especie diurna, aunque con cierta actividad por la noche. Mugil curema se vio favorecida por aguas no tan cálidas, bajas concentraciones de salinidad y oxígeno, y no se vio perjudicada por la baja concentración de fitoplancton y zooplancton en el sistema. 


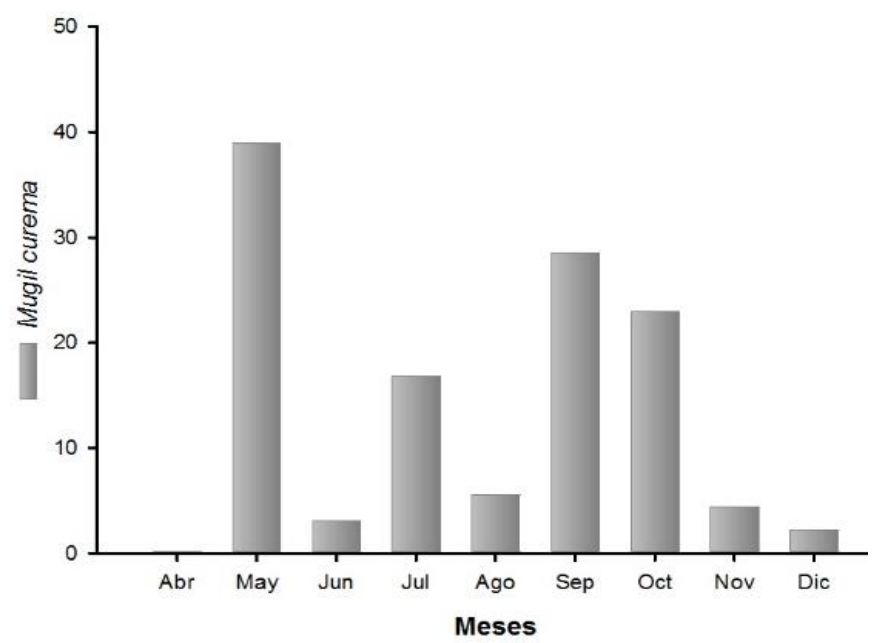

Figura 19. Variación estacional de la abundancia de Mugil curema y su relación con alguna de las variables ambientales.

Caranx. Tanto Caranx hippos, como C. latus mostraron hábitos diurnos en la laguna costera. Caranx hippos se registró solamente en la época de lluvias, con un importante pulso en el mes de julio (Figura 20a). Debido a su relación con altas precipitaciones ( $r=0.706, p=0.033)$, la especie fue común en condiciones de concentraciones bajas en la salinidad, oxígeno, fitoplancton, zooplancton y temperaturas bajas, en el agua. Por otro lado, $C$. latus se encontró en el sistema durante la época de lluvias, el periodo de transición y la época de secas frías, con un pulso bastante marcado en el mes el julio (Figura 20b). C. latus mostró preferencias por temperaturas bajas, concentraciones moderadas de salinidad y bajas en el oxígeno, además, de verse relacionada con la abundancia de fitoplancton. 

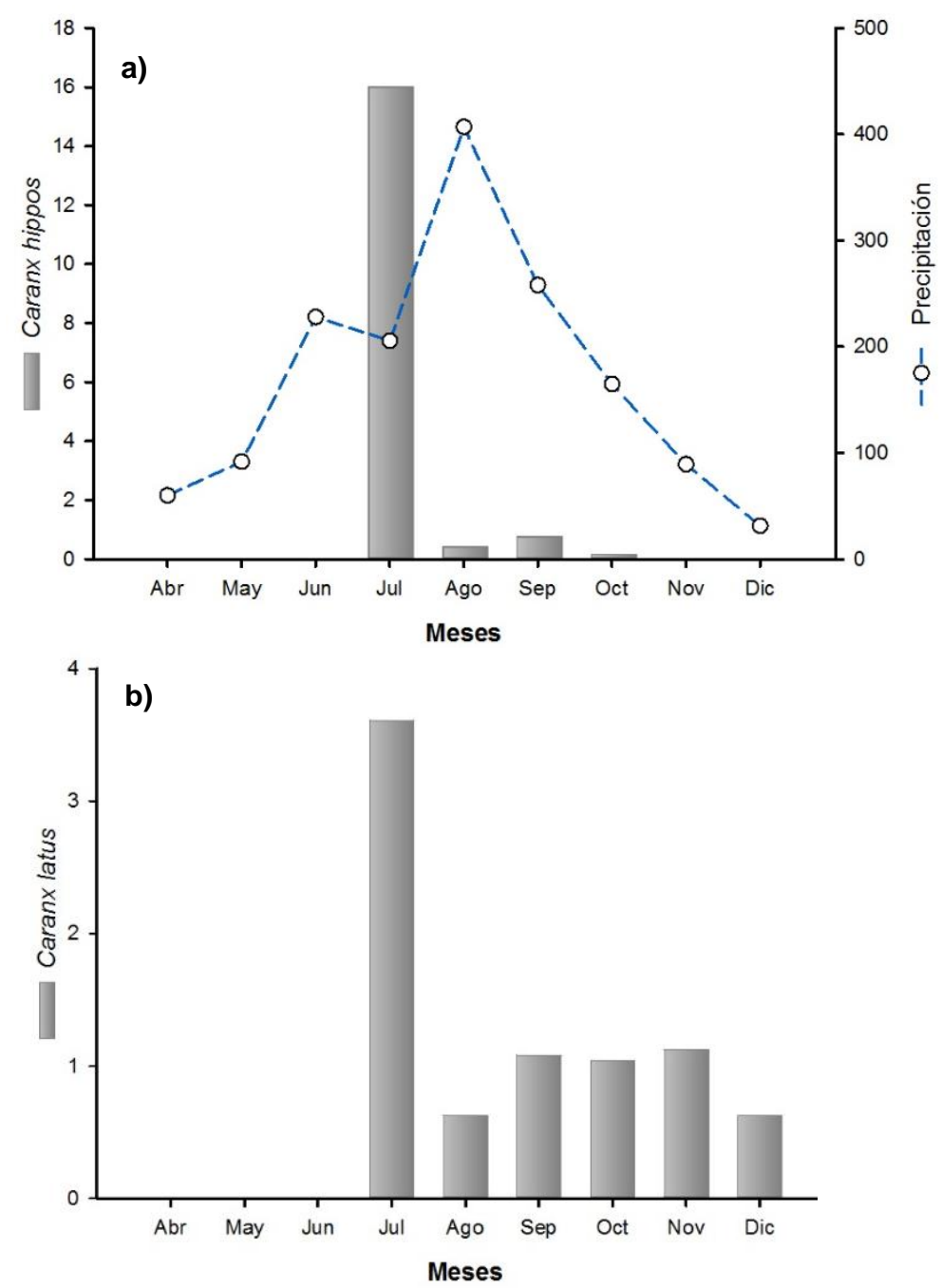

Figura 20. Variación estacional de la abundancia de a) Caranx hippos; y b) Caranx latus.

Citharichthys macrops. Este lenguado mostró hábitos diurnos, con pulsos de abundancia en la época de lluvias, en el mes de septiembre, y en el periodo de transición, en el mes de octubre (Figura 21). La especie estuvo relacionada de manera directa con la abundancia del fitoplancton $(r=0.842, p=0.008)$, como se observa con la Figura 21, así como con la abundancia del zooplancton, pero esta última con menor grado. Citharichthys macrops mostró preferencias por temperaturas bajas, en el agua, concentraciones bajas de oxígeno disuelto y altas concentraciones en la salinidad. 


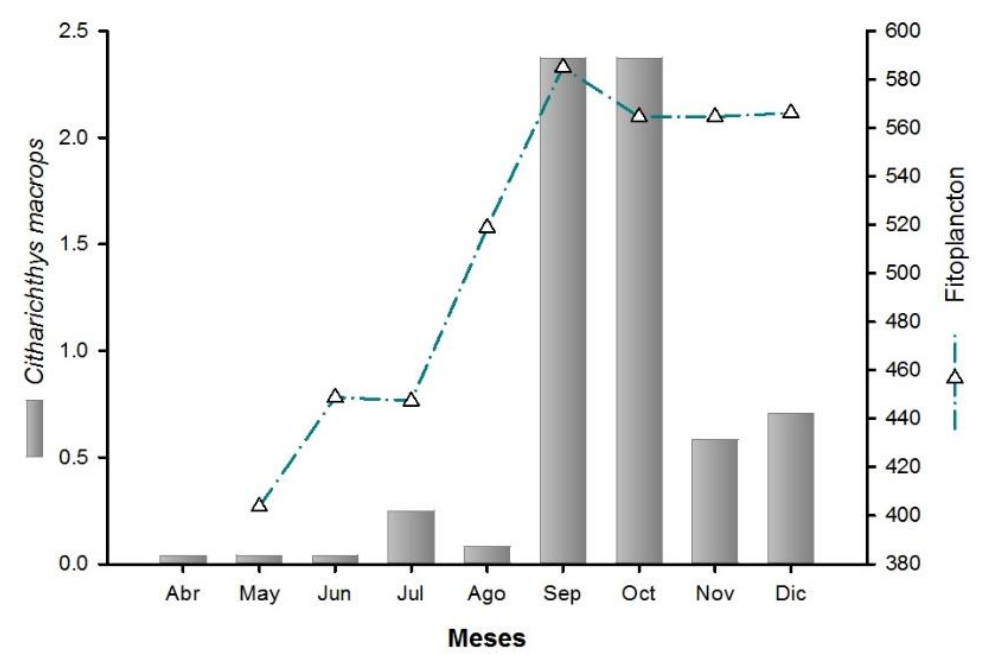

Figura 21. Variación estacional de la abundancia de Citharichthys macrops y su relación que tiene con el fitoplancton de las variables ambientales.

Citharichthys spilopterus. Al igual que la otra especie de lenguado, fue una especie con hábitos nocturnos. Dicha especie mostró los mismos pulsos de abundancia que C. macrops (Figura 22), viéndose favorecida por condiciones ambientales específicas, las cuales fueron altas concentraciones de sal y bajas de oxígeno disuelto, temperaturas moderadas en el agua, mostrando preferencias por el fitoplancton y poco para el zooplancton.

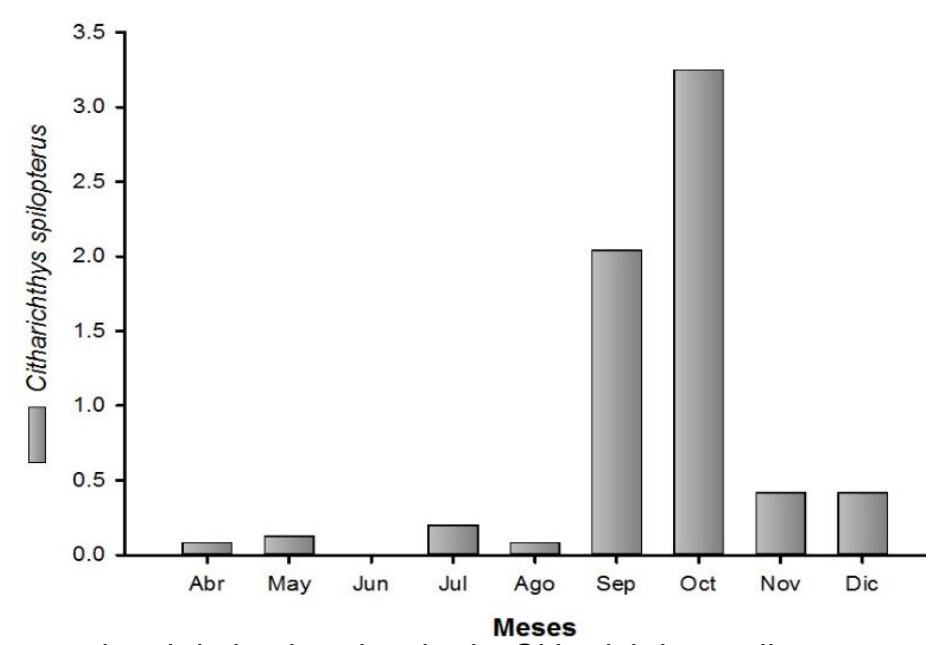

Figura 22. Variación estacional de la abundancia de Citharichthys spilopterus. 
Centropomus undecimalis. Esta especie de robalo permaneció durante todo el año en el sistema costero, pero su abundancia fue mayor durante el mes de octubre, en el periodo de transición (Figura 23), con importante actividad en el día. La especie mostró una relación inversa con el régimen de precipitación $(r=-0.785$, $\mathrm{p}=0.020$ ), prefiriendo concentraciones altas de sal en el agua, además, de verse favorecida por temperaturas moderadas, concentraciones de salinidad altas y de verse influenciada por pulsos en la abundancia en el zooplancton y fitoplancton.

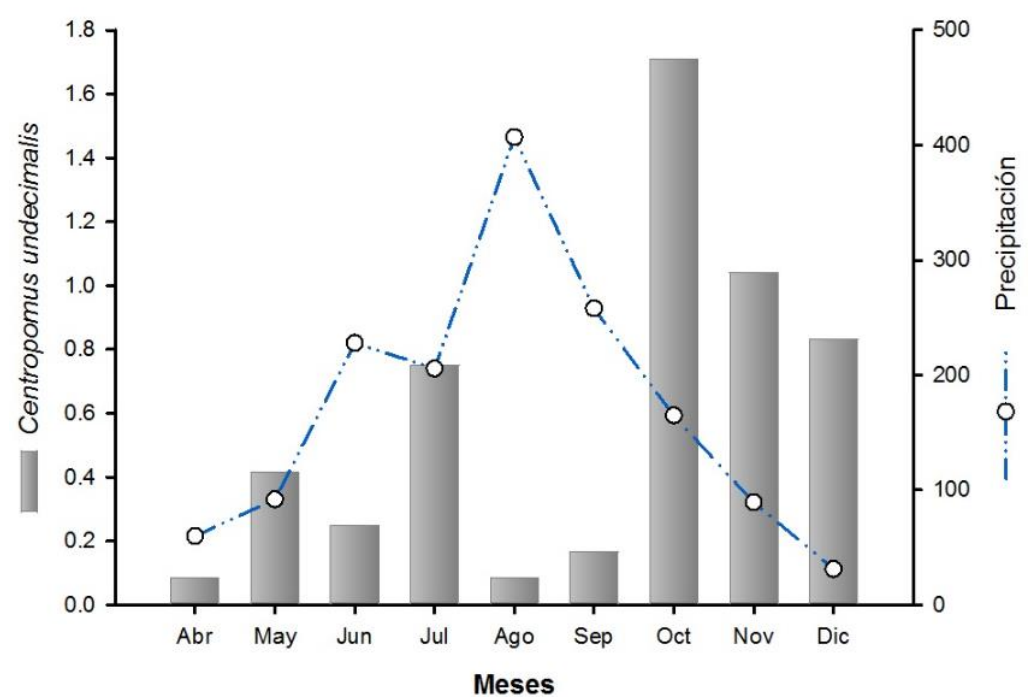

Figura 23. Variación estacional de la abundancia Centropomus undecimalis y su relaciona con el régimen de precipitación.

Diapterus auratus. Esta especie de mojarra fue de las que permaneció en la laguna costera, durante todas las épocas del año. La abundancia de la misma mostró un pulso importante en julio, durante la época de lluvias (Figura 24), además, se observó que durante la noche su abundancia fue mayor. Diapterus auratus fue favorecida por altas temperaturas, concentraciones altas de oxígeno disuelto y bajas de salinidad. Asimismo, se pudo observar que la especie no mostró afinidad al fitoplancton ( $r=-0.780, p=0.022)$, como se ve en la Figura 24 , ya que al 
aumentar el fitoplancton la abundancia del guerreado disminuyó, esto mismo sucede con el zooplancton, pero con menor grado.

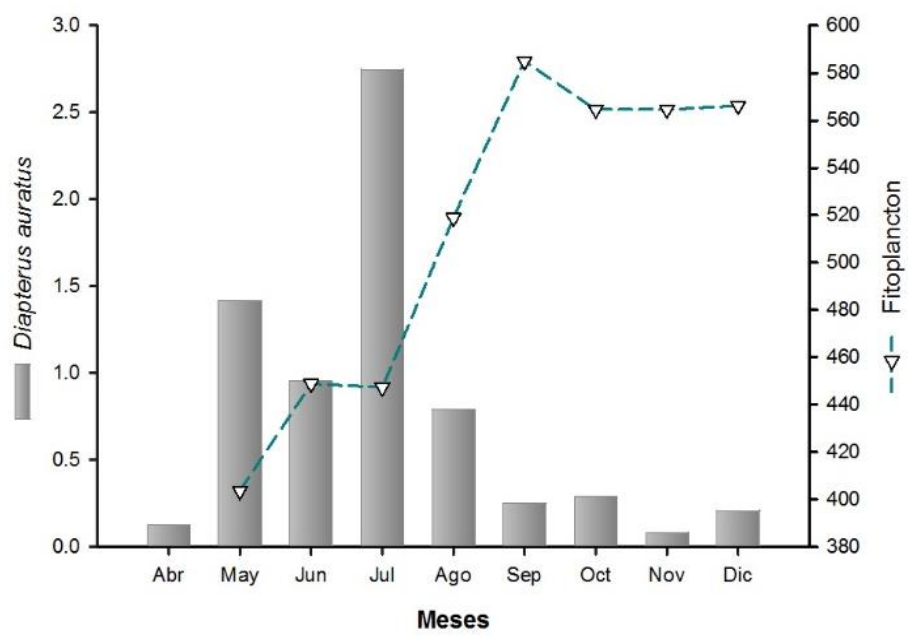

Figura 24. Variación estacional de la abundancia de Diapterus auratus y su relación con la abundancia del fitoplancton.

Diapterus rhombeus. Así como D. auratus estuvo en el sistema durante todo el periodo de estudio, siendo mayor su abundancia también en la época de lluvias, pero observando que el pulso fue en el mes de septiembre, como se ve en la Figura 25. Tuvo actividad durante todo el día, pero su abundancia aumento durante la noche. Se observó que la especie fue favorecida por altas concentraciones de salinidad, concentraciones relativamente bajas de oxígeno, aguas cálidas y afinidad por el fitoplancton y el zooplancton. 


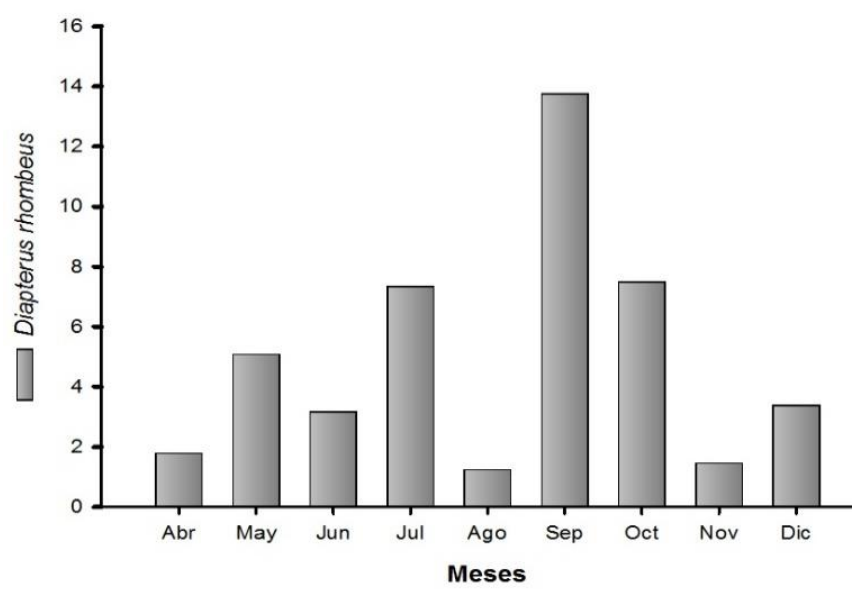

Figura 25. Variación estacional de la abundancia de Diapterus rhombeus.

Eucinostomus argenteus. Esta mojarra fue una especie con pulsos en la época de secas cálidas, en el mes de abril (Figura 26). Eucinostomus argenteus fue una especie con hábitos diurnos, la cual mostró una relación con el oxígeno disuelto $(r=0.732, \quad p=0.038)$, aguas cálidas, debido a sus preferencias a temperaturas altas, así también, se vio favorecido por concentraciones moderadas de salinidad y no mostró preferencias por el zooplancton y el fitoplancton.

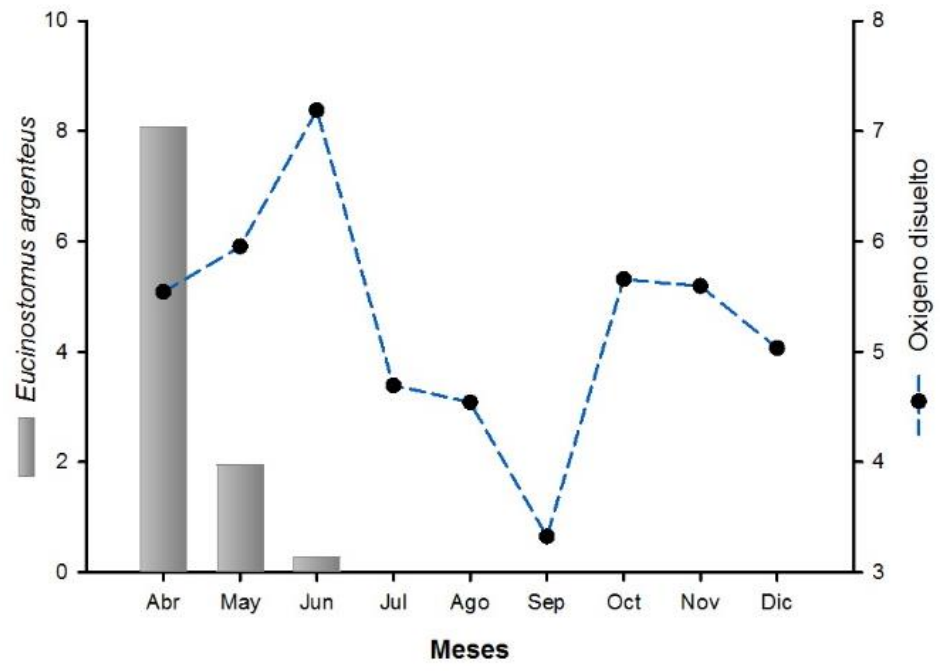

Figura 26. Variación estacional de la abundancia Eucinostomus argenteus y su relación con el oxígeno disuelto. 
Eucinostomus gula. La mayor abundancia que se registró para E. gula fue en el mes de junio, a principios de la época de lluvias (Figura 27), durante el día. Eucinostomus gula también mostró preferencias por el oxígeno disuelto ( $\mathrm{r}=0.771$, $\mathrm{p}=0.014$ ), debido a que el mayor pico de abundancia de las especie se encuentra relacionado con la mayor concentración de factor, como se puede observar en la Figura 27. Además, mostró preferencias por temperatura bastante cálidas, concentraciones moderadas de salinidad en el agua y no se vio que mostrara preferencias por grandes concentraciones de zooplancton, pero con fitoplancton ( $r=-0.765, p=0.018)$ sí.

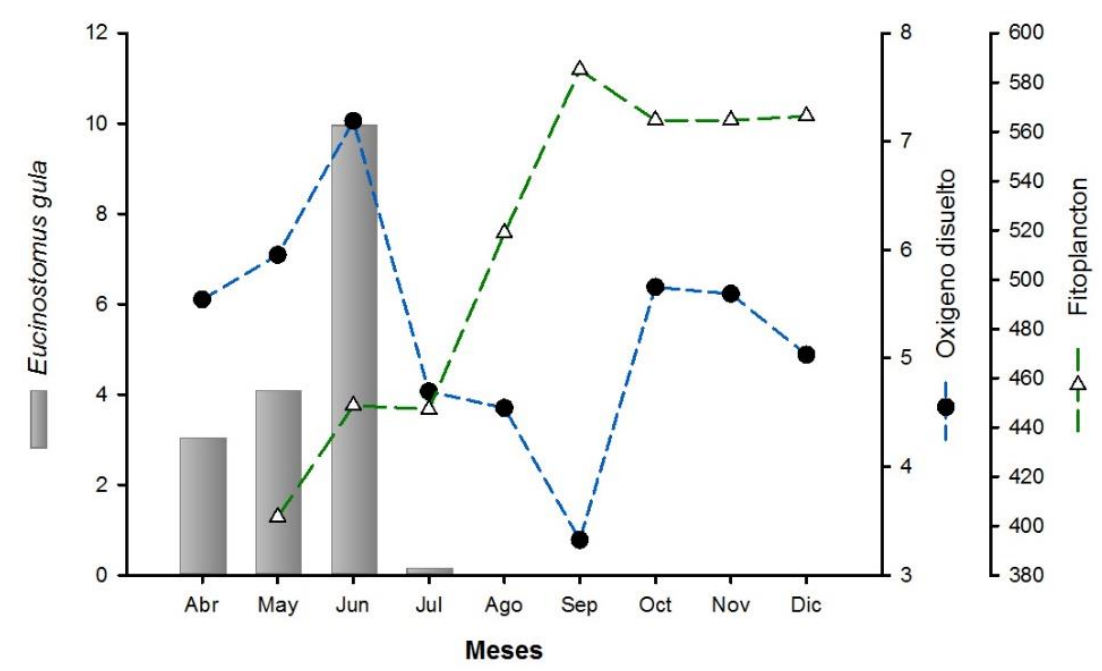

Figura 27. Variación estacional de la abundancia de Eucinostomus gula y su relación con el oxígeno disuelto y el fitoplancton.

Eucinostomus melanopterus. Esta fue la única especie del género que estuvo en el sistema durante todo el periodo de estudio, siendo más abundante en el mes de octubre, mes que corresponde al periodo de transición (Figura 28). Fue 
una especie con hábitos diurnos, mostrando preferencias por concentraciones moderadas de oxígeno disuelto, altas concentraciones de sal y temperaturas cálidas ( $r=0.683 ; p=0.042)$ en el sistema, además, mostró baja influencia hacia el fitoplancton y el zooplancton.

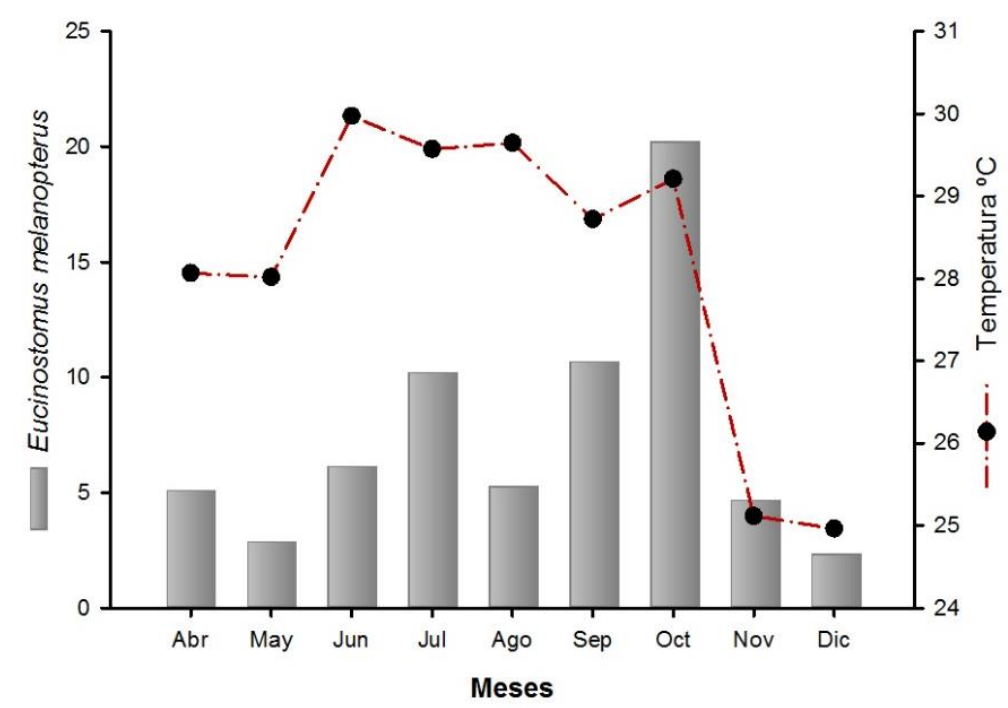

Figura 28. Variación estacional de la abundancia de Eucinostomus melanopterus y su relación con la temperatura.

Lutjanus griseus. Fue una especie permaneció en el sistema durante todo el periodo, teniendo un pulso importante en el mes de julio, época de lluvias Figura 29). La especie tuvo una importante actividad durante el día. Esta se vio influenciada directamente por la temperatura del agua $(r=0.816, p=0.007)$, ya que al aumentar esta, la abundancia de la especie se incrementó, como se puede observar en la Figura 29. Asimismo, prefirió concentraciones moderadas de sal y bajas concentraciones de oxígeno disuelto, además, de no verse influenciada por el de fitoplancton $(r=-0.742, p=0.034)$ y el zooplancton. 


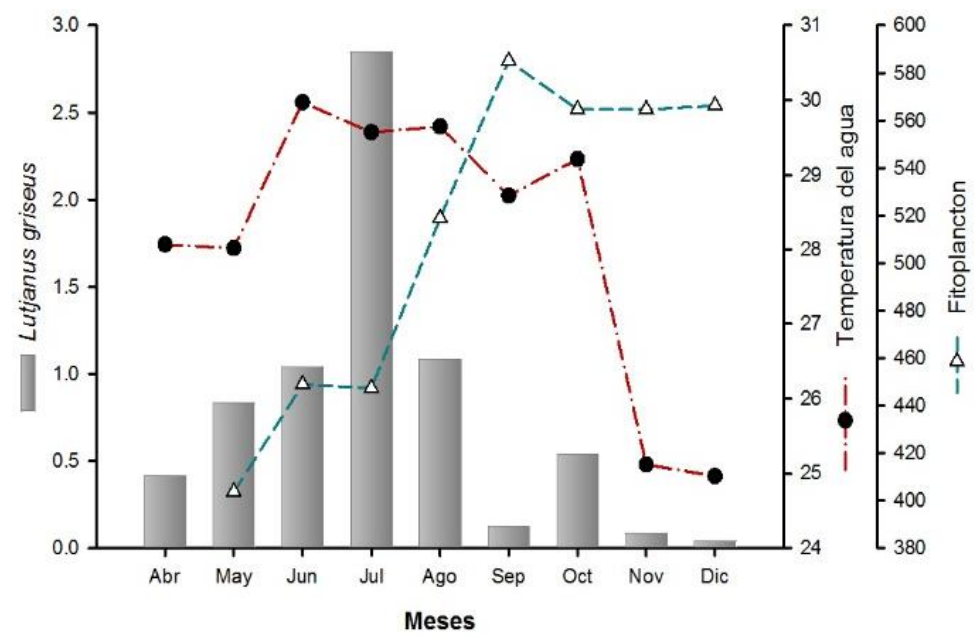

Figura 29. Variación estacional de la abundancia Lutjanus griseus.

Finalmente, de acuerdo en las condiciones ambientales en las que fueron capturadas las especies, temperatura del agua, salinidad, oxígeno disuelto y precipitación, se observaron especies tolerantes, mientras que otras especies se vieron restringidas a pequeños cambios en estas variables. Asimismo, de acuerdo a la clasificación de Castro-Aguirre et al. (1999), sobre el tipo de componente al que corresponde cada especie, las especies quedaron de la siguiente manera: 9 especies (11.11\%) son del componente permanente estuarino-lagunar; 57 especies (70.37\%) son del componente marino eurihalino; 13 especies (16.04\%) son del componente marino estenohalino; y 2 especies (2.46\%) corresponden al componente catádromo. 


\section{Discusión}

\section{Aspectos generales de la comunidad}

De acuerdo con los resultados obtenidos respecto al total de número de familias, géneros y especies capturadas, se registró en la laguna costera una riqueza mayor que la encontrada por Lozano-Vilano et al. (1993) con 26 familias y 43 especies; Juárez-Eusebio et al. (2006) con 25 familias y 44 especies; y DíazRuiz et al. (2018), con solo 25 familias y 50 especies.

Asimismo, se comparó la riqueza de especies capturadas La Mancha con otros sistemas costeros. En la laguna de Términos se han realizado varios estudios, de entre los cuales, en 1982 se registraron un total de 59 especies (Yáñez-Arancibia et al., 1982); en 2003, 37 familias, 76 géneros y 197 especies (Ayala-Pérez et al., 2003); en 2007,106 especies (Sosa-López et al., 2007). En Pueblo Viejo, se han registrado 31 familias y 77 especies (Zárate-Hernández et al., 2012); Tamiahua, con 41 familias y 82 especies (Franco-López \& Chavez-Lopez, 1992); Alvarado con 33 familias y 93 especies (Chávez-López et al., 2005); en Sontecomapan, en 1989, se registraron 18 familias y 30 especies (Fuente et al., 1989), mientras que en 2010, se capturaron 24 familias y 52especies (Rodríguez-Varela et al., 2010); en Candelaria-Panlau, 52 especies (Ayala-Pérez et al., 1998); Laguna Madre 81 especies; Salinas del Padre 19 especies (Raz-Guzman et al, 2002); Celestún, 27 familias y 56 especies (Arceo-Carranza et al., 2010); La Cruz, 34 familias, 63 género y 96 especies (Grijalva-Chon et al., 1996); Las Guásimas, 38 familias, 67 géneros y 95 especies (Padilla-Serrato et al., 2016); la laguna de Santa María la Reforma, 
con 47 familias y 191 especies (Amezcua \& Amezcua-Linares, 2014). De acuerdo con Pérez-Hernández y Torres-Orozco (2000), estas diferencias en la riqueza de especies se deben al área de la laguna, al tipo y selectividad del arte de pesca, a la ubicación de los sitios de colecta y a la intensidad del muestreo ("duración de los períodos de muestreos, distribución temporal y frecuencia de las recolectas, número de estaciones, etc.").

Todo lo mencionado demuestra que lo muestreos de alta frecuencia a nivel temporal y circadiano permiten obtener una mejor representación de la diversidad ictiofaunística en los sistemas acuáticos, en términos de órdenes, familias y especies, como sucedió en el presente trabajo, debido a que en los trabajos de Juárez-Eusebio et al (2006) y Díaz-Ruiz et al (2018) no consideraron muestreos de ciclos de 24 hrs, tomando muestras sólo en horas de luz. Asimismo, se observó, que a pesar de la baja o alta representatividad de especies de peces en la comunidades en los otros sistemas costeros respecto a la Mancha, mostraron una baja intensidad de los muestreos que no fueron regulares, por ejemplo en los trabajos de Hernández et al. (2006), Yáñez-Arancibia et al (1982), ZárateHernández (2003), Castillo-Rivera et al (2010; 2011), Arceo-Carranza et al (2010) y Zárate-Hernández et al (2012), realizaron muestreos durante un ciclo de 24 hrs, pero los muestreos a nivel estacional fueron irregulares o solo consideraron muestreos bimestrales en relación con los procesos biológicos que realizan las especies dentro del sistema. También se presentaron los casos de los estudios de Franco-López y Chavez-Lopez (1992), Ayala-Pérez et al (1998), Chávez-López et al. (2005) y Amezcua y Amezcua-Linares (2014) en donde realizaron muestreos 
estacionales regulares, pero no consideraron muestreos diarios, realizando solo muestreos diurnos. Y finalmente, está el caso de los trabajos donde los muestreos estacionales fueron irregulares, sin considerar los cambios que ocurren en la composición de las especies a lo largo de un ciclo de 24 hrs como lo fueron los estudios de Rodríguez-Varela et al. (2010), Raz-Guzman et al (2002), en Laguna Madre, y Ocaña-Luna y Sánchez-Ramírez (2016), en Tamiahua.

Lo anterior, muestra que casi la totalidad de los estudios realizados en las lagunas costeras, los muestreos solo se han llevado a cabo durante horas de luz, como se ha ido mencionado, lo cual pierde la representatividad de las especies que solo presentan actividad nocturna, así como el conocimiento que se puede obtener sobre la ecología/biología de estos organismos, así de los cambios puntuales de la estructura de la comunidad, como pudo haber pasado en el presente trabajo, ya que la mayoría de las especies tuvieron mayor actividad nocturna, al no hacer nuestros de ciclos de $24 \mathrm{hrs}$, la representatividad de las especies hubiera bajado considerablemente. Esto mismo sucede con la irregularidad de los muestreos estacionales, demostrando con ello la importancia del esquema de intensos muestreos estacionales y circadianos.

Cabe mencionar, que faltó considerar la escala espacial en el estudio, como lo hicieron Ayala-Pérez et al (1998), Raz-Guzman et al (2002), Sosa-López et al (2007), Arceo-Carranza et al (2010), entre otros, para tener aún un mejor representatividad de las especies en el sistema. 


\section{Análisis de la abundancia y la biomasa}

El patrón estacional de la precipitación determina las condiciones ambientales de los sistemas costeros, reflejados en los cambios en la composición y abundancia de las especies de peces (Díaz-Ruiz et al., 2006; Castillo-Rivera, 2013). La variación de la abundancia a lo largo de los nueve meses, mostró pulsos importantes en mayo (época de seca cálida) y octubre (lluvias), y un pequeño incremento de la abundancia en diciembre (época de seca fría), meses que representan el término de cada época climática. Algunos como Castillo-Rivera (2013) y Díaz-Ruíz et al. (2018) explican que esto es debido a que la mayor abundancia corresponde a especies visitantes eurihalinas y estenohalinas del componente marino; a los patrones de migración estacional durante el ciclo de vida de propias de cada especie; y a los cambios propios en las condiciones ambientales de los sistemas costeros que afectan a los peces (Castillo-Rivera, 2013; Díaz-Ruíz et al., 2018).

En cuanto al pulso de abundancia observado en octubre, Ayala-Pérez y colaboradores (2012a) observaron un fenómeno similar en la laguna de Términos, Campeche, y lo explicaron cómo un incremento y acumulación en la producción primaria, con efecto de retardo debido al aporte de aguas continentales y a la influencia de lluvias muy fuertes, dada la frecuencia de frentes fríos, las cuales favorecen un gran número de individuos, pero con un decremento en la abundancia posterior a este fenómeno. Esto mismo sucedió en La Mancha, además de mostrar una disminución considerablemente de la abundancia en el mes de noviembre. 
Asimismo, se observaron pulsos importantes de la biomasa por encima de la abundancia en junio, julio y diciembre, así como un patrón inverso en los meses de abril, mayo y octubre. Este comportamiento estacional se asemeja a lo reportado con Bairdiella chrysoura en la laguna de Términos (Chavance et al., 1984), la abundancia de peces en Candelaria-Panlau, Campeche (Ayala-Pérez et al., 1998); en la laguna de Pueblo Viejo (Castillo-Rivera et al., 2005); en sistemas lagunares al sur de Chiapas (Díaz-Ruíz et al., 2006); en la costa del estado de Campeche (Ayala-Pérez et al., 2012a); y en una localidad dentro de la Reserva Estatal Ciénagas y Manglares de la costa Norte de Yucatán (Solano-Mendoza, 2017). En todos estos estudios se relacionan esto pulsos en la abundancia lo relacionan con valores altos en individuos de tallas pequeñas (juveniles), pero con un reducido valor en la biomasa total, mientras que los pulsos de la biomasa se encuentran relacionados con un predominio de individuos de tallas grandes, pero un número reducido de organismos. Lo anterior refleja un uso preferencial del sistema en las diferentes etapas del ciclo biológico de las especies, donde los individuos pequeños utilizan la laguna como zona de reclutamiento biológico, crianza y protección, mientras que los organismos más grandes la usan como un área de alimentación (respuestas tróficas) o de maduración (Chavance et al., 1984; Castillo-Rivera et al., 2005; Díaz-Ruíz et al., 2006).

Se ha observado en la laguna de Pueblo Viejo (Castillo-Rivera \& ZárateHernández, 2001) y en el sistema lagunar de Chantuto-Panzacola (Díaz-Ruíz et al., 2006), pulsos importantes en la época de lluvias respecto a la época de secas, a pesar de no haber diferencias entre épocas en La Mancha, se observó un gran 
número de individuos que ingresaban al sistema en lluvias. Esto autores mencionan que puede deberse a la influencia que la precipitación ejerce sobre el comportamiento estacional de la abundancia de las especies de peces, ya que la abundancia se encuentra determinada por los patrones de producción primaria misma que está influenciada por el régimen de precipitación. En esta época se ha observado un incremento en la descarga de los ríos aledaños a los sistemas costeros, los cuales aportan cantidades considerables de materia orgánica alóctona y nutrientes. Estos componentes son importantes en la dinámica trófica, debido a que la materia orgánica estimula la ruta detritívora y los nutrientes estimulan la ruta de herbívora, favoreciendo un incremento en la disponibilidad de recursos tróficos y por ende a los organismos que ingresan a los sistemas para alimentarse (CastilloRivera \& Zárate-Hernández, 2001; Zárate-Hernández, 2003; Castillo-Rivera et al., 2005; Díaz-Ruíz et al., 2006).

La abundancia en los meses de la época de seca fría fue menor a la de los meses la época de secas cálidas. Puede deberse a que algunos individuos salieran del sistema en busca de temperaturas más cálidas, como en la laguna de Términos, en donde la abundancia de las especies de la comunidad disminuyó en la época de frías debido a las bajas temperaturas del agua y a la preferencia por temperaturas altas (Ayala-Pérez et al., 2012b; Zambrano et al., 2013) o en busca de alimento, debido a la baja disponibilidad de éste en La Mancha (Amezcua-Linares et al., 1987). 
Por otro lado, aunque el análisis de la variación diaria no mostró diferencias significativas de la abundancia y biomasa, éstas mostraron un incremento importante en la noche. Zárate-Hernández (2003) y Yáñez-Arancibia et al. (1982) sí observaron estas diferencias, con pulsos durante la noche en las lagunas de Pueblo Viejo y Términos, respectivamente. Este comportamiento lo relacionan con estrategias propias de cada especie como evasión de depredadores, reclutamiento de individuos juveniles, depredación y actividades de alimentación de ciertas especies al haber mayor disponibilidad y abundancia de organismos a esas horas como peces, moluscos, poliquetos, crustáceos, entre otros (Yáñez-Arancibia et al., 1982; Castillo-Rivera et al., 2005; 2010; 2011; Martínez-Aguilar, 2015). Asimismo, en La Mancha se observaron pulsos al amanecer y al atardecer, lo cual se atribuye a periodos de transición entre el inicio y el final de las actividades diurnas y nocturnas de las especies, generando una superposición de las poblaciones (Zárate-Hernández, 2003; Castillo-Rivera et al., 2005).

Finalmente, las interacciones entre los factores estacionales y circadianos de la abundancia y biomasa fueron significativos. Asimismo, cabe mencionar que la variación estacional de estas variables fue significativa cuando los meses se encontraban anidados en las épocas climáticas, es decir, hubo mayor variabilidad dentro que entre épocas. Estos cambios en los patrones de abundancia de los peces, dentro del sistema, entre día y noche, según el mes o la época en la que se encuentran, se pueden deber a estrategias que implementan las especies para adecuarse a los cambios temporales de los recursos, y así, poder optimizar y disponer de los mismos dentro del sistema (Zárate-Hernández et al., 2012). 


\section{Análisis de los parámetros de la comunidad}

La variación estacional de los parámetros de riqueza, diversidad y equidad sí mostró diferencias significativas, mientras que entre épocas climáticas no.

La riqueza de especies mostró fluctuaciones a lo largo del periodo de estudio, de las cuales, las mayores se registraron en los meses de la época de lluvias. Castillo-Rivera et al., 2003; Mendoza et al., 2009 observaron en las lagunas de Pueblo Viejo y Chacahua un aumento importante en la riqueza de especies durante la época de lluvias y una disminución en la época de seca fría; asimismo, en un estudio sobre especies dominantes, en la laguna de Pueblo Viejo, se observó un pulso importante en julio (Castillo-Rivera et al., 2005). Los valores obtenidos durante la época de lluvias, en La Mancha, como ya se señaló en el análisis de la abundancia total y biomasa, esto se debe a la influencia de la precipitación que ejerce la descarga de ríos, aporte de nutrientes y materia orgánica, que estimulan las redes tróficas, favoreciendo a las especies que ingresan al sistema. Así también, se ha observado que el patrón estacional de la riqueza se encuentran relacionadas con la temperatura, la concentración de la salinidad, en este caso bajas, mismo que han observado autores en otros sistemas lagunares (Castillo-Rivera et al., 2003; $2005 ; 2011)$. Por otro lado, la disminución de las especies en noviembre y diciembre (seca fría), también se debe a que durante este periodo salen en búsqueda de sitios con ambientes más cálidos o térmicamente más estables (Castillo-Rivera et al., 2003). 
La riqueza de especies mostró pulsos al final de cada época climática igual que la abundancia en número, lo cual puede estar relacionada con los mismos factores, es decir, el intercambio de especies con el ambiente marino durante dichos periodos, además de los patrones estacionales propios del ciclo de vida de cada especie y a los cambios en las condiciones ambientales del sistema (BenítezValle et al., 2007; Castillo-Rivera, 2013; Díaz-Ruíz et al., 2018). Asimismo, DíazRuiz et al. (2006), Mendoza et al. (2009) y Ayala-Pérez (1998; 2012a) observaron pulsos en la época de lluvias relacionado también con una mayor abundancia de especies del componente marino, al intercambio de especies entre la época de lluvias y seca fría y a la variación estacional de la salinidad (Castillo-Rivera et al., 2003; 2011; Díaz-Ruiz et al., 2018).

El comportamiento en la diversidad y equidad fue similar a lo observado en lagunas costeras como Chacahua (Mendoza et al., 2009), Pueblo Viejo (CastilloRivera et al., 2003; 2010; 2011; Zárate, 2003; Zárate et al., 2012), La Mancha (DíazRuiz et al., 2018), Términos (Ayala-Pérez et al., 2012a), en los sistemas de Candelaria-Panlau (Ayala-Pérez et al., 1998) y de Carretas-Pereyra (diversidad) y Chantuto-Panzacola (Díaz-Ruiz et al., 2006). Se ha observado, en diversos estudios, que las fluctuaciones mensuales en estos parámetros se encuentran relacionadas con las variaciones en los factores fisicoquímicos, condiciones hidrológicas y a la influencia de ciertos factores ambientales, alguno de estos factores son la profundidad, turbidez, salinidad, temperatura y oxígeno disuelto, por un lado, la diversidad principalmente correlacionadas positivamente con el oxígeno disuelto, salinidad (ligada a las lluvias) y la temperatura, en tanto que la equidad la 
se relaciona con la temperatura del agua (Zárate, 2003; Castillo-Rivera et al., 2010; 2011; Díaz-Ruiz et al., 2006; 2018). Estas variables han sido consideradas por algunos autores, como controles de los patrones temporales de los parámetros ecológicos de la comunidad (Díaz-Ruiz et al., 2018), determinando los cambios estacionales en el número de especies (migraciones entre el mar y el sistema estuarino) de acuerdo a las tolerancias fisiológicas de éstas (Castillo-Rivera et al., 2012).

La diversidad en este tipo de sistemas se encuentra determinada por factores bióticos como la producción primaria, misma que se encuentra relacionada con la época de lluvias, lo cual favorece el ingreso de peces al sistema (Castillo-Rivera et al 2003; Zárate et al., 2012), y en consecuencia aumenta la riqueza de especies. Por otro lado, los valores de la diversidad y de la equidad disminuyen en octubre, probablemente por la disminución de la temperatura u otros factores, pero en noviembre-diciembre mostraron pulsos importantes, como sucedió en la laguna de Pueblo Viejo (Zárate, 2003), los cuales se podrían relacionar con el ingreso de especies templadas (Zárate et al., 2012).

La baja diversidad, en ciertos meses, se encuentra relacionada con la pérdida de recursos alimenticios y la heterogeneidad del hábitat (Ayala-Pérez et al., 2012a), así también, el sistema podría encontrarse en un grado de perturbación, como mencionan Uribe y Orrego (2001). Dicha perturbación puede estar relacionada con el gasoducto de PEMEX que se encuentran cerca de la laguna, el cual ha causado alteraciones como la reducción de la superficie de los pastos marinos debido al aumento de sólidos en suspensión, tasas de sedimentación y azolve, así como 
formar una barrera que no permite el paso de las corrientes del mar al sistema (Barreiro-Güemes \& Balderas-Cortés, 1991). Asimismo, la laguna podría estar sufriendo eutrofización gracias a un incremento en el aporte de nutrientes por un aumento de la actividad agrícola y pecuaria, cerca de la misma (López-Portillo et al., 2009).

A nivel nictémero, la riqueza de especies no mostró diferencias significativas entre el día/noche ni horas anidadas en esta última. Castillo-Rivera et al. (2005; 2010; 2011) y Zárate-Hernández et al. (2012), reportaron en la laguna de Pueblo Viejo, que la riqueza registraba valores altos durante las horas nocturnas para los meses evaluados. Este fenómeno podría deberse al hecho que existe mayor presencia de especies con hábitos nocturnos como depredadores o grandes segregaciones de peces durante este periodo, los cuales obtienen diversas ventajas como mayor acceso y disponibilidad de alimento o disminuir el riesgo de depredación por parte de otras especies de peces (Castillo-Rivera et al., 2005; 2010; Zárate-Hernández et al., 2012) y que probablemente puede estar relacionado con los pulsos en la noche observados en las zona de estudio.

Asimismo, se observaron pulsos importantes a las 6-8 y 16-18 hrs, los cuales podrían deberse al inicio y término de la actividad de especies diurnas y nocturnas, como sucedió en la abundancia total en número, la cual podría estar generando una superposición de las poblaciones de dichas especies en el sistema. En la laguna de Pueblo Viejo, tanto en hábitat con vegetación sumergida como en hábitat de sustrato blando sin vegetación sumergida, la abundancia tuvo un importante comportamiento en la noche con ciertos picos durante horas de día, como sucedió 
en La Mancha (Castillo-Rivera et al., 2005; 2010; 2011; Zárate-Hernández et al., 2012).

En Pueblo Viejo (Castillo-Rivera et al., 2005; 2010; Zárate-Hernández et al., 2012) se observaron pulsos importantes de la diversidad y la equidad, a lo largo del día, donde el valor más alto de la diversidad fue registrado a las $14 \mathrm{hrs,} \mathrm{mientras}$ que el de la equidad fue a las 12 hrs. Aun a pesar, de que la diversidad como la equidad no mostraron diferencias entre día/noche y horas anidadas, en nuestra zona de estudio se observaron pulsos similares a los de Pueblo Viejo. Esto implica que existe una mayor homogeneidad en la abundancia de las especies presentes en el día y una mayor dominancia de las especies por la noche, aun a pesar de la alta riqueza a estas horas del día (Castillo-Rivera et al., 2005; 2010; ZárateHernández et al., 2012), lo cual puede deberse principalmente a una mayor preferencia por temperaturas altas por los organismos.

La riqueza de especies, la diversidad y la equidad mostraron diferencias significativas en la interacción entre los factores de día/noche respecto a los meses de año, anidados en las épocas climáticas, así como diferencias dentro que entre épocas climáticas. De acuerdo a esto, la variación estacional y circadiana de los componentes de la riqueza de especies, diversidad, equidad muestran una estructuración de las especies en las diferentes épocas climáticas y un ciclo de 24 hrs, con el fin de obtener ventajas sobre el hábitat que ofrece el sistema costero, como disminuir los niveles de competencia entre las especies y optimizar el uso de los recursos como el alimento y el espacio (Ayala-Pérez et al., 2012a; ZárateHernández et al., 2012). 


\section{Variación estacional y circadiana en la estructura de la comunidad}

Al igual que la variación de la abundancia total en número, biomasa y los parámetros de la comunidad, el comportamiento de las abundancias del conjunto de las especies de la comunidad, mostró una interacción entre los factores estacionales y nictémeros, debido a los cambios de hábitos, de diurnos a nocturnos o viceversa, de Anchoa mitchilli, Diapterus rhombeus, Eucinostomus gula y Mugil curema, que pueden estar relacionadas con las mismas razones que las anteriores variables. Estas razones están dadas por las estrategias que implementan cada una de las especies, para adecuarse a los cambios temporales de los recursos, a disminuir los niveles de competencia entre las especies, y de esta manera optimizar el espacio y alimento de la laguna (Ayala-Pérez et al., 2012a; Zárate-Hernández et al., 2012).

Los notables e importantes cambios estacionales en los ensambles de peces, hablando en términos de la variación de las especies y su abundancia, observadas entre meses y épocas climáticas, es el reflejo de la influencia que ejercen las condiciones ambientales sobre la comunidad de especies presente en el sistema. En los resultados obtenidos se puede observar que los grupos formados se debe al reflejo de la similitud en las condiciones entre los meses, viendo una clara agrupación de los meses entre boca abierta y los meses de boca cerrada, como sucedió en el trabajo realizado en la laguna de Chacahua (Mendoza et al. 2009), en donde mencionan que este efecto en el estado de la boca del sistema, influye en los cambios estacionales y arreglos en la composición de especies, trabajando en conjunto con la variación en la temperatura del agua, la concentración de 
oxígeno y salinidad de la laguna (Díaz-Ruiz et al., 2004; Mendoza et al. 2009; Castillo-Rivera et al., 2011), dado principalmente, por el efecto de las lluvias, así como por el aporte fluvial y a la influencia marina, modificando los factores ambientales antes mencionados (Díaz-Ruiz et al., 2018).

Asimismo, los cambios significativos en la composición de especies de la comunidad en las dos escalas temporales (épocas climáticas y meses), se deben muy probablemente a una sucesión estacional entre las poblaciones de las especies de peces, mediante sustituciones progresivas o drásticas, es decir, las sucesiones poblacionales entre las épocas climáticas o entre los meses con mayor similitud representan una sustitución más progresiva o gradual, respecto a los que tienen una menor similitud y del cual se podría deberse a un recambio de especies más drástico. Esto puede deberse como una consecuencia de los desfases en los tiempos de desove, las emigraciones e inmigraciones de las especies (CastilloRivera et al., 2011), para la optimización de los recursos y espacio, en alguna etapa de sus ciclos de vida, adaptándose a las variaciones ambientales de estos sistemas costeros (Arceo-Carranza \& Vega-Cendejas et al., 2009; Mendoza et al., 2009), como se observó cuando en los meses en los que la boca se encuentra cerrada, la abundancia de la mayoría de las especies fue menor, creyendo que el sistema fue utilizado por individuos adultos, que al contrario de cuando está la boca abierta, en donde ciertas especies aumentaron su abundancia, lo cual se cree que eran individuos juveniles, lo que supone que esos cambios en la abundancia de las especies y la presencia/ausencia de las mismas, a lo largo del periodo de estudio, 
se debe a la utilización de la laguna para diferentes fines alimenticios, reproductivos, de protección, etc., (Díaz-Ruiz et al., 2004).

Por otro lado, se observó que la mayoría de los meses estudiados estuvieron dominados por $A$. mitchilli (abril, mayo, junio, octubre y noviembre) y $M$. curema (mayo, julio, agosto, septiembre. La dominancia de $A$. mitchilli fue observada también en la laguna de Pueblo Viejo, en donde Castillo-Rivera et al., (2011) mencionan que al encontrarse en casi todos los meses y ser muy abundante, es considerada como una especie estuarina-residente, además, de ser dependientes de este tipo de sistema ya que lo utilizan en muchas fases de su ciclo de vida. En el caso de Mugil curema, también se ha observado en otros sistemas que tiene una alta dominancia a lo largo del año, tal es el caso del sistema-lagunar TeacapánAgua Brava en Nayarit, en el cual Alvarez-Rubio et al. (1984), mencionan que su dominancia se debe a su alta capacidad fisiológica de osmorregulación que le ayuda a adaptarse a este tipo de ambientes y al permanecer casi todos los meses en La Mancha, lo cual, también podría considerarse una especie estuarinaresidente como $A$. mitchilli.

A nivel nictémero, Castillo-Rivera et al. (2010; 2011) y Yañez-Arancibia et al. (1982) observaron en la laguna de Pueblo de Viejo y de Términos, que la composición de especies se separa entre las muestras del día y de la noche. En La Mancha se observó algo similar en donde las muestras se dividieron en diurnascrepusculares y nocturnas-amanecer. Estos autores indican que durante un ciclo de 24 hrs, comúnmente, existen cambios significativos en la abundancia de las poblaciones o en la presencia/ausencia de las especies, de una manera gradual o 
rápida entre el día y la noche, por lo que mencionan que el ciclo luz/oscuridad es una variable que juega un papel importante en la estructura de las especies (Castillo-Rivera et al., 2011), mismo que se encuentra relacionado con la transición de las poblaciones de las especies entre estos dos periodos. Por otro lado, se observó una semejanza entre las 6-8 hrs (hora nocturna y hora del amanecer, respectivamente), con las horas nocturnas y las 16-18 hrs (hora luz y hora crepuscular respectivamente), con el día, y que muy probablemente dichos cambios entre horas luz y oscuridad corresponde a una transición larga o gradual entre las primeras horas del día y de la noche (Castillo-Rivera et al., 2010; 2011).

La estructura de la comunidad de peces en un ciclo de 24 hrs, además, de verse influenciada por el ciclo de luz/oscuridad, puede estar también asociada a las estrategias de alimentación, depredación o evasión de depredadores de cada especie, esto debido a que la composición de las especies durante el día fue dominada principalmente por Mugil curema (se alimenta de algas microscópicas, filamentosas y pequeños organismo juveniles planctónicos) y Eucinostomus melanopterus (se alimenta de organismos como peces, crustáceos camarones, moluscos, zooplancton, detritos y poliquetos bentónicos) que son omnívoros. La dominancia en la noche de Anchoa mitchilli (se alimenta de Mysis, copépodos, peces pequeños, isópodos y gasterópodos), pequeño depredador del zooplancton, se debe a que se encuentra relacionada con los pulsos de zooplancton, además, de ser una especie potencial para los depredadores nocturnos (Yáñez-Arancibia et al., 1982; Castillo-Rivera et al., 2010; 2011). 


\section{Influencia de las variables ambientales sobre la abundancia de las especies}

Estudios realizados en los sistemas de Pueblo viejo (Castillo-Rivera et al., 2002; 2010; 2011), Chacahua (Mendoza et al., 2009), Candelaria-Panlau (AyalaPérez et al., 1998), Términos (Ayala-Pérez et al., 2012a), Chantuto-Panzacola (Díaz-Ruiz et al., 2004; 2006), Carretas-Pereyra (Díaz-Ruiz et al., 2006), Bocas de Dzilam (Arceo-Carranza \& Vega-Cendejas, 2009), Sentocomapan (RodríguezValera et al., 2010), Isla Contoy (Vega-Cendejas \& Hernández-de-Santillana, 2014), La Mancha (Díaz-Ruiz et al.,2018), entre otros, han mostrado la importancia de la influencia que ejercen las variables ambientales (como temperatura, salinidad, transparencia, profundidad, precipitación, oxígeno disuelto), sobre la distribución, estructura y composición de las especies en estos sistemas costeros. En nuestra zona de estudio, lo antes dicho, no fue la excepción. De acuerdo con los resultados obtenidos en el ACC, las condiciones ambientales abióticas (horas luz, estado de la boca temperatura del agua, precipitación, salinidad; oxígeno disuelto), respecto a las bióticas (fitoplancton y zooplancton), condicionaron de manera importante el comportamiento y estructura de las especies (Ayala- Pérez et al., 1998; ArceoCarranza et al., 2009), como sucedió en el estudio realizado por Castillo-Rivera et al. (2011).

De acuerdo con el ACC se observó la formación de dos grupos, las especies que preferían en mayor o menor grado cada una de estas variables analizadas. Un gran número de especies mostraron preferencias por concentraciones de moderadas a altas de salinidad (D. rhombeus, A. felis, C. aguadulce, C. spilopterus, C. macrops, A. lamprotaenia, A. lyolepis, C. parallelus, C. undecimalis, $P$. 
octonemus y Eugerres plumieri) mientras que otras especies (E. gula, L. griseus, $D$. auratus y S. notata) prefirieron concentraciones bajas de salinidad. Por otro lado, A. mitchilli, A. hepsetus, E. argenteus, C. edentulus entre otras, mostraron preferencias por temperaturas altas y concentraciones de oxígeno disuelto altas, pero otras como Mugil curema, E. melanopterus, C. hippos, C. latus, Oligoplites saurus y Gobionellus oceanicus se vieron favorecidas por concentraciones bajas de oxígeno disuelto y temperaturas bajas con altas precipitaciones.

Según lo anterior, las diferencias preferenciales a las condiciones ambientales por las especies, se debe a las barreras físicas que se generan entre ciclos diarios, estacionales o entre los diferentes hábitats en un mismo sistema (Vega-Cendejas et al., 2014). Estas barreras físicas, son principalmente generadas por la salinidad y por la combinación del oxígeno disuelto y altas temperaturas en el medio ambiente (Arceo-Carranza et al., 2009; Vega-Cendejas et al., 2014), mismas que se encuentran bajo la influencia del régimen de precipitación en la región, principalmente sobre la concentración de salinidad en el sistema. Estas barreras físicas se observaron en la laguna costera, las cuales se pueden ver en el diagrama de ordenación. Debido a esto, las especies desarrollan niveles altas o bajas tolerancias de acuerdo con sus capacidades fisiológicas (Arceo-Carranza et al., 2009). Esto se pudo observar en el estudio ya que se capturaron especies en amplios intervalos de tolerancia a la temperatura, salinidad, oxígeno disuelto y precipitación, mientras que otras fueron capturadas en uno menor. Por otro lado, especies como Hypanus sabinus, A. mitchilli, A. felis, Cathorops aguadulce, G. oceanicus, Mugil curema, S. notata, C. macrops, C. spilopterus, C. parallelus, C. 
undecimalis, Diapterus auratus, D. rhombeus, E. melanopterus, L. griseus y Micropogonias undulatus ingresaron y/o permanecieron, en la laguna, casi todo o todo el periodo de estudio, por lo que les atribuyó amplios intervalos de tolerancia para las diferentes condiciones ambientales abióticas. Dichas especies al tener amplias tolerancias les puede permitir habitar en condiciones estresantes que otras especies que no pueden, dándoles ventaja sobre esas, teniendo una mayor disponibilidad de los recursos alimenticios y poder disminuir la competencia con otros organismos (Vega-Cendejas et al., 2014).

La apertura y cierre de la boca del sistema, fue una de las variables ambientales que mostró mayor influencia sobre la comunidad de peces, la cual, como ya se ha mencionado, se encuentra bajo la influencia del régimen de precipitación para su apertura. Las variables de temperatura del agua, salinidad, oxígeno disuelto, concentración de fitoplancton y zooplancton también se vieron influenciadas por el estado de la boca, variando entre la apertura y cierre de la boca de la laguna. De acuerdo con los resultados obtenidos, la abundancia y el número de especies variaron entre la apertura y el cierre de la boca, en relación a las condiciones ambientales del sistema, siendo mayor en boca abierta, es decir, se capturaron 25 especies, especies tolerantes a concentraciones bajas de salinidad, pero altas de oxígeno y temperaturas relativamente altas (boca cerrada), mientras, que las 56 especies restantes son tolerantes a temperaturas más bajas, en el agua, con concentraciones bajas de oxígeno disuelto y altas concentraciones de sal (boca abierta, esto debido a la comunicación directa con el mar). Este fenómeno se observó en la laguna de Chacahua (Mendoza et al., 2009), en donde hacen 
mención que el cierre de la boca tiene una fuerte e importante influencia sobre en los patrones estacionales de las variables ambientales, principalmente de la salinidad, oxígeno disuelto y de la temperatura, esta última con un menor grado de impacto, actuando de manera importante sobre la estructura de la comunidad de peces (Mendoza et al., 2009). Estudios han demostrado que estos cambios estacionales en la estructura de peces están mayormente relacionados con los cambios en el estado de la boca del sistema, como se pudo observar en La Mancha, además, de que este fenómeno, autores lo asocian con el grado de concentración de salinidad en los sistemas costeros (Mendoza et al., 2009). Asimismo, la gran abundancia de individuos registrada en boca abierta, puede deberse al ingreso de un gran número de individuos juveniles, tolerantes a las condiciones, para aprovechar la producción primeria y secundaría, y así poderse alimentar, ya que en este periodo se registró una mayor concentración de fitoplancton o zooplancton, o para utilizar el lugar para resguardo o sitio de reproducción para la renovación de la poblaciones que crecen en dichos sistemas (Franco-López \& Chávez-López, 1992).

Debido a esto, la boca de estos sistemas lagunares, es considerada como el límite/frontera ya que controla los movimientos de circulación de las especies (entrada y salida), en las diferentes épocas climáticas del año, las cuales tienen gran capacidad adaptativa y han desarrollado estrategias especializadas (biológicas y ecológicas) para ingresar a estos sitios, de gran variabilidad ambiental, para el desarrollo de actividades en alguna etapa de sus ciclos biológicos (AyalaPérez et al., 2012a; 2014; Díaz-Ruíz et al., 2018). 
Por otro lado, se registró que el $2.46 \%$ del total de organismo corresponden a especies catádromas, el $11.11 \%$ son especies permanentes del conjunto estuarino lagunar y el $86.41 \%$ corresponde al componente marino eurihalino y estenohalino, datos que coincidieron con los registros de Franco-López y Chávez-López (1992) y Díaz-Ruiz et al. (2018), además, se registró que el 74.07\% de especies penetran en más de un ambiente, lo cual demostró la importancia del intercambio y vínculo con la zona marina y dulceacuícola adyacentes al sistema costero (Ayala-Pérez et al., 1998; 2014).

En el caso de la variable día/noche fue una de las variables que impulsó de manera importante la estructura y la composición de las especies, en donde se generaron dos grupos importantes, aquellas especies con mayor abundancia en el día y aquellas que dominaron durante la noche. Esto indica que las preferencias de las especies a lo largo de un ciclo de $24 \mathrm{hrs}$, se encuentran relacionadas con las preferencias a altas o bajas temperaturas, como se observó en la laguna de Pueblo Viejo (Castillo-Rivera et al., 2010). También estas preferencias, pueden deberse con actividades de forrajeo, evasión de depredadores, detección y captura asociada a la intensidad de la luz a causa de su dependencia de la capacidad visual de especies depredadoras o poca luz para atenuar dicha actividad o para la reducción de interacciones competitivas con otras especies (Castillo-Rivera et al., 2010; 2011; Zárate-Hernández et al., 2012).

Por otro lado, se observó que la influencia de las condiciones ambientales bióticas fue menor que las abióticas, sobre la estructura de la comunidad. A pesar de lo anterior, se debe de considerar que estas interacciones y otras como la 
relación presa-depredador, disponibilidad de alimento, biología reproductiva y preferencias de hábitat, actúan en conjunto con los factores abióticos sobre la variación estacional y nictémera de la estructura y composición de las especies de peces (Castillo-Rivera et al., 2003; Arceo-Carranza et al., 2009; Díaz-Ruiz et al., 2018).

Finalmente, se sugiere que las fluctuaciones estacionales y circadiana de la abundancia, distribución y composición de las especies, que ocupan estos sistemas lagunares, en particular La Mancha, son debidas al desarrollo de estrategias, mecanismos (aclimatación, osmorregulación) y adaptaciones (fisiológicas y morfológicas), de acuerdo a sus capacidades eurihalinas, euritérmicas, etc., y a los cambios en las condiciones ambientales, para usar estos hábitats para actividades asociadas con sus historias de vida y así optimizar el uso del espacio y los recursos de estos sistemas costeros (Mendoza et al., 2009; Castillo-Rivera el al., 2010; DíazRuiz et al., 2004; 2006; 2018; Vega- Cendejas et al., 2014 ). 


\section{Conclusiones}

Se registraron 81 especies, del total de organismos capturados. Este número de especies hasta el momento ha sido el mayor registrado en comparación con otros trabajos llevados a cabo en La Mancha. Esto muestra la importancia del tipo y de la intensidad de los muestreos realizados para este tipo de estudios.

La abundancia total en número, en peso, así como los parámetros de la comunidad, riqueza, diversidad y equidad, variaron entre cada época climática, meses y horas del día. Asimismo, se observó tanto en el ACC como en los dendogramas (resultantes del análisis de conglomerados), que la composición y estructura de la comunidad de especies se encuentran agrupadas de una manera particular dentro del sistema. Lo anterior, se debe a la influencia que ejercen las variables ambientales sobre estos parámetros, es decir, dentro las variables analizadas se observó que la precipitación y su influencia sobre apertura y cierre de la boca del sistema, concentración de oxígeno disuelto y salinidad fueron las variables más importantes, junto con la temperatura, en la determinación de los cambios de la estructura de la comunidad. Así, las lluvias actúan de manera significativa en la regulación de los factores ambientales, observándose que tiene una estrecha relación (inversa) con la concentración de la salinidad y oxígeno, y apertura y cierra de la boca. Por otra parte, otras de las variables que ejerció una influencia sobre la comunidad fueron las horas luz/oscuridad registradas en el estudio. 
Las tolerancias fisiológicas de cada individuo y especie, están asociadas con el tipo de alimentación, protección, reproducción o alguna etapa de su ciclo de vida de las especies, lo cual genera intercambios y sucesiones de las poblaciones de peces en una escala temporal y en un ciclo de $24 \mathrm{hrs}$. Esto muestra, que para ver los cambios en la composición y estructura de las especies, más puntualmente, es necesario considerar escalas a nivel circadiano y estacional, y no solo estacional como en la mayoría de los trabajos han propuesto. Ya que de lo contrario dichos cambios no se podrán observar con mayor precisión, además, de no poder registrar y/o capturar especies que solo tienen actividad durante una solo época de año o una hora en específico del día.

Por otro lado, los resultados obtenidos en el estudio, al ser La Mancha, un sistema con categoría Ramsar, y por tanto de importancia internacional, en términos biológicos y ecológicos, importante en la crianza, alimentación, resguardo y reproducción, no solo de las especies de peces, sino de una gran diversidad de plantas y animales, ayudarán para la toma de decisiones futuras en temas de conservación, ya que si recordamos se registraron valores bajos en la diversidad en algunos de los meses analizados, lo cual probablemente sea un indicador importante de perturbación en el sistema, y que de actuar de una manera pronta las consecuencias en el ecosistema sean menores. Asimismo, el presente estudio en conjunto con los resultados de los trabajos antes realizados en la laguna, serían de gran importancia en estudios presentes y futuros sobre la evaluación biológica de especies de importancia económica y ecológica, mismas que podrán apoyar en plantear ideas y tomar decisiones sobre el manejo y aprovechamiento de los 
recursos pesqueros de la zona, de manera responsable, sin perjudicar el sistema. Esto debido a que la pesquería artesanal es una importante actividad en el sistema. 


\section{Bibliografía}

Allen R. I. \& Baltz D. M. 1997. Distribution and microhabitat use by flatfishes in a Louisiana estuary. Environmental Biology Fishes, 50:85-103.

Alvarez-Rubio M., Amezcua-Linares F. \& Yáñez-Arancibia A. 1986. Ecología y estructura de las comunidades de peces en el sistema lagunar Teacapán- agua Brava, Nayarit, México. Anales del Instituto de Ciencias del Mar y Limnología, Universidad Nacional Autónoma de México, 13(1):185-242.

Amezcua-Linares F. Álvarez-Rubio M. \& Yáñez-Arancibia A. 1987. Dinámica y estructura de la comunidad de peces en un Sistema ecológico de manglares de la costa del Pacífico de México, Nayarit. Anales del Instituto de Ciencias del Mar y Limnología, Universidad Nacional Autónoma de México, 14 (2): 221-248.

Amezcua F. \& Amezcua-Linares F. 2014. Seasonal Changes of Fish Assemblages in a Subtropical Lagoon in the SE Gulf of California. The Scientific World Journal, 1-15.

Anderson M. J. 2001. A new method for non-parametric multivariate analysis of variance. Austral Ecology, 26(1):32-46.

Anderson M. J., Gorley R. N. \& Clarke K. R. 2008. PERMANOVA+ for PRIMER: Guide to software and statistical methods. PRIMER-E. Plymouth: UK.

Arceo-Carranza S. \& Vega-Cendejas Ma. E. 2009. Spatial and temporal characterización characterizacion of fish assemblages in a tropical coastal system influenced by freshwater input: northrwestern Yucatan península. Revista de Biología Tropical, 57(1-2): 89-103.

Arceo-Carranza D., Vega-Cendejas M. E. Montero-Muñoz J. L. \& Hernández de Santilla M. J. 2010. Influencia del hábitat en las asociaciones nictimerales de peces en una laguna costera tropical. Revista Mexicana de Biodiversidad, $81: 823-837$.

Ayala-Pérez L. A., Avilés-Alatriste O. A. \& Rojas-Galaviz J. L.1998. Estructura de la comunidad de peces en el sistema Candelaria-Panlau, Campeche, México. Revista de Biología Tropical, 46(3):763-774.

Ayala-Pérez L. Ramos-Miranda J. \& Flores-Hernández D. 2003. La comunidad de peces de la Laguna de Términos: estructura actual comparada. Revista de Biología Tropical, 52(3-4): 783-793.

Ayala-Pérez L. A., Terán-González G. J., Flores-Hernández D., Ramos-Miranda J. \& Sosa-López A. 2012a. Variabilidad espacial y temporal de la abundancia y 
diversidad de la comunidad de peces en la costa de Campeche, México. Latin American Jornual of Aquatic Research, 40(1):68-78.

Ayala-Pérez L. A., Terán-González G. J. Ramos-Miranda J. \& Flores-Hernández D. 2012b. Cambios interanuales en la abundancia de la comunidad de peces en la costa occidental de Campeche, México. Ciencias del Mar, 38(2):395-410.

Ayala-Pérez L. A., Vasco-Villa O. \& Sosa-López A. 2014. Evaluación de las asociaciones de peces dominantes influenciadas por el ciclo nictemeral y la variación temporal en la reserva de la de la Biósfera los Petenes, Campeche, México. CienciaUAT, 9(1): 33-43

Barreiro-Güemes M. T. \& Balderas-Cortés J. 1991. Evaluación de algunas comunidades de productores primarios de la Laguna de la Mancha. Veracruz. Anales del Instituto de Ciencias del Mar y Limnología, Universidad Nacional Autónoma de México, 18(2): 229-245

Benítez-Valle C., Ruíz-Velazco A. J. M., Peña-Messina E., Blanco y Correa M., López-Rivas C., López-Lugo P. \& Castañeda-Martínez A. 2007. Diversidad y abundancia de la comunidad de peces de estero "El Custodio", Municipio de Compostela, Nayarit, México. Revista electrónica de Veterinaria, 3(5): 15957504.

Berlanga-Robles C. A., Ruiz-Luna A. \& de la Lanza-Espino G. 2008. Esquema de clasificación de los humedales de México. Investigaciones Geográficas, Boletín del Instituto de Geografía, UNAM, 66:25-46.

Castillo-Rivera M. \& Zárate-Hernández R. 2001. Patrones espacio-temporales de la abundancia de peces en la laguna de Pueblo Viejo, Veracruz. Hidrobiológica, 11(1):75-84.

Castillo-Rivera M., Zavala-Hurtado J. A. \& Zárate-Hernández R. 2002. Exploration of spatial and temporal patterns of fish diversity and composition in a tropical estuarine system of Mexico. Reviews in Fish Biology and Fisheries, 12:167-177.

Castillo-Rivera, M., Zárate, R. \& Sanvicente-Añorve, L. 2003. Patrones de diversidad de peces en la laguna de Pueblo viejo, Veracruz, México. Hidrobiológica, 13(4): 289-298.

Castillo-Rivera M., Zárate-Hernández R. \& Ortiz-Burgos S. 2005. Variación nictímera y estacional de la abundancia, riqueza y especies dominantes de peces, en un ambiente salobre de sustrato blando. Hidrobiológica, 15 (2 Especial):227-238.

Castillo-Rivera M., Zárate-Hernández R., Ortiz-Burgos S. \& Zavala-Hurtado J. 2010. Diel and seasonal variability in the fish community structure of a mudbottom estuarine habitat in the Gulf of Mexico. Marine Ecology, 31:633-642. 
Castillo-Rivera M., Ortiz-Burgos S. \& Zárate-Hernández, R. 2011. Estructura de la comunidad de peces estuarinos en un hábitat con vegetación sumergida: variación estacional y nictímera. Hidrobiológica, 21(3):311-321.

Castillo-Rivera M. 2013. Influence of Rainfall Pattern in the Seasonal Variation of Fish Abundance in a Tropical Estuary with Restricted Marine Communication. Journal of Water Resource and Protection, 5:311-319.

Castillo-Rivera M., Ortiz-Burgos S. \& Zárate-Hernández R. 2017. Temporal changes in species richness and fish composition in a submerged vegetation habitat in Veracruz, Mexico. Acta Ichthyologica et Piscatoria, 47(1):23-32.

Carpenter K. E. (Ed.). 2002a. The Living Marine Resources of the Western Central Atlantic. Volumen 2 Bony fishes part 1 (Acipenseridae to Grammmatidae). Rome: Food and Agriculture Organizacion of the United Nations.

Carpenter K. E. (Ed.). 2002b. The Living Marine Resources of the Western Central Atlantic. Volumen 3 Bony fishes part 2 (Opistognathidae to Molidae), sea turtles and marine mammals. Rome: Food and Agriculture Organizacion of the United Nations.

Castro-Aguirre J. L., Espinosa-Pérez H. S. \& Schmitter-Soto. 1999. Ictiofauna esturino-lagunar y vicaria de México. Distrito Federal, México: Limusa.

Chapman M. G. \& Underwood A. J. 1999. Ecological patter in multivariate assebleges informatio and interpretation of negative values in ANOSIM. Marine Ecology Progress series, 180:257-265.

Chatterjee S. \& Hadi A. S. 2006. Regression Analysis by Example. USA: Wiley.

Chavance P., D. Flores-Hernández, A., Yáñez-Arancibia \& Amezcua-Linares, F. 1984. Ecología, biología y dinámica de las poblaciones de Bairdiella chrysoura (Lacépede, 1803) en la Laguna de Términos, sur del Golfo de México (Pisces: Sciaenidae). Anales de Instituto de Ciencias del Mar y Limnología, Universidad Nacional Autónoma de México, 11(1):123-161.

Chávez-López, R., Rocha-Ramírez, A. \& Ramírez-Rojas, A. 2005. Cambios en los ensamblajes de peces del sistema laguna de Alvarado (SLA), Veracruz, México. Revista Digital Universitaria, 6(8): 2:19.

Christensen J. D., Monaco M. E. \& Lower T. A. 1997. An index to assess the sensitivity of Gulf of Mexico species to changes in estuarine salinity regimes. Gulf Research Reports, 9:219-229.

Clarke K. R. 1993. Non-parametric multivariate analyses of changes in community structure. Australian Journal of Ecology, 18:117-143. 
CONAGUA (Comisión Nacional del Agua, Servicio Meteorológico Nacional). 2012. Precipitación a nivel nacional y por Entidad Federativa. En línea: http://smn.cna.gob.mx/es/climatologia. Consultado el 5 de Septiembre de 2016.

CONAGUA 2019. Información Climatológica por Estado. En línea:

https://smn.conagua.gob.mx/es/climatologia/informacion-

climatologica/normales-climatologicas-por-estado. Consultado 23 de octubre de 2019.

CONAGUA (Comisión Nacional del Agua). 2016. Ley de Aguas Nacionales. Diario Oficial de la Federación. 1 de Diciembre de 1992.

CONANP (Comisión Nacional de Áreas Naturales Protegidas). 2003. Ficha Informativa de los Humedales de Ramsar (FIR). En línea: http://ramsar.conanp.gob.mx/docs/sitios/FIR_RAMSAR/Veracruz/La_Mancha_y El_Llano/La\%20Mancha\%20y\%20El\%20Llano.pdf. Consultada el 4 de marzo de 2017.

CONANP (Comisión Nacional de Áreas Naturales Protegidas). 2014. Humedales de México. En línea: http://www.conanp.gob.mx/conanp/dominios/ramsar/lsr.php. Consultada el 29 de enero de 2019.

Constante-Pérez L. G. 2016. Caracterización molecular, taxonómica y ecológica de las especies de pargos (Familia Lutjanidae) en la laguna La Mancha, Veracruz (Tesis de Maestría en Biología). Universidad Autónoma Metropolitana. Ciudad de México, México.

Contreras F. 1993. Ecosistemas costeros mexicanos. Iztapalapa, México: CONABIO-Universidad Autónoma Metropolitana.

Contreras E. F. \& Castañeda L. O. 2004. La biodiversidad de las lagunas costeras. Ciencias, 76:46-56.

Contreras-Espinosa F., Rivera-Guzmán N. E. \& Segura-Aguilar R. 2005. Nutrientes y productividad primaria fitoplanctónica en una laguna costera tropical intermitente (La Mancha, Ver) del Golfo de México. Hidrobiológica, 15(3):299-310.

Contreras-Espinosa F. 2010. Ecosistemas costeros Mexicanos, Una Actualización. Iztapalapa, México: Universidad Autónoma Metropolitana.

Díaz-Ruíz S., Cano-Quiroga E., Aguirre-León A. \& Ortega-Bernal R. 2004. Diversidad, abundancia y conjuntos ictiofauníticos del sistema lagunarestuarino Chantuto-Panzacola, Chiapas, México. Revista de Biología Tropical, 52(1):187-199. 
Díaz-Ruiz S., Aguirre-León A. \& Cano-Quiroga E. 2006. Evaluación ecológica de las comunidades de peces en dos sistemas lagunares estuarinas del sur de Chiapas, México. Hidrobiológica, 16(2):197-210.

Díaz-Ruiz, S., Aguirre-León, A., Mendoza-Sánchez., E. \& Lara-Domínguez, A. 2018. Factores ambientales que influyen en la ictiofauna de la laguna $\mathrm{La}$ Mancha, sitio Ramsar, Golfo de México. Revista de Biología Tropical, 66(1): 246-265.

Day J.W., Hall A.S, Kemp W.M. \& Yáñez-Arancibia A. 1989. Estuarine Ecology. New York, USA: Wiley

Franco-López, J. \& Chávez-López. 1992. Síntesis sobre el conocimiento de la ictiofauna de la Laguna de Tamiahua. Veracruz, México. Hidrobiológica, 2(12):53-63.

Flores-Verdugo F., Agraz-Hernández C. \& Benítez-Pardo D. 2007. Parte tres: Ecosistemas costeros: importancia, retos y prioridades por su conservación. En O. Herzing, R. Márquez-Huitzil, E.P. Recagno, L. Zambrano. (Eds), Perspectivas sobre conservación de ecosistemas acuáticos en México. México. P.147-166.

Froese R. \& Pauly D. (Eds.). 2019. FishBase. Publicación electrónica de la World Wide Web. www.fishbase.org, versión (02/2019).

Fuentes M., Espinosa P. \& Luna W. 1989. Nuevos registros de peces en la laguna de Sontecomapan, Veracruz, México. Anales del Instituto de Biología, UNAM, Serie Zoológica, 60(2):257-262.

García E. 2004. Modificaciones al sistema de clasificación climático de Köppen. Instituto de Geografía UNAM. México D. F. Serie de Libros No. 6. 90 p.

Gillson J. 2011. Freshwater flow and fisheries production in estuarine and coastal systems: Where a drop of rain is not lost. Reviews in Fisheries Science, 19(3):168-186.

Grijalva-Chon J. M., Niñez-Quevedo S. \& Castro-Longoria. 1996. Ictiofauna de la laguna Costera La Cruz, Sonora, México. Ciencias Marinas, 22(2):129-150.

Hernández U. R., Valdez-Zenil, J. \& Zavala-García F. 2006. Composición y abundancia del ictioplancton durante la temporada de estiaje en la laguna de Tampamachoco, Veracruz, México. Revista UDO Agrícola, 6(1):138-149.

Hernández-Gorrosquieta M. E. (2016). Patrones de distribución y abundancia de peces bentónicos de la Laguna La Mancha, Veracruz (Tesis de Maestría en Biología). Universidad Autónoma Metropolitana-Iztapalapa. Ciudad de México, México. 
Herrera-Silvera J., y Morales-Ojeda S. 2010. Capítulo 1: Contexto físico. Lagunas Costeras. En SEDUMA (Secretaria de Desarrollo Urbano y Medio Ambiente). (Ed), Biodiversidad y desarrollo humano en Yucatán (pp.24-26). Mérida, Yucatán.

Juárez-Eusebio, A., Rojas-Galaviz, J. L., Mora-Peréz, C. \& Zárate-Lomelí, D. 2006. Los peces. En Moreno-Casasola. (Ed.), Entornos Veracruzanos: la costa de La Mancha (pp. 327-340). Xalapa, Veracruz, México: Instituto de Ecología, A.C.

Krebs C. 1999. Ecological Methodology. California; USA: Addison-Wesley

Lara-Domínguez A. L., Franco-López J., Bedia-Sánchez C., Abarca-Arenas L. G., Díaz-Ruiz S., Aguirre-León A., González-Gándara C. \& Castillo-Rivera M. 2011. Diversidad de peces en los ambientes costeros y plataforma continental Vol. II: p. 505- 516. En CONABIO, Gobierno del Estado de Veracruz. (Eds.), La Biodiversidad en Veracruz: Estudio de Estado. Universidad Veracruzana. Instituto de Ecología.

López-Portillo, J., Lara-Domínguez A. L., Ávila-Ángeles A. \& Vázquez-Lule A. D. 2009. Caracterización del sitio de manglar La Mancha, en Comisión Nacional para el Conocimiento y Uso de la Biodiversidad (CONABIO). 2009. Sitios de manglar con relevancia biológica y con necesidades de rehabilitación ecológica. CONABIO, México, D.F.

Lozano-Vilano M. L., García-Ramírez M. E. \& Contreras-Balderas. 1993. Peces Costeros y Marinos del Estado de Veracruz. En Salazar-Vallejo S. I. \& González N. E. (Eds.), Biodiversidad Marina y Costera de México (pp. 576595). Comisión Nacional de Biodiversidad y CIQRO, México.

Marchant R., Wells F. \& Newall. 2000. Assesment of an ecoregion approach for classifying macroinvertebrate assemblages from streams in Victoria, Australia. Journal of the North amerucan Benthological Society, 19(3):497-500.

Martínez-Aguilar C. I. 2015. Variación estacional y nictímera en la captura y distribución de tallas de especies de Mojarras en una laguna costera, Categoría ramsar (Tesis de Maestría en Biología). Universidad Autónoma Metropolitana. Ciudad de México, México.

Mendoza, E., Castillo-Rivera, M., Zárate-Hernández, R. \& Ortiz-Burgos, S. 2009. Seasonal variations in the diversity, abundance, and composition of species in an estuarine fish community in the Tropical Eastern Pacific, Mexico. Icthyological Research, 56:330-339.

McEachran J. D. \& Fechhelm J. D. 2005. Fishes of the Gulf of Mexico, Volume 2: Scorpaeniformes to Tetraodontifores. Texas, USA: University of Texas Press, Austin. 
McGarigal K., Cushman S. \& Stafford S. 2000. Multivariate statistics for wildlife and ecology research. New York, NY, USA: Springer-Verlag.

Mendenhall W., \& Sincich T. 2003. A second course in statistics. Regression analysis. New Jersey, USA: Prentice Hall, Upper Saddle River

Meynecke J. O., Lee S. Y., Duke N. C. \& Warnken J. 2006. Effect of rainfall as a component of climate change on estuarine fish production in Queensland, Australia. Estuarine, Coastal and Shelf Science, 69(3-4):491-504.

Miller R. R. 2009. Peces dulceacuícolas de México. Distrito Federal, México: CONABIO.

Nelson J. O., Grande T. C. \& Wilson M. V. H. 2016. Fishes of the world. USA: Wiley.

Ocaña-Luna, L. \& Sánchez-Ramírez, M. 2016. Estructura de la comunidad ictioplanctónica en la laguna de Tamiahua. Revista Mexicana de Biodiversidad, 87: 123-132.

Padilla-Serrato J., López-Martínez J. Rodríguez-Romero J., Lluch-Cota D., GalvánMagaña F. \& Acevedo-Cervantes A. 2016. Composición y aspectos biogeográficos del ensamble de peces de la laguna costera Las Guásimas, Sonora, México. Latin American Journal of Aquatic Research, 44(1):85-98.

Penk 2018. M. Estuarine ecosystems. En línea: http://www.coastalwiki.org/wiki/Estuarine_ecosystems. Consultado el $11 \mathrm{de}$ octubre de 2019.

Pérez-Hernández M. A. \& Torres-Orozco R. E. 2000. Evaluación de la riqueza de especies de peces en las lagunas costeras mexicanas: Estudios de un caso en el Golfo México. Revista de Biología Tropical, 48(2/3):425-438.

Pessanha A. L. M., Araújo F. G., De Azevedo M. C.C. \& Dias Gomes I. 2003. Diel and seasonal changes in the distribution of fish on southeast Brazil sandy beach. Marine Biology, 143(6):1047-1055.

Ramsar. 1971. Criterios para sitios Ramsar. En línea: https://www.ramsar.org/sites/default/files/documents/library/ramsarsites_criteria _sp.pdf. Consultado el 16 de marzo de 2018.

Raz-Guzman A. \& Huidobro L. 2002. Fish communities in two environmentally different estuarine systems of Mexico. Journal of Fish Biology, 61:182-195.

Rodríguez-Varela, A. C., Cruz-Gómez, A. \& Vázquez-López. 2010. List of the icthyofauna in the Sontecomapan Lagoon, Veracruz, Mexico. BIOCYT, 3(9):107-121. 
Román-Hernández, U., Valdez-Zenil, J., \& Zavala-García. 2006. Composición y abundancia del ictioplancton durante la temporada de estiaje en la laguna de Tampamachoco, Veracruz, México. Revista UDO Agrícola, 6(1):138-149.

SEMARNAT. 2010. Norma Oficial Mexicana NOM-059. Protección ambientalEspecies nativas de México de flora y fauna silvestres-Categorías de riesgo y especificaciones para su inclusión, exclusión o cambio-Lista de especies en riesgo. Diario Oficial. 30 de diciembre de 2010.

Solano-Mendoza F. G. 2017. Estructura de las comunidades de peces y aves en un humedal costero: Estudio base para la conservación de la biodiversidad de la costa de Yucatán (Tesis de Licenciatura). Universidad Nacional Autónoma de México, Facultad de Estudios superiores-Zaragoza, Ciudad de México, México.

Sosa-López A., Mouillot D., Ramos-Miranda J., Flores-Hernandez D. \& Do-Chin T. 2007. Fish species richness decreases with salinity in tropical coastal lagoons. Journal of Biogeography, 34:52-61.

ter Braak C. J. F. \& Verdonschot P. F. M. 1995. Canonical correspondence analysis and related multivariate methods in aquatic ecology. Aquatic Sciences, 57:255-289.

Uribe, J. \& Orrego O. 2001. Modelos de distribución en comunidades de briofitos. Caldasia, 23(1): 261-267.

Vega-Cendejas Ma. E. \& Hernández-de-Santillana M. 2014. Ictiofauna que habita los sistemas costeros del parque marino Isla Contoy. CienciaUAT, 9(1):44-59.

Wootton, R. J. 1990. Ecology of Teleo st Fishes. Great Britain: Champan \& Hall.

Yáñez-Arancibia A., Lara-Domínguez A., Sánchez-Gil P., Vargas-Maldonado I., Chavance P., Amezcua-Linares F., Aguirre-León A. \& Díaz-Ruíz S. 1982. Ecosystem dynamics and nichthemeral and seasonal programming of fish community structure in a tropical estuarine inlet, Mexico. In: P. Lasserre and $\mathrm{H}$. Postma (Eds.), Coastal Lagoons. Oceanologica Acta, 5(4):417-429.

Yañéz-Arancibia A. 1985. Ecología de comunidades de peces en estuarios y lagunas costeras. México: Universidad Nacional Autónoma de México.

Yáñez-Arancibia A., Lara A. L. \& Pauly D. 1994. Coastal lagoons as fish habitats, p. 363-376. In B. Kjerfve (Ed), Coastal lagoons processes. Elsevier, Amsterdam, $577 \mathrm{p}$.

Zambrano L., Córdoba-Tapia F., Pacheco-Muñoz R. \& Levy-Gálvez K. 2013. Capítulo 4. La comunidad de peces del lago Pátzcuaro. En Estudio ecosistémicos del lago de Pátzcuaro: aportes en gestión para el formato del 
desarrollo sustentable. Instituto de Tecnología del agua. 304pp. México: Instituto Mexicano de Tecnología del Agua.

Zar J.H. 2010. Biostatistical Analysis. London: Prentice Hall.

Zárate-Hernández R. 2003. Variación nictímera y estacional de la diversidad y composición de especies de peces, en la Laguna de Pueblo Viejo, Veracruz (Tesis de Maestría en biología). Universidad Autónoma Metropolitana, Cuida de México, México.

Zárate-Hernández R., Castillo-Rivera M., Sanvicente-Añorve L., \& Ortiz-Burgos S. 2012. Spatial, diel, and seasonal changes in the fish community structure of a Mexican tropical estuary. Ciencias Marinas, 38(4):665-676. 


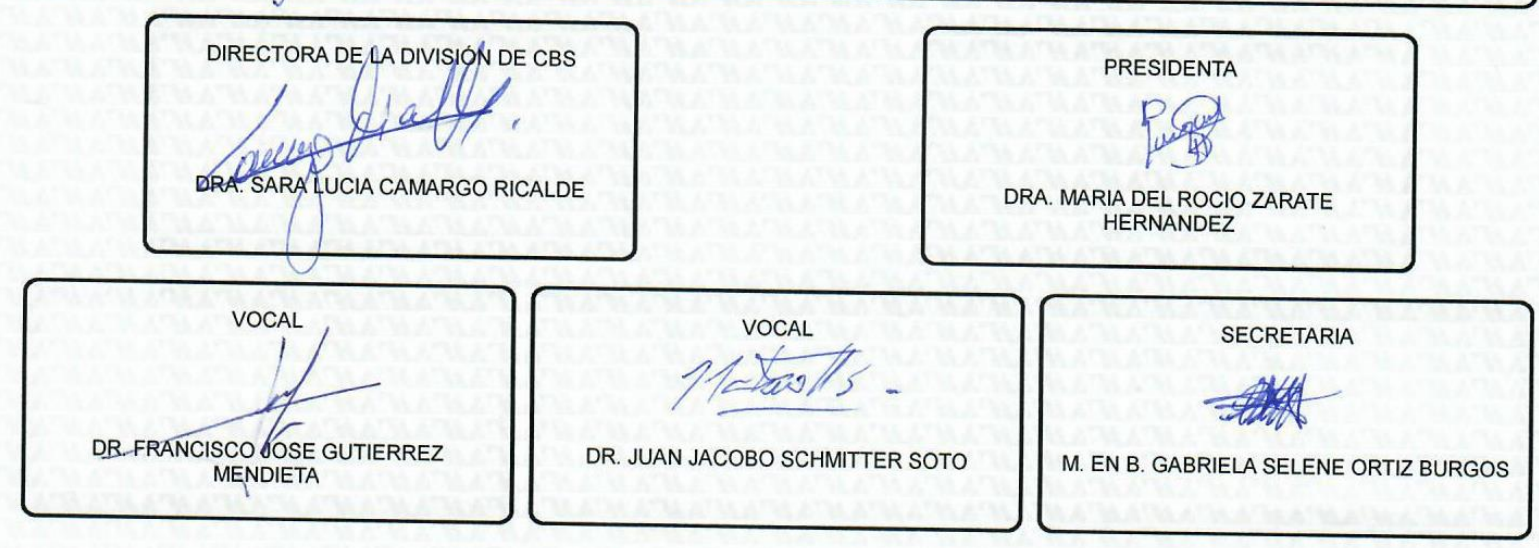

